\title{
The cost of repetition in South Africa
}

\author{
SERVAAS VAN DER BERG \\ GABRIELLE WILLS \\ REBECCA SELKIRK \\ CHARLES ADAMS \\ CHRIS VAN WYK
}

\section{Stellenbosch Economic Working Papers: WP13/2019}

www.ekon.sun.ac.za/wpapers/2019/wp132019

August 2019

KEYWORDS: education, repetition, drop-out, education finance, human capital, economic development, South Africa

JEL: I220, O150, H410

\author{
ReSEP (Research on Socio-Economic Policy) \\ http://resep.sun.ac.za \\ DEPARTMENT OF ECONOMICS \\ UNIVERSITY OF STELLENBOSCH \\ SOUTH AFRICA
}

A WORKING PAPER OF THE DEPARTMENT OF ECONOMICS AND THE BUREAU FOR ECONOMIC RESEARCH AT THE UNIVERSITY OF STELLENBOSCH 


\title{
THE COST OF REPETITION IN SOUTH AFRICA
}

\author{
Servaas van der Berg (Resep, Department of Economics, Stellenbosch University) \\ Gabrielle Wills (Resep, Department of Economics, Stellenbosch University) (corresponding \\ author: email gabriellewills@gmail.com) \\ Rebecca Selkirk (Resep, Department of Economics, Stellenbosch University) \\ Charles Adams (Department of Economics, University of the Western Cape) \\ Chris van Wyk (Resep, Department of Economics, Stellenbosch University)
}

\begin{abstract}
An almost unnoticed problem in the South African education system is the high rate of grade repetition. In this report, a combination of household and administrative datasets is used to identify patterns in learner repetition and dropout in South African schooling and the costs associated with these issues. According to the most conservative estimate, the number of learners in public schools repeating in grades 1 to 12 could have been 1180 000. In monetary terms, this implies that the cost of having repeaters in the public education system was at least R20 billion (in 2018 prices), absorbing $8 \%$ of the total national budget allocated to basic education in $2018 / 2019$. At least a half of these repetition costs is attributed to the high prevalence of repetition in the secondary school phase, with the largest number of repeaters located in grade 10 (at least 1 in every 5 grade 10 learners repeat). Despite the promulgation of repetition policy that limits the number of times learners can repeat a school phase, repetition trends in the past decade display a strong inertia, especially in higher grades. To monitor these trends better, and to track the implementation of these policies, significant improvements will need to be made to the quality of reporting on repeaters and dropout in EMIS data. While repetition is a problem, it is merely a symptom of a weakly functioning education system. The repetition debate is thus secondary to the need to address the quality of the education provided in our schools, and particularly in the foundation phase. Quality improvements will also make it easier to implement sensible policies on repetition and to provide remediation and support where these are needed. Moreover, by freeing resources currently needed to deal with repetition, improved education quality would also make remediation more feasible.
\end{abstract}

Acknowledgment: This paper was produced as a study for the DG Murray Trust and funded by this trust. 


\section{FOREWORD}

The DG Murray Trust (DGMT), a philanthropic organisation that focuses its support strongly on human development, has expressed concern about school dropout and is actively involved in interventions to prevent such dropout. Against this background, DGMT requested Resep to investigate this issue and highlight the costs of repetition, as repetition at earlier grades largely acts as a precursor to drop out from the school system. It is the combination of repetition and dropout rather than inadequate demand for education that stops many from continuing to higher levels of education. This study aims to contribute to an understanding of the cost of repetition and dropout in terms of their impact on the affected individuals and on society, and their wider impact on productivity, social mobility, and fiscal costs.

Data for this study were made available by the Department of Basic Education and the Northern Cape Provincial Department of Education. The researchers wish to thank them for making the data available and hope that this study would be of benefit to them and indeed the full education system. 


\section{CONTENTS}

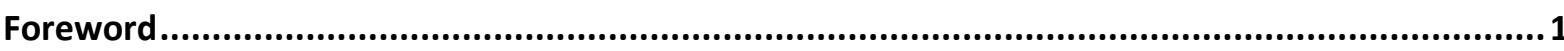

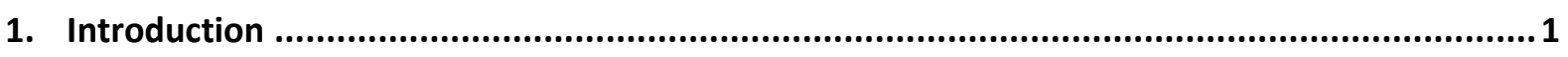

1.1 Dropout and repetition as a South African issue ............................................................ 1

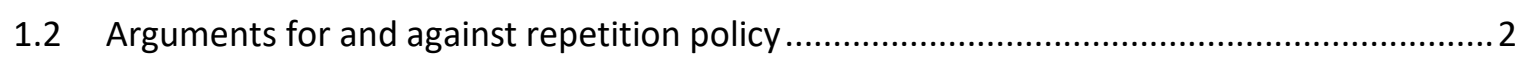

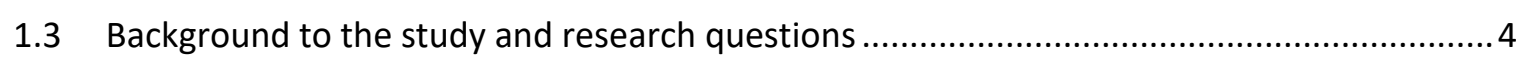

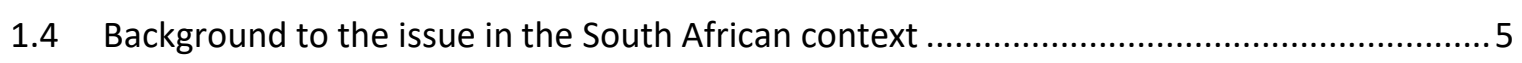

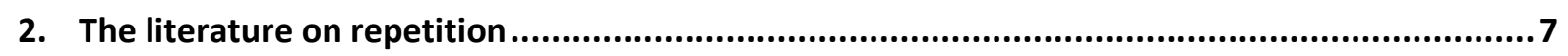

2.1 Automatic promotion versus repetition: Current state of the international debate............. 7

2.1.1 Repetition vs automatic promotion: still controversial.......................................... 7

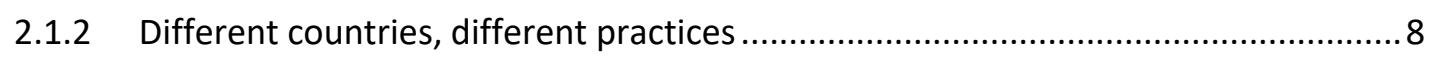

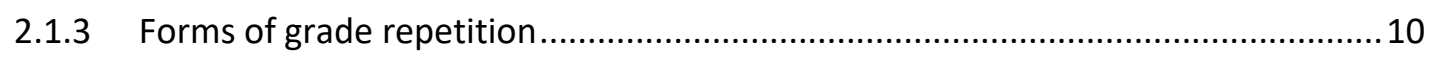

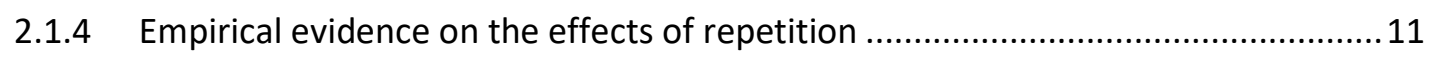

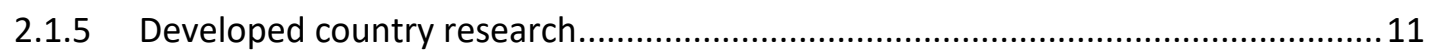

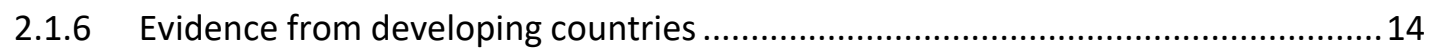

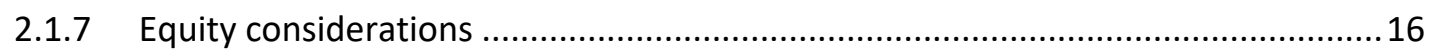

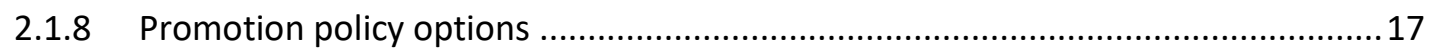

2.2 Repetition in South Africa - what we know from previous studies .................................... 18

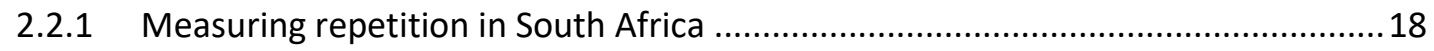

2.2.2 Repetition policy and repetition rates in the FET phase ......................................18

2.2.3 Determinants of repetition and dropout, and how they are linked.......................19

2.2.4 Does grade repetition lead to improved academic performance? Evidence from repeater scores in the Western Cape .................................................................20

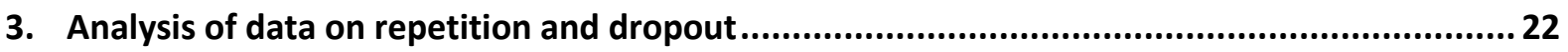

3.1 Analysis using household survey and school census data .................................................22

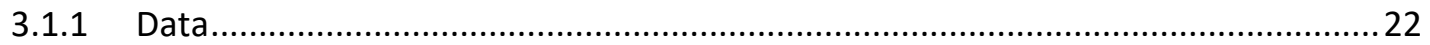

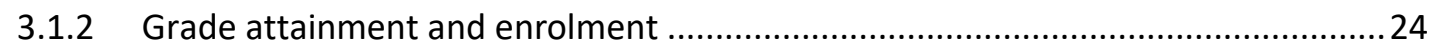

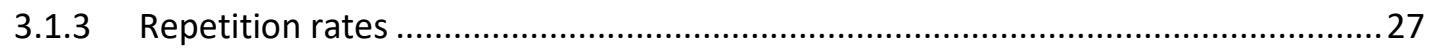

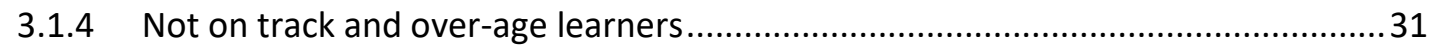

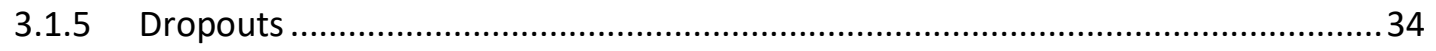

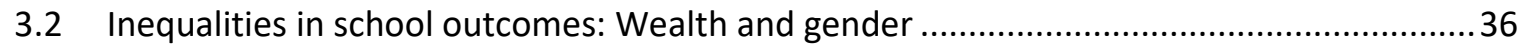

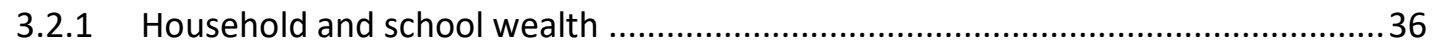

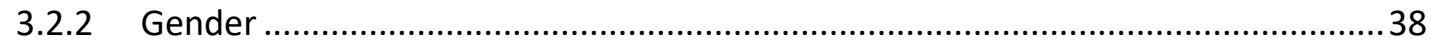

3.3 An analysis of repetition and dropout in the Northern Cape using SA-SAMS data..............41

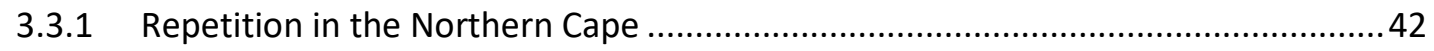


3.3.2 Dropout in the Northern Cape: 1 year transitions

3.3.3 The implementation of repetition policy in the Northern Cape......

3.3.4 Probabilities of promotion, dropout and reaching grade 12 in the Northern Cape 45

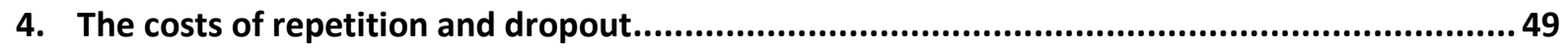

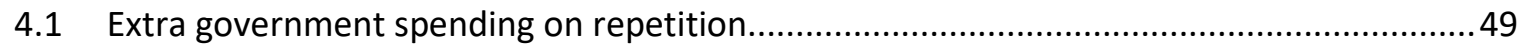

4.2 Costs of repeating and dropping out: The story of a 21-year-old ......................................51

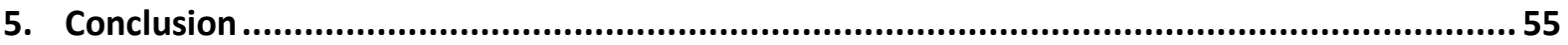

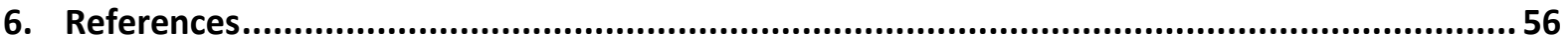

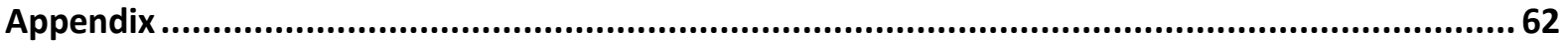




\section{TABLES}

Table 1: A summary of the advantages and disadvantages of repetition

Table 2: Repetition rates at the end of various school phases in public schools in francophone African countries, SERCE 1999

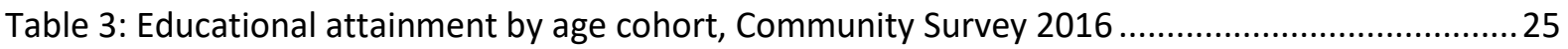

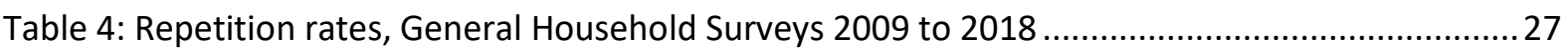

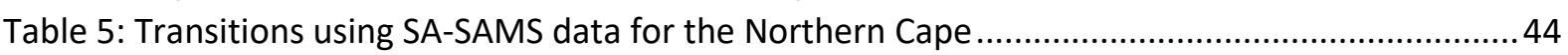

Table 6: Repetition per phase, SA-SAMS data for the Northern Cape ............................................ 45

Table 7: Estimating the probability of promotion, dropout or reaching matric, 2015 SA-SAMS

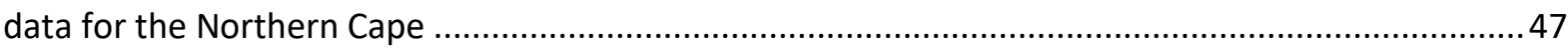

Table 8: Estimating public spending on repetition in South Africa in 2016 .........................................50

Table 9: An example of the costs of repetition and dropout......................................................... 54

Table A 1: Government spending, estimates used for the 21-year-old costing example .66

Table A 2: Cumulative annual earnings in 2018 prices used for the 21 -year-old costing example...... 67 


\section{FIGURES}

Figure 1: Average years of schooling by age cohort, Community Survey 2016................................25

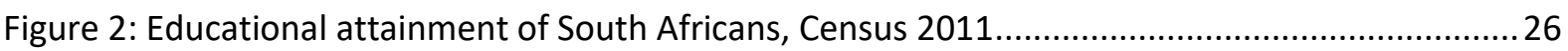

Figure 3: Percentage of each age group attending school in SACU countries....................................26

Figure 4: National repetition rates by grade over the period 2009-2013 and 2014-2018, GHS ......... 28

Figure 5: Trends in national repetition rates for grades 9 to 12,2009 to 2018, GHS............................2 28

Figure 6: Trends in national repetition rates in the foundation phase, 2009 to 2018 , GHS................. 29

Figure 6: Repetition rates using a reliable and consistent ASS school-level sample from 7

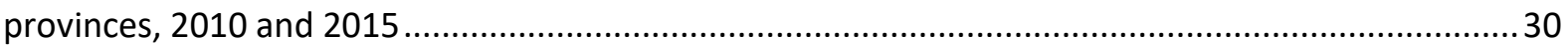

Figure 7: Percentage of learners repeating, LURITS (Reproduced from DBE 2016 'Progress in the

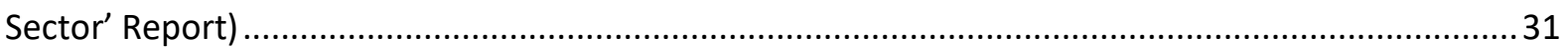

Figure 8: Educational status of youth aged 8 to 20, Community Survey 2016................................... 32

Figure 9: Percentage of children aged 11 to 18 enrolled in school that are not on track,

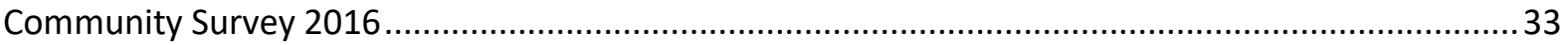

Figure 10: Trends in the percentage of learners by grade that are over-age, EMIS 2000 to 2016

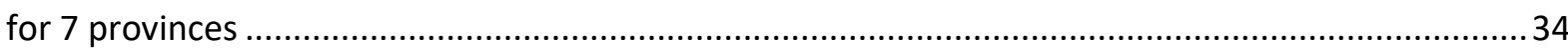

Figure 11: Dropout rates using a reliable and consistent ASS school-level sample from 7

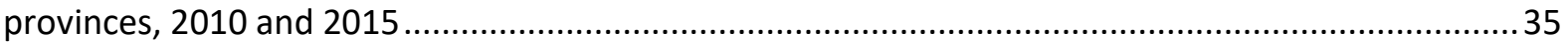

Figure 12: Percentage of children in school that are not on track by household wealth quintile, Community Survey 2016.

Figure 13: Percentage of youth aged 7 to 19 not enrolled in any educational institution by household wealth quintile, Community Survey 2016.

Figure 14: Repetition rates across Quintile 1 and Quintile 5 schools using a reliable and consistent ASS school-level sample from 7 provinces for 2010 and 2015 ........................................38

Figure 15: Percentage of children that are in school but not on track by gender, Community Survey 2016

Figure 16: Repetition rates by gender using a reliable and consistent ASS school-level sample

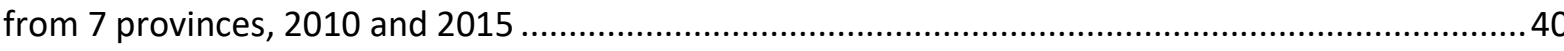

Figure 17: Dropout rates by gender using a reliable and consistent ASS school-level sample from

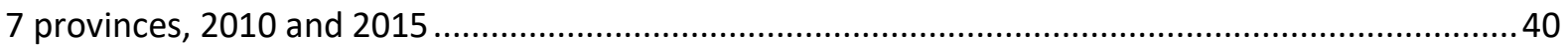

Figure 18: Gender parity index by grade, national EMIS statistics $(2009,2016,2018)$....................... 41

Figure 19: Percentage of previous year's learners repeating, Northern Cape SA-SAMS sample ......... 43

Figure 20: A monthly earnings profile for South Africans with a grade 9, matric or a 3-year degree

Figure A 1: Educational status of children aged 13 by province, Community Survey 2016

Figure A 2: Educational status of children aged 16 by province, Community Survey 2016 ................62

Figure A 3: Educational status of children aged 17 by province, Community Survey 2016 ................63 Figure A 4: Percentage of age-cohorts with a completed matric by province, Community Survey 2016

Figure A 5: Trends in the percentage of learners by grade that are over-age, EMIS 2000 to 2016

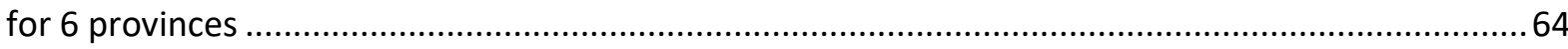

Figure A 6: Provincial repetition rates averaged across the years 2014 to 2018 , GHS......................65 


\section{INTRODUCTION}

\subsection{DROPOUT AND REPETITION AS A SOUTH AFRICAN ISSUE}

An almost unnoticed problem in the South African education system is the inordinately high rate of grade repetition. According to most conservative estimate, the number of learners in public schools repeating in grades 1 to 12 could have been $1180000 .{ }^{1}$ In monetary terms, this implies that the cost of having repeaters in the public education system was around R20 billion (in 2018 prices). At these costs, repetition could absorb at least $8 \%$ of the total national budget allocated to basic education in 2018/2019.

At least a half of these repetition costs are attributed to the high prevalence of repetition in the secondary school phase (Grades 8 to 12) with the largest number of repeaters located in grade 10 (at least 1 in every 5 grade 10 learners repeat that grade). Spending on teachers, classrooms, textbooks and other learning materials to accommodate repetition can generally be regarded as wasted expenditure, as repeating (especially at the higher grades) is unlikely to add to learners' educational and labour market prospects.

Apart from those who repeat, available estimates of dropouts indicate that around another 300000 drop out of public schools each year without having reached matric. Most of these who drop out had also failed their current grade, or were likely to fail. If this was the case for about two-thirds of those dropping out, it may well add a further R4 billion to the annual cost of failures in the school system. Failing the grade, or repetition, is very often the precursor to dropping out. Children who are overaged for their grade are more likely to drop out, especially in secondary school, and even more so if they repeat multiple times. The probability that someone who is over-aged in grade 9 (failing that grade also) but eventually reaches or even passes matric, is extremely low.

However, government expenditure on repeaters is only one part of the overall costs of repetition and especially dropout. If children end up with less school education than they could have achieved, this constrains their potential productivity and therefore also their earnings in the labour market. Repetition has direct and immediate costs for the state, but dropout presents an even inferior outcome to that. The costs to the individual in forgone earnings, and the cost to the state of lower productivity than would have been possible with a more educated labour force, are massive over the lifetime of each cohort of children progressing through school.

Section 4 of this report addresses some of the cost issues - direct costs and forgone earnings - that are associated with repetition and dropout. When the foregone lifetime earnings of not obtaining a matric are considered, the direct costs of repetition account for just a fraction (around 1\%) of the total lost value of reaching grade 10 after three years of repetition rather than obtaining a matric pass in 12 years. The R20 billion annual cost of repetition is roughly equivalent to the additional lifetime earnings of having 12000 more youth obtain a matric every year rather than dropping out after grade 10. If the effect of repetition in stimulating dropout outweighs the benefits of skills mastery that could

\footnotetext{
${ }^{1}$ This figure is based on the 2016 General Household Survey (GHS) estimates which tend to underestimate repetition. Using a reliable sample from the Annual Survey Schools suggests that total repeaters in the public education system may even have been as high as 1690 000. The fiscal cost of this would have been around R29 billion in 2016, expressed in 2018 Rand values.
} 
encourage successful advancement through the school system, then repetition is a sub-optimal practice.

\subsection{ARGUMENTS FOR AND AGAINST REPETITION POLICY}

There is no agreement in the international literature about the benefits of a system of repetition. As is discussed in Section 2, many educationists, especially in developed countries, believe that the benefits of repetition as a policy that incentivises hard work do not weigh up against the harmful effects of such a policy for child well-being. They also contend that repetition only makes real sense if there is specialised support for the child who repeats, something that is usually not realistic in developing countries.

Proponents of a repetition policy in turn point to the learning deficits observed amongst high school children. They argue that promoting children to higher grades without them having mastered basic skills of reading, writing and arithmetic makes further learning almost impossible. Moreover, promoting children to higher grades increases heterogeneity at higher grades, making it very difficult for teachers to teach at the right level. The key arguments for and against repetition from a review of the literature is summarised in Table 1 below. But moving beyond theory to evidence, preliminary analyses from the Western Cape Province and other country studies, seem to indicate that if repetition is applied, it is more likely to be beneficial in the earlier foundation grades than later grades.

In South Africa, repetition policy already constrains how many times a child may repeat. Currently the policy is that a child can only repeat once in each of the four education cycles: the Foundation Phase (grades 1 to 3), the Intermediate Phase (grades 4 to 7 ), the Senior Phase (grades 8 to 9) and the Further Education and Training Phase (grades 10 to 12). However, the available data indicate that this policy is often not applied, so that some children already fall several years behind their correct grade for age before they reach secondary school. By age 14, only around 58\% of children are still in school and in the appropriate grade. Moreover, patterns of repetition are marred by social inequities with considerably larger proportions of repeaters coming from poorer backgrounds. Repetition often perpetuates patterns of social inequities in school attainment. This is an argument against repetition policy in a country striving for social equality.

The arguments for repetition as policy are also somewhat weakened by the fact that assessment within the schooling system is often inaccurately implemented, a problem which is more exaggerated in the least functional schools (Van der Berg \& Shepherd, 2015). Lam, Ardington and Leibbrandt (2011) even compare grade progression in many poorer schools to a lottery due to of the weak correlation between being promoted and student ability. There are significant limitations in the extent to which available data can be used to explore this issue further due to problems in accurately linking repetition to test performance measures. However, earlier analysis of the Western Cape's Systemic Tests for grade 3 showed that $87 \%$ of children who performed extremely poorly in the Systemic Mathematics Test, scoring less than $20 \%$, were promoted to grade 4 . But 118 children (less than $1 \%$ ) amongst the select group who obtained more than $50 \%$ in the test (scoring among the top $20 \%$ of performers) had to repeat grade 3 (Van Wyk, Gondwe, \& De Villiers, 2017; Von Fintel \& Van der Berg, 2017). This points to some randomness in progression, which is also one reason for the surprisingly good results in the National Senior Certificate (matric) of children who could progress to grade 12 after failing grade 11. 
Table 1: A summary of the advantages and disadvantages of repetition

\begin{tabular}{|c|c|}
\hline Disadvantages of repetition & Advantages of repetition \\
\hline $\begin{array}{c}\text { Impacts on government and schools } \\
\text { Foregone spending: How else could the money } \\
\text { spent on repeaters have been used? }\end{array}$ & $\begin{array}{c}\text { Potential reduction in the cost of remediation } \\
\text { at later ages }\end{array}$ \\
$\begin{array}{c}\text { Higher pupil to teacher ratios (and larger class } \\
\text { sizes) in early grades }\end{array}$ & $\begin{array}{c}\text { Potential reduction in the variability of learner } \\
\text { abilities within classrooms, allowing for } \\
\text { increased alignment between learner ability } \\
\text { and grade-level curriculum. }\end{array}$ \\
\hline $\begin{array}{c}\text { Increased range of learner ages within } \\
\text { classrooms }\end{array}$ & Impacts on the child \\
\hline $\begin{array}{c}\text { Potential harmful psychological impacts } \\
\text { failure) }\end{array}$ & $\begin{array}{c}\text { Potential for mastery of concepts ('catch-up') } \\
\text { (lowered self-esteem/motivation and stigmas of }\end{array}$ \\
$\begin{array}{c}\text { Higher risks of drop-out if learners repeat, } \\
\text { where lower grade attainment reduces chances } \\
\text { of higher employment opportunities and higher } \\
\text { earnings after school }\end{array}$ & $\begin{array}{c}\text { Threat of being held back may induce more } \\
\text { effort on the part of learners }\end{array}$ \\
\hline \multicolumn{2}{|c|}{ Impacts on society } \\
\hline $\begin{array}{c}\text { Social exclusion of the poorest learners from } \\
\text { higher grades as they are more likely to repeat } \\
\text { than wealthier learners (equity) }\end{array}$ & $\begin{array}{c}\text { Improves the signalling of school qualifications } \\
\text { in the labour market if grade promotion is } \\
\text { more closely tied to mastery of concepts. }\end{array}$ \\
\hline
\end{tabular}

High rates of repetition and dropout are costly. The costs include the internal inefficiencies in the education system: Many of those who matriculate only manage to do so after spending more than 12 years in school, while those who drop out earlier often regard much of their education as wasted, because they did not achieve a matric pass. Such emphasis on matric does not fully acknowledge the intrinsic value of education and the human capital it builds. But given the large benefits associated with achieving a matric or even a higher qualification- the improved probability of finding a good job and the likelihood of earning much higher wages -, it is understandable that many parents and learners measure educational success by achieving at least matric.

Another way to consider the costs is to do so from the perspective of a youth of 21 years old who has only completed grade 10, despite spending thirteen years in the school system, i.e. having repeated three times. Such a youth would have cost the state $8.3 \%$ more to educate than a successful matriculant who achieved matric without repeating, i.e. 13 years of education instead of 12 . In addition, whereas matriculated youths, if they did not go on to further studies, could potentially have 
been earning if they were fortunate in finding employment, the youth who only achieved grade 10 would earn $32 \%$ less per year ${ }^{2}$, if both found employment.

In this respect, repetition is very costly. It is a waste of public resources, a waste of years and often a waste of children's potential. However, this does not necessarily mean that the correct policy response is automatic promotion - this is too complex an issue to resolve so easily and requires significantly more research in country specific contexts. As will be explained, the international evidence on the benefits of repetition for skills mastery is mixed, particularly in the foundation phase where holding back learners in some country contexts can positively improve their learning outcomes. Yet it is apparent that the high repetition rates generated in the South African school system (especially at higher grades) are wasteful, and that improvement in this regard - preferably generated by improved quality of learning at younger ages, starting in the Foundation Phase - should be strived for.

This report uses EMIS obtained from the Department of Basic Education. Resep is grateful for the opportunity to use this data and believes that this data should be utilised much more intensely, which would occur if it is more generally available to researchers. Using this data has, however, made the researchers aware of the considerable deficiencies in the data, something that often applies to administrative data. School-level EMIS data for two provinces (Free State and Mpumalanga) were not made available for 2015 or 2016 . But even the data that are available suffer from serious deficiencies. Some schools do not even record enrolment data for all grades, for instance, and even more schools do not record repetition numbers for all grades, and sometimes do not record any repetition at all. This problem persists despite moves away from paper-based Annual Survey of Schools reporting at the school-level to the electronic use of SA-SAMS. This problem should receive serious attention from the DBE, as accurate educational planning is constrained without such data.

\subsection{BACKGROUND TO THE STUDY AND RESEARCH QUESTIONS}

The aim of this study is to illuminate the repetition and dropout problems in South African schools, focusing on flow-throughs in secondary school. This study was initiated in response to concerns raised by the DG Murry Trust about dropout and repetition and the cost implications of these two issues for the South African fiscus and economy. Five key research questions were proposed at project inception. Each question is covered in this report with varying degrees of completeness and certainty.

1) What does the international literature tell us about repetition and dropout in other countries?

Section 2 of the report weighs up the existing international evidence on the arguments for and against repetition. This is followed by a discussion of available, yet limited research on repetition in South Africa.

2) How large is repetition and dropout at different grades and ages in all the provinces, and how are dropout, repetition and flow-throughs related?

Sections 3 addresses this research question within the limitations of available data. Both household survey and administrative data are used to obtain estimates of repetition and dropout.

\footnotetext{
${ }^{2}$ This is 1 less the averaged median annual earnings (between ages 19 and 21) for someone with a grade 10 over the averaged median annual earnings (between ages 19 and 21) for someone with a grade 12. Earnings estimates are from median earnings in the Post-Apartheid Labour Market series.
} 
Two further questions relate to the fiscal costs, and the opportunity costs (the costs of the opportunity forgone) for persons who enter the labour market with less school education than they would have obtained if not for repetition or dropout.

3) What difference would it make, in monetary terms, if a 21-year-old who had repeated 3 times and failed to attain matric, had been more successful?

4) What is the cost of such repetition in fiscal terms?

These issues are addressed in Section 4.

The final question was:

5) How random is repetition, based on the limited information available?

Grade 3, 6, and 9 learners in the Western Cape write an external assessment in language and mathematics. This assessment is unique to the Western Cape. These data were unfortunately not available for this study, but Section 2.3 summarises Resep's recent analysis for the Western Cape Education Department using the CEMIS and Systemic Evaluation data to evaluate the linkages between repetition and learner performance.

\subsection{BACKGROUND TO THE ISSUE IN THE SOUTH AFRICAN CONTEXT}

Almost half of any cohort of South African youths never complete matric, which leaves them with few opportunities in the labour market. This does not receive any dedicated national attention in education policy. Though government has put in place a repetition policy that states that no child should be held back more than once in any education phase, this does not necessarily keep repetition rates low, nor is this policy always fully complied with by many schools, including primary schools. In secondary schools, moreover, the policy has never achieved great traction and many schools apply measures referred to as "weeding" or "culling", holding back weaker students to keep the schools' matric pass rate high. Recently, the Minister of Basic Education announced steps whereby many children who have failed grade 11 were automatically progressed to grade 12 . Surprisingly notable proportions of the progressed learners passed matric on their first attempt. However, this policy could increase incentives for schools that wish to achieve good matric pass rates to hold back weaker performers at even earlier grades.

Internationally, there is strong opposition to repetition in developed countries, as discussed in the literature review in the next section. This is in part based on psychological research that has shown the negative impact of repeating on many children who had to repeat. In addition, there has not been convincing evidence that holding back children who perform weakly improves their future performance. It is usually considered better in developed countries to devote more resources to remediation to prevent weak performing students from falling too far behind or to ensure that they catch up once they have fallen behind.

Developing country contexts make it more difficult to prevent repetition. As many more children fail to achieve at appropriate levels due to poor home learning resources or poorly performing school systems, repetition is very common, which may perhaps lessen the psychological scars of repetition somewhat. Furthermore, developing countries usually do not have the resources for remediation, thus classes become increasingly heterogeneous in terms of cognitive performance as children progress to higher grades. High repetition rates then simply lead to greater heterogeneity in terms of age groups in classes. In Lesotho, for instance, only $28 \%$ of children in grade 6 are the appropriate age. Another $28 \%$ are one year over-aged, $20 \%$ are two years, and $24 \%$ are three or more years too old for 
their grade. Many developing countries have a high-stakes exit examination at the end of primary school that determines progression to secondary school. Failure rates in these examinations are often high, and the performance of schools is often measured by how children perform in these examinations. For that reason, "weeding" may be applied in the previous year, leading to high repetition in that grade (usually grade 6, as primary exit examinations are mostly in grade 7).

In investigating progress to secondary education in Francophone African countries, Calloids (2001: 134) concluded that "... while there is probably a problem of low quality, recent research carried out at the primary-education level shows, however, that decisions regarding repetition can be fairly arbitrary, having more to do with the existence of a culture of repetition than with an independent assessment of pupils' achievements."

The table below shows rates of repetition in the last year of primary, lower secondary and upper secondary (years in which external examinations take place) at around 1999 in public schools in some francophone African countries.

Table 2: Repetition rates at the end of various school phases in public schools in francophone African countries, SERCE 1999

\begin{tabular}{|l|l|l|l|}
\hline & End of primary & End of lower secondary & End of upper secondary \\
\hline Burkina Faso & $35 \%$ & $44 \%$ & $34 \%$ \\
\hline Mali & $37 \%$ & $35 \%$ & $\mathrm{n} / \mathrm{a}$ \\
\hline Senegal & 29 & $24 \%$ & $28 \%$ \\
\hline Madagascar & $30 \%$ & $37 \%$ & $41 \%$ \\
\hline Côte d'Ivoire & $43 \%$ & $14 \%$ & $32 \%$ \\
\hline
\end{tabular}

Source: Calloids 2001: 147

In South Africa, many children are poorly prepared for entering the Intermediate Phase (grade 4 to 7), given how weak the learning of reading is in the Foundation Phase. The PIRLS 2016 study found that $78 \%$ of South African grade 4 children could not read for meaning in the language they were taught in in the Foundation Phase. Repetition in the Foundation Phase is already quite high: Van Wyk et al (2017: 11) found that of the almost 78000 learners in Western Cape schools in grade 1 in 2007, only just over 44000 (56\%) had reached grade 7 in 2013, 6 years later. Almost 34000 (44\%) had repeated at least once, and just over 1200 had dropped out of the Western Cape public school system (this could have implied dropout, moving to another province or moving to private schools not participating in CEMIS). For the grade 9 cohort, flow-through patterns appear even worse: Of the 85000 in grade 9 in 2010, only 34000 (40\%) were in matric 3 years later, and another 18000 had repeated at least once but still remained in the system, implying that only around 52000 out of those that started in grade 9 three years earlier were still in the schools system, while $38 \%$ had dropped out.

Some of the consequences of repetition is that class sizes in some lower grades remain large when few learners drop out at these levels. At higher age levels, however, repetition is closely associated with dropout. Van Wyk et al. (2017: 25-6) tracked children who had failed grade 9 in the Western Cape in 2008 to 2010 and found that such failure was for many a precursor to drop out. Of the cohorts who failed grade 9 , only $8 \%$ to $10 \%$ were in matric four years later, and another $16 \%$ to $18 \%$ were still in school but had repeated at least once more. That implies that around three-quarters of those who had failed grade 9 had dropped out within the next four years.

High rates of repetition are symptomatic of weak education system performance. This gives rise to costs for the individuals and households concerned, but also for the national budget. Such internal inefficiency in the school system means that children need to spend more than the required number 
of years at school to achieve a particular level of education. This raises overall fiscal costs of education whilst also raising pupil-teacher ratios. The greater heterogeneity of ages in classes make them more difficult to manage. Moreover, for many children the slow progress through school makes the attainment of a school leaving certificate (the National School Certificate, NSC, more commonly referred to as the matric certificate) impossible, weakening their opportunities for good jobs in the labour market, and also negatively affecting productivity in the workplace.

Against this background, Resep undertook this study for the DG Murray Trust to illuminate the repetition and dropout problems in South African schools, with particular focus on flow-throughs in secondary school. In order to do this, Resep wished to make use of various data sets. The process of obtaining data and permission to use it was quite slow and not all of it successful. Eventually only national EMIS (Education Management Information System) data and data from the Northern Cape SA-SAMS system were available. Drawing from earlier analyses of CEMIS and Systemic Evaluation data in the Western Cape, an indication is also presented of how random repetition is in the South African context.

\section{THE LITERATURE ON REPETITION}

\subsection{AUTOMATIC PROMOTION VERSUS REPETITION: CURRENT STATE OF THE INTERNATIONAL DEBATE}

\subsubsection{REPETITION VS AUTOMATIC PROMOTION: STILL CONTROVERSIAL}

The public education system is tasked with providing learners with a basic set of skills and knowledge that may enhance their potential life outcomes. In accomplishing this task, a key challenge to teachers and education policymakers is responding to diversity in the classroom. School classes in any grade, but more so at lower grades, are highly heterogeneous: with individual learners exhibiting varying levels of cognitive ability, behavioural traits and general 'readiness' for the demands of schooling. Such heterogeneity manifests most consequentially in assessment outcomes, the strongest indicator of whether learners have achieved some prescribed level of competency in core subjects. Each year many learners do not demonstrate such competency and will require remediation. Commonly, remedial action is instantiated as grade repetition ${ }^{3}$.

Grade repetition occurs when, at the end of a given school year, a learner is not promoted to the next grade but returns to the same grade in the following year. Repeating a grade is no trivial event. As with dropping out of school entirely, grade repetition is commonly experienced as a severe manifestation of learner failure. The harm to self-esteem and motivation is indeed one of the arguments held by detractors of repetition who claim such harm to outweigh any benefits that may flow to repeaters. Many researchers argue that the effect of repetition on scholastic outcomes is negative or, at best, negligible (Holmes \& Matthews, 1984; Brophy, 2006; Jimerson, 2001b). However, others argue that this view is not entirely well founded (Lorence, 2006; Reschly \& Christenson, 2013). Whether repetition hurts or helps repeating learners has now been studied for a century and has been in dispute for as long.

3 Sometimes called 'grade retention'. For consistency, this report will use the term 'grade repetition' throughout. 
Going beyond the individual learner, the effect of high repetition rates on educational expenditure is indisputable. Understanding whether repetition is an effective remedial practice for straggling learners is thus of importance for policymakers who wish to promote learning while ensuring sustainability and credibility of the education system. Detractors of grade repetition usually advance the alternative of automatic promotion as a superior policy. However, it is intuitively clear that promotion without learning too is undesirable. Graduating learners without the requisite skills and knowledge does not prepare them for further education and limits career opportunities. Increasing heterogeneity of outcomes among graduated learners also imposes costs on higher education institutions and employers who must then remediate learning deficits accumulated earlier. It also reduces the signalling value of education in the labour market, as it causes doubts for employers about the expected productivity of individuals with specific levels of education. Further, it lowers trust in the education system as a tool for social and economic progress.

It is important to distinguish between the causes and implications of repetition. Low achievement may result from a myriad factors that exist outside the reach of education policy. Adverse factors at the individual level such as a non-stimulating home environment, low cognitive ability or a lack of 'readiness' for learning are not easily remediated in schools. However, factors residing within the system, including school-level factors and even regional education administrations (Gustafsson \& Taylor, 2018), may bear a significant influence on learner achievement. Where there is evidence of the latter, policy should perhaps be concentrated on ameliorating the school/system level factors.

Beyond increasing both the education budget and the learner/teacher ratio, the implications of repetition are not easily discerned. Yet promotion policy is in the control of education officials and must be implemented in the interest of learners. It is a common finding that repetition is associated with dropout. If this relation is causal - that repeating a grade reduces the likelihood of a given learner completing the school cycle - then the repetition policy merely exacerbates the adversity of low achieving learners and is a counterproductive policy. Conversely, should evidence emerge that repeaters, in the main, benefit from the extra year(s) spent in the same grade, then the policy is, perhaps, desirable.

Lowering repetition rates and school dropout is a noble goal. Efficiency enhancement in the education system confers substantial benefits on society over multiple time horizons. Short-term gains include less resource wastage and, consequently, greater efficiency in budget allocations. Greater efficiency also results in better educational outcomes that potentially translate into higher long-term economic growth. Understanding the effects of repetition therefore has an efficiency argument as well as a pedagogical one.

\subsubsection{DIFFERENT COUNTRIES, DIFFERENT PRACTICES}

A preponderance of education research supports the notion that grade repetition increases the risk of adverse outcomes for affected learners and carries negligible benefits, if any ${ }^{4}$. The policy explains little in achievement differences across countries (Eisemon, 1997, p. 10; Ndaruhutse, Brannelly, Latham, \& Penson, 2008, p. 17). High repetition and dropout rates risk the credibility and sustainability of the education system. Repetition is an expensive policy. Increasing the average number of years, it takes a learner to progress through the mandatory school cycle can substantially increase the

\footnotetext{
${ }^{4}$ Lorence (2006) argues that much of the earlier research suffers from methodological shortcomings that invalidate their findings. He therefore suggests that the evidence for negative effects of repetition is less persuasive than is suggested in education research.
} 
expenditure required for education ${ }^{5}$. Eide and Goldhaber (2005, p. 212) conduct a cost benefit analysis of the policy and conclude that even when "optimistic assumptions" are made about positive effects of repetition on achievement, the costs to the individual of being retained exceed the benefits ${ }^{6}$. Darling-Hammond and Falk (1997) highlight three further issues related to the policy that operate at the individual level:

1) Intellectual and social development is a continuous progressive process. Forcing a child to repeat a grade may harm the developmental process. Children's development should rather be supported by a school structure and rules that enhance the natural development cycle.

2) Repetition is often based on simple easily measured criteria like standardised testing. Such tests may provide an imperfect measure of a given learner's knowledge.

3) Repetition assumes that the fault of poor performance in a given grade is due to the learner's failure to master the grade level content. The pattern of repetition incidence points to the importance of other factors, such as socio-economic-status, school quality and the home environment. Targeting all these factors is not a feasible option for education policy but recognising them steers the focus away from the learner's effort or aptitude as the sole target variable. If all these and other potential adverse factors interact to present poor scholastic performance, repetition will likely exacerbate, rather than remediate the problem.

Given its consequences for learner outcomes and educational expenditure, it is natural to seek justification for grade repetition as a desirable education policy. When looking across countries it appears that adopting the practice depends on several contextual factors independent of pedagogical considerations. Education serves multiple goals with different objectives variously emphasised across countries. N'tchougan-Sonou (2001, p. 150) highlights the competing objectives of selecting elites and promoting shared social progress. Elite selection operates by filtering out the less capable (the nonelites), thus effectively offering more education opportunities and resource to those who advance in accordance with set standards (the elites). Anagnostopoulos (2006) presents evidence of this mechanism operating in Texas schools where repeaters were not only held back but also segmented from the promoted cohort, receiving a qualitatively different standard of instruction.

While cross-country repetition rates are fundamentally explained by policy choices, Goos et al. (2013), looking particularly at OECD countries, suggest other factors contribute to this variation. In developing countries, promotion policies are often inherited from their colonial past so that Francophone African countries typically practice repetition while Anglophone countries do not do so to the same extent (Eisemon, 1997, p. 32). In some low-income countries, high repetition rates result from limited educational resources ( $N$ 'tchougan-Sonou, 2001, p. 151). This seemingly paradoxical result follows from the observation that a broader distribution of enrolment across grades requires greater educational resources than having enrolment skewed to primary schools with restricted access to (scarce) skills-intensive and cost-intensive secondary schools. Some countries with high repetition rates also appear to have normalised the practice, creating over time what Eisemon (1997, p. 31) calls 'cultures of repetition', where the historical practice of keeping low achieving learners behind gains

\footnotetext{
${ }^{5}$ Fiske et al. (1998) estimated that in 1995 sub-Saharan Africa countries' wastage made up for 33 per cent of total educational expenditure.

${ }^{6}$ The author derives estimates for the discounted present value of life-time returns to academic achievement to make the comparison.
} 
legitimacy and gives rise to the expectation of high repetition rates that in turn feed into decisionmaking regarding learner promotions.

\subsubsection{FORMS OF GRADE REPETITION}

Brophy (Grade repetition) highlights five forms of grade repetition, separated into voluntary and involuntary forms. The voluntary forms include repetition due to limited space or access at higher grades, forcing those who wish to remain in school to repeat grades in the hope of gaining access to higher grades in the subsequent year. Family induced repetition too is considered voluntary and may occur if a learner's parents are not satisfied that their child has satisfactorily achieved at a given grade and, fearing failure at the next grade, they prefer to have the child repeat and improve her/his chances in subsequent grades. The third form of repetition occurs where there is a mismatch between the learner's home language and the language of instruction. In these instances, repetition is primarily linked to achieving fluency in the language of instruction that does not occur at home. A fourth form is explicitly involuntary, involving failure of a high-stakes assessment. This type of repetition is typically practised at higher grade levels that determine the future academic course of learners. Here students may have options other than repetition, such as branching into a vocational stream or dropping out entirely to enter the workforce. The fifth form of repetition is both involuntary and without alternative options. Imposed by schools, this form requires learners to achieve at a certain level to graduate to the next grade. Not achieving at the prescribed level leaves the learner with no option but to repeat the grade.

Intuitively the case for grade repetition has merit. Large variation in learner attributes with in the same grade complicates the task of teachers and the education system. Grade repetition is one means of reducing such variation. Setting thresholds for grade promotion ensures that all learners in a given grade have achieved above some prescribed standard, thus keeping learners within a grade similar. In this way grade repetition signals enforced quality standards in the school system. Another outcome of the policy is that repetition tends to increase age ranges within grades. Trading off age heterogeneity within grades for achievement similarity must take into consideration the pedagogical and social implications of having a wider age range within a grade or classroom (Reschly \& Christenson, 2013, pp. 321-322). For instance, Jones (2013), using data from three East African countries, finds substantial negative achievement effects of raising the ratio of over-age for grade learners in a classroom.

Another argument in favour of grade repetition is the promotion of standards. Repetition rates are often viewed as evidence that the school system is performing its function of promoting learning. Learners who do not progress through the system in the minimum number of school years are assumed not to have met the standard required for grade promotion. Indeed, for adherents, viewing repetition as punitive does not detract from its appeal. The very threat of being held back is meant to induce effort on the part of learners who wish to avoid this fate (Eider \& Goldhaber, 2005, p. 206; Välijärvi \& Sahlberg, 2008, p. 386). Viewed in this light, it is assumed that the school system provides adequate support to all learners to progress smoothly through the grades.

There is, furthermore, an assumption that curricula are appropriately designed for the learners who are meant to master its content. Pritchett and Beatty (2012) summarise the results of several experiments and observational studies in developing countries investigating the alignment between learner ability and education material and instruction and how misalignment influences learning. They find instances of significant misalignment in several developing country education systems and report substantial negative effects on learning as a result. They argue that making instruction sensitive to learners' ability can significantly improve learning. For instance, in Pakistan where learners in private 
schools tend to outperform their public school counterparts, Pritchett and Beatty $(2012$, p. 44) find that misalignment between instruction and learner ability is much lower in the private schools. The implication may be that existing 'standards' are deemphasised (or, perhaps, seemingly sacrificed) in favour of the pursuit of mastery of more basic but achievable and useful skills (Pritchett \& Beatty, 2012, p. 48).

\subsubsection{EMPIRICAL EVIDENCE ON THE EFFECTS OF REPETITION}

In an early survey, Jackson (1974) reviewed 44 research papers aiming to estimate the effects of grade repetition in developed countries. Reviewed papers exhibited three primary research designs: the comparison of repeaters with matched promoted learners, simply tracking the outcomes of repeaters, and a few experimental designs where matched learners were randomly assigned either to repeat a grade or to be promoted. In discussing the relative benefits of grade repetition or promotion, Jackson (1974, p. 627) concluded his review stating that "the accumulated research evidence is so poor that valid inferences cannot be drawn concerning the relative benefits of these two options". Although current research designs tend to be better, no consensus has yet emerged as to whether repetition or promotion should be the favoured policy response to low achievement. Throughout the $20^{\text {th }}$ century, research findings on the effects of repetition have been somewhat consistent and negative (Fiske, Rwehera, Chu, \& Mputu, 1998, pp. 37-39). Grade repetition was found to be closely correlated with later school dropout and low achievement. However, methodological innovations over the last two decades resulted in a challenge to earlier findings. Recent research, which explicitly controls for selection effects - pre-conditions that may explain dropout that also correlate positively with the probability of repeating a grade - has in some cases found positive effects for repeaters (Lorence \& Dworkin, 2006; Lorence, 2006; Jacob \& Lefgren, 2004).

Given the scale of the challenge and the magnitude of associated costs, determining which is the better alternative remains important. Reporting findings at the level of individual countries is also important. Various scholars point out the importance of country-specific factors when evaluating education policy (Eisemon, 1997; Nalova, 2016) ${ }^{7}$. This section will present empirical findings on the effects of grade repetition and automatic promotion. Findings from developed countries are presented first, followed by developing country evidence.

\subsubsection{DEVELOPED COUNTRY RESEARCH}

\subsubsection{REPETITION AND DROPOUT}

Establishing the link between grade repetition and dropout is complicated by the fact that both these outcomes may be explained by other factors, such as low ability or an adverse home environment that hinders academic achievement. Researchers wanting to measure whether repetition causes dropout (at least to some degree) must account for the fact that learners who eventually drop out may have pre-existing risk factors that predate their repetition and, indeed, may explain both outcomes. Typically, researchers use a technique known as 'matching' to overcome this issue of 'confounding variables'. Matching is the practice of grouping learners with similar observable characteristics believed to be associated with an outcome of interest together. Testing the hypothesis that repetition causes dropout thus requires researchers to group learners with similar characteristics that may

\footnotetext{
${ }^{7}$ As an illustration of the importance of understanding varying causes of repetition, N'tchougan-Sonou (2001) provides the example of Togo, a country that effectively limited the number of entrants into high school, which had the implication of 'failing' a high number of learners in the final year of primary school
} 
predict their propensity to drop out. This 'matched' group is then split into two subgroups: one comprising those learners who have repeated a grade and the other group comprising learners who have never repeated a grade. It could then be argued that comparisons between these two subgroups may isolate the effect of repetition on other outcomes.

Conceptually, a causal relationship between repetition and dropout seems reasonable. Repetition could result in learners having a negative attitude towards school which reduces motivation and induces disengagement. Repeaters may also present lower self-esteem or feeling 'out of place' among a younger cohort of learners (Holmes \& Matthews, 1984). All these factors could in turn increase the risk of dropout.

Roderick (1994) investigated whether being over-age for grade is a mediating factor for repeaters who eventually drop out. She tracked the outcomes of a cohort of learners from a single school in the state of Massachusetts in the United States. Controlling for achievement results and school attendance, the study found that repeating a grade doubled the risk of dropout at age seventeen ${ }^{8}$ (Roderick, 1994, pp. 739-741). She then tested whether being over-age-for-grade is a mediator for dropout. Exploiting the fact that the cohort under study included over-age learners who had never repeated a grade, Roderick repeated her estimation of the effect of repetition on dropout but included an age variable, which was found to be highly explanatory. While the limited scope of the study precludes generalisations, the impact of being over-age for grade on dropout is worth investigating in contexts where repetition is a standard practice.

Jimerson (2001b, p. 52) reports on the findings of three meta-analyses on the effects of grade repetition. Among the 83 studies included in the review, a subset of 17 studies estimated the effect of repetition on dropout. All 17 these studies found a negative effect, leading Jimerson (2001b, p. 53) to assert that "grade retention has been identified as the single most powerful predictor of dropping out". In a subsequent paper, Jimerson et al. (2002) focus on repetition's effect on dropping out of school.

Chicago's experience with transitioning from an automatic promotion policy ${ }^{9}$ to grade repetition has received much research interest. Allensworth (2004) analysed the differences in dropout rates among under-achieving learners in the eighth grade. She found no effect of the promotion gate policy on dropout, as the slight increase in dropout among low achievers was offset by a decline in dropout among non-repeaters. She highlighted the distinction between teacher-initiated and purely assessment-determined repetition (a promotion gate policy) and claimed that the association between teacher-initiated repetition and dropout was three times stronger than the association between repetition due to the promotion gate policy and dropout. One interpretation of this finding is that the promotion gate serves as a credible signal of learning quality. In general, Allensworth (2004, p. 29) concluded that the promotion gate adversely affected "the most vulnerable" learners, yet had only "modest" positive effects for other learners' likelihood of completing the full school cycle.

Jacob and Lefgren (2009) found mixed effects of repetition on dropout depending on the grade in which a learner was held back. Using data on schools in Chicago, they estimated that the effect was insignificant on sixth grade learners but negative for eighth grade learners. They argued that the null effect size on sixth grade learners was partly due to opportunities to 'catch up' to their original cohort. In the cohorts they studied, two thirds of repeaters were able to catch up to their original cohort by

\footnotetext{
${ }^{8}$ Seventeen is the legal threshold for school dropout.

${ }^{9}$ The new policy instituted 'promotion gates' at third, sixth and eighth grades.
} 
the eighth grade. These findings support Roderick's salience-of-age hypothesis above, as do the findings in Ou and Reynolds (2010), who focused their analysis on low-income minorities in Chicago.

\subsubsection{REPETITION AND LEARNING}

School systems offer education as a service with learning as the desired outcome. For learning to happen, healthy children who are motivated and prepared must encounter a well-functioning education service. The interaction of the demand side (children and households) and supply side (teachers, schools, and education systems) determine educational outcomes.

Jimerson (2001) reviewed findings generated over a 75-year period from analyses investigating the effects of repetition on academic achievement. He reported that only nine of the 175 analyses reviewed found favourable effects for repeaters in terms of their academic achievement in subsequent years.

The United States, where important education policy is made at the state level, offers a useful set of data for these analyses (Zinth, 2005). In addition to heterogeneous within-country policies, several states have at various times changed repetition policy. These factors allow for testing the effects of repetition using various techniques and thereby raising the confidence in estimation results. One of these policy shifts occurred in the Chicago Public Schools system in 1996 and has attracted much research interest since.

Using data on learners in the Chicago school system measured both before and after the policy change, Jacob and Lefgren (2004) tested the effects of the summer school programme (mandatory for learners who failed reading and maths assessments) and grade repetition (learners who failed the exam at the end of summer school) on later achievement outcomes. They found that both summer school and grade repetition had positive effects on achievement scores, but only for third grade learners. The effect on sixth grade learners was not significant for maths and was negative for reading. The authors noted that long-term effects were not determined in their analysis and the positive effects found in the short term may peter out over time. Similarly, Lorence and Dworkin (2006) found positive learning effects for repeaters in Texas public schools. The effects, moreover, were found to persist over several years. In a follow up study, Lorence (2014) argued that learners held back in the third grade consistently outperformed matched non-repeaters on reading tests through to the $10^{\text {th }}$ grade. He suggests that the timing of repetition may be important for later outcomes. He further proposed that early retention (grades one and two) could be harmful due to a lack of maturity, while later repetition is unable to remediate accumulated learning deficits.

A meta-analysis conducted by Allen et al. (2009) found that harmful effects of repetition may have been overstated. Evaluating 22 studies conducted over the period 1990-2007, the authors concluded that the effects of grade repetition on academic achievement was negligible.

Looking at the Chicago Public Schools experience with their grade repetition policy, Nagaoka and Roderick (2004) argued that repetition had no effect on achievement growth (relative to matched non-repeaters) for learners who repeated the third grade, while sixth grade repeaters showed significantly lower achievement growth. A noteworthy finding reported in the study is that low achievers began the school cycle with an achievement deficit that grew further up to the first promotion gate in the third grade.

\subsubsection{REPETITION AND SOCIO-EMOTIONAL ADJUSTMENT}

A positive interpretation of being held back in a grade is that it presents an opportunity to prepare better for the next grade. An alternative interpretation is that one is being punished for failure to meet 
prescribed achievement requirements. Still another possible view is that it signals ineptitude relative to promoted peers. These various interpretations matter. What happens in schools affects not only learners' academic outcomes but also influences soft skills that are important for success in the labour market. In addition, failure to advance has been associated with repeaters displaying lower selfesteem and more negative attitudes toward school (Fiske, Rwehera, Chu, \& Mputu, 1998, p. 16; Brophy, 2006, p. 16).

Holmes and Matthews (1984) conducted a meta-analysis of 44 repetition studies conducted between 1929 and 1981. They found that repeaters on average lagged non-repeaters on measures of social adjustment, emotional adjustment, behaviour and self-concept, and displayed a relatively negative attitude toward school (Holmes \& Matthews, 1984, p. 231). Jimerson's (2001b) meta-analysis of twenty studies spanning the decade 1990-1999 included 148 analyses of the socio-emotional outcomes of repeaters. These analyses estimated differences between repeaters and a matched group of non-repeaters on measures of self-concept, behavioural adjustment and socio-emotional adjustment. Jimerson (2001b) found that repeaters scored consistently lower on these measures relative to matched peers who did not repeat a grade.

Wu and West (2010) found positive effects of first grade repetition on a range of psychosocial variables for a small sample of learners in the United States. However, positive effects were short-lived and evaporated by the third year after repetition.

\subsubsection{EVIDENCE FROM DEVELOPING COUNTRIES}

Repetition rates have long been known to be significantly higher in developing countries. Fiske et al. (1998) reported repetition rates for various regions around the world. Their report estimated that in 1995 sixteen per cent of school enrolees in sub-Saharan Africa were repeaters. UNESCO (2012, p. 21) reports that 35 per cent of primary school repeaters reside in Africa with South and West Asia comprising 28 per cent of the total.

\subsubsection{REPETITION AND DROPOUT}

Andre (2009) investigated the relationship between repetition and dropout using enrolment and achievement data from 98 Senegalese schools. Controlling for various confounding variables, he found a substantial and positive effect of repetition on dropout. The estimated effect translated to a threefold increase in dropout risk for repeaters relative to non-repeaters.

Manacorda (2012) studied the effects of Uruguay's repetition policy on learner outcomes. He estimated that repetition was associated with dropout while the effect on educational attainment was also negative, with repeaters exhibiting -0.8 school years deficit relative to non-repeating peers five years after repetition.

Glick and Sahn (2010) showed that among Senegalese learners of similar ability, repeaters were more likely to drop out of primary school than non-repeaters. The study was able to exploit the variation in assessment thresholds for determining promotions. This variation allowed the researchers to compare learners of similar observed ability but with different progression rates resulting purely from variation in school policies. 
Reversing the common trend of establishing the effect of repetition on outcomes, Okurut (2018) estimates the impact of grade promotion on school dropout in Uganda ${ }^{10}$. Uganda adopted the practice of automatic promotion in the public school system without compelling the private sector to do so. Okurut (2018) exploits the resulting 'dual' system by comparing dropout outcomes for similarly performing learners across the two systems. He finds that the adoption of automatic promotion resulted in a lower likelihood of dropout among students at the lower grade (primary 3) while the results show minor effects at the higher grade (primary 6 ).

\subsubsection{REPETITION AND LEARNING}

King et al. (1999) investigated the relationship between promotion policy and years of schooling in the Northwest Frontier Province of Pakistan. The authors exploited the fact that learner promotion policies were not consistently applied - that is, decisions to promote or retain learners were often based on factors other than academic performance. They then contrasted the outcomes of poor performing learners who had been promoted with learners whose promotion was apparently based on merit. The study found that promotions not based on observed achievement were associated with higher dropout rates. King therefore suggested that shifting towards a practice of automatic promotion would have a negligible effect on learner retention in Pakistan. This finding is in line with Hanushek et al. (2006) who derived a similar result in Egypt. Although the focus was on dropout rather than repetition, Hanushek et al. (2006) found that school quality mattered for individual or household decisions on whether to stay in school. Ndaruhutse et al. (2008, p. 14) argued that this mechanism is in operation in sub-Saharan Africa, where education is often of low quality and enrolment is weighed against employment opportunities for children. These findings point to an important linkage between school quality on the one hand and grade progression and learner retention on the other hand. Learner (and, indeed, household) investment is a key input into the learning process, and these investments are apparently influenced by the observed quality of other inputs and the expected value of a school's output.

Koppensteiner (2014) examines the effect of automatic promotion on achievement in Brazil. Having had a history of grade repetition as the promotion policy, Brazil introduced automatic promotion in early 2000's, in part as a cost reduction measure following large scale enrolments associated with the Bolsa Familia programme (Koppensteiner, 2014, p. 278). He estimates that automatic promotion lowered achievement on math assessments by 7 per cent of a standard deviation. This finding supports the view that the threat of repetition provides a disincentive for low effort and thereby raises academic achievement.

\subsubsection{REPETITION AND INTERNAL EFFICIENCY}

Ndaruhutse et al. (2008, pp. 24-25) report wastage estimates for various African countries. Estimates range between 17 per cent in Ethiopia (due to repetition) and 65 per cent in the Central African Republic (ascribed to both repetition and dropout) of total education expenditure. These striking figures illustrate the inefficient use of resources where it is most scarce. They also reflect a lot of variation in this regard within Africa, suggesting high-waste systems could perhaps learn from neighbours nearby. N'tchougan-Sonou (2001) compared rates of internal efficiency across two education systems with differing promotion policies. Ghana practiced automatic promotion while Togo had adopted grade repetition and exhibited relatively high repetition rates. The authors

\footnotetext{
10 The Ugandan education system follows the practice of automatic promotion. The country thus exhibits a relatively low repetition rate. Last measured at
} 
compared rates of internal efficiency ${ }^{11}$ between the two systems and judged the Ghanaian system as having greater internal efficiency, although missing data precluded the derivation of conclusive evidence of this outcome.

\subsubsection{EQUITY CONSIDERATIONS}

Expanding opportunities for all is an important objective of education. It is thus reasonable to ask whether the promotion policy of a school system aligns with equality objectives. Besides scholastic outcomes, repeaters share other similarities. They are more likely to have been exposed to poverty, single parent households, lower quality of education, and less stimulating home environments. Given these circumstances, grade repetition may merely compound pre-existing maladies and further entrench disadvantage among already vulnerable groups. While not entirely causal, the association between socio-economic status and educational outcomes is significant and focusses attention on the bearing of grade promotion policies on equality of access for all learners (Brophy, 2006, p. 18; OECD, 2014). These considerations are generally adjudicated via political processes (N'tchougan-Sonou, 2001 , p. 153) and will ultimately reflect societal preferences ${ }^{12}$. A debate point that emerges in this context is the trade-off between quality and equity, which holds grade repetition and automatic promotion as opposite poles in terms of school promotion policy.

A foundational feature of automatic promotion is the egalitarian ideal of granting all learners the opportunity to experience all that the education system offers. There are opposing views on whether the nature or even the existence of a trade-off between equity and quality of education (N'tchouganSonou, 2001, p. 153). The case against automatic promotion is straightforward: advancing leaners on to the next grade regardless of achievement means that some learners will be ill-prepared for more advanced material, ultimately deferring failure to a point in the life-course where necessary remediation is more difficult to achieve. Moreover, the perception of lower standards undermines credibility of the system as a purveyor of learning. It would then appear that school systems must sacrifice the quality of education in service of equity considerations. N'tchougan-Sonou (2001) argues this to have been the case in Ghana, where in 1987 an education policy reform included automatic promotion and saw a rise in access accompany a drop in average learning as measured by achievement tests.

However, some researchers have found that both quality and equity can be simultaneously attained. The Finnish education system is routinely cited as proof that educational reforms can promote both quality and equity goals (World Bank, 2018, p. 15; Välijärvi \& Sahlberg, 2008, p. 385). In the developing country context, Hanushek et al. (2006) suggested that a trade-off between equity and quality in education is 'misstated'. These authors investigated the dropout behaviour of learners in Egypt and found support for the view that school quality informed dropout decisions. Controlling for learner ability and achievement, the study found that learners in lower-quality schools were more likely to drop out than observationally similar learners in higher-quality schools (Hanushek, Lavy, \& Hitomi, 2006, p. 27). School quality therefore supports learner retention and grade promotion.

\footnotetext{
${ }^{11}$ Broadly, internal efficiency relates the ratio of the learning taking place in a school system (the output) to the costs incurred by the system (the inputs). In their study, N'tchougan-Sonou used the difference between gross enrolment rates and net enrolment rates as proxies for system efficiency.

12 In countries with some sub-national autonomy education systems exhibit different practices, as in the United States (Zinth, 2005). Different practices are even evident within systems reflecting diverging district or schoollevel views on the policy (Bali, Anagnostopoulos, \& Roberts, 2005).
} 
Automatic promotion need not mean that learners are held to a lower standard. However, its adoption must be accompanied by increased quality in other inputs and remediation to support low achieving learners (Brophy, 2006, p. 22). Proponents of automatic promotion do not necessarily suggest that promoted under-achievers benefit academically from the policy but rather that low achievers will, on average, suffer less harm from promotion relative to being held back.

In a qualitative study, Anagnostopoulos (2006) closely examined the implementation of grade repetition in two Texan schools and found that the policy may itself have been a source of social exclusion. A striking observation, invisible to purely quantitative analyses, is how implementation affected perceptions and outcomes of repeating learners. In the schools examined, repeaters were grouped into classes separate from non-repeaters and received a qualitatively different, less inclusive and less affirming style of instruction (Anagnostopoulos, 2006, p. 29). The stigma of failure is also one reason cited for Finland's education reform away from grade repetition in the 1970s (Välijärvi \& Sahlberg, 2008, p. 387).

Social promotion or automatic promotion aims to advance equity in the education system but raises tension between advancing social outcomes and maintaining quality standards.

\subsubsection{PROMOTION POLICY OPTIONS}

Alexander et al. (2003) suggested that there are three types of responses in instances where learners fail to demonstrate grade level competence typically required for advancement to the next grade. These comprise grade repetition, automatic promotion, possibly with supportive remedial activities; and overhaul of the system. Much research is focused on producing support for or against either of the first two of these alternatives. In recent years, the option of system overhaul has received increasing attention.

Low academic achievement should ideally be prevented rather than remediated. In instances where repetition rates are excessive or learning profiles are relatively flat, curriculum alignment with learners' aptitude, as advocated by Pritchett and Beatty (2012), may be an effective strategy.

Early detection of low achievement means the problem can be countered with measures less drastic than grade repetition. Picklo and Christenson (2005) recommended variable instruction strategies to meet diversity among learners in the classroom. They emphasised the importance of using 'evidencebased instructional options' which may emerge from educational reforms stressing accountability (Picklo \& Christenson, 2005, p. 267). This sentiment is in keeping with that expressed in the most recent World Bank Development Report, which argues that more measurement is required in education (World Bank, 2018, p. 17).

Fiske et al. (1998) offer several policy proposals to reduce wastage in the education system. These proposals are echoed throughout the literature and include, among other things, improving teaching methods by emphasising teachers' responsibility for learner outcomes; early identification of and early intervention in response to low learning and achievement; and accelerated classes for repeaters to 'catch up' to age peers.

Summer schools are a common intervention in US states with a grade repetition policy. Jimerson et al. (2006, p. 91) noted that struggling learners may well need additional time with the same material to achieve at desired levels and this extra time could be granted during the first year in a grade. This intervention relies on either early identification of low achievement risk or identification via a summative assessment with subsequent remediation and a second opportunity for promotion. In the former scenario, at-risk learners could enrol in an after-school programme, while in the latter case, 
learners could be invited to enrol for a 'summer school' programme. In either case, low-achieving learners are offered additional and perhaps more intensive instruction tailored to their needs without having to repeat a grade.

\subsection{REPETITION IN SOUTH AFRICA - WHAT WE KNOW FROM PREVIOUS STUDIES}

Having considered the international literature and the arguments for and against repetition policy, this section briefly sets out information from available studies that reflect on repetition in the South African context. The available literature can be distinguished into three parts:

- Reports that document rates of repetition from household surveys or administrative data.

- Studies on the determinants on repetition, or the links between repetition and dropout.

- Studies on the linkages between repetition policy and rates of repetition.

\subsubsection{MEASURING REPETITION IN SOUTH AFRICA}

Studies on grade repetition in South Africa are generally limited. Reasons for this pertain to either the limited number of household surveys asking direct questions on repetition or concerns about the reliability of data in the schooling system that do collect repetition information. This makes it difficult to carefully study this issue.

Evidence from the Census, Community Survey or the Labour Force Survey (LFS) on age distributions among those currently enrolled in a given grade, suggest that there are high rates of grade repetition (particularly in the FET phase), but this evidence is only indirect. In more recent years, questions on repetition have been included in the General Household Survey (GHS) and the National Income Dynamics Study (NIDS) - a longitudinal study that tracks individuals over time in 5 waves. NIDS is unique as it collects retrospective data on grades failed, the number of times an individual failed a specific grade and the age at which individuals started school and completed their schooling. The discussion that follows considers three very useful studies that exploit the value of NIDS in considering the determinants of repetition or whether repetition may have been affected by policy changes (Branson \& Lam, 2010; Branson, Hofmeyr, \& Lam, 2013; Kika \& Kotze, 2018).

The analysis in this section will reflect on reported repetition rates from existing studies. However, some important caveats are revealed in reading the local literature. Even within the same year, different household surveys suggest different rates of repetition. It is also evident that both existing studies on repetition using household data and analyses using administrative data are subject to limitations. In this respect, it is best practice to consult various sources of data to get estimates of repetition than to rely on one source alone. Furthermore, household surveys are potentially providing under-estimates of repetition, particularly at grade 1 . This highlights the importance of having high quality administrative data that tracks learners across grades and schools to monitor repetition (and dropout) trends in the system. Unfortunately, South African administrative data is currently not yet of such quality.

\subsubsection{REPETITION POLICY AND REPETITION RATES IN THE FET PHASE}

Repetition policy has received considerable attention over the years, with policy changes in recent years that affect repetition in the Further Education and Training (FET) phase, covering grades 10 to 12. In 1998, the then Department of Education adopted the Admission Policy for Ordinary Public Schools. The guideline for repetition in this policy was "one year (of repetition) per school phase where 
necessary" (Department of Education, 1998). This grade progression policy, since gazetted in 1998, was largely applied to the General Education and Training Phase (grade R-9). However, for the FET phase this policy was only specifically endorsed at the start of 2013 (Department of Basic Education, 2012). The aim was to address the particularly high repetition rates observed in the FET phase which is strongly driven by schools holding back learners in attempts to achieve better results in the matric examination.

Kika and Kotzé (2018) use all 5 waves of NIDS to explore whether repetition in the FET phase has declined since the introduction of the policy in 2013. The NIDS questionnaire asked individuals aged 15 to 30 to report how many times they had repeated a grade when at school and which grade/s were repeated. With this data they compare the repetition rates of youths aged 15 to 30 years old who had completed their highest grade before 2013 with a group who completed their highest grade after 2013. Their findings suggest that the group completing their highest grade after 2013 have a lower probability of repeating more than once in the FET phase than those completing their highest grade pre-policy. Prior to the introduction of the policy in 2013, Kika and Kotzé observe patterns in NIDS pointing to rising rates of repetition in the FET phase (grades 10 to 12) between the years 2000 to 2013 but declines from 2013 to 2016.

Although this suggests that the introduction of this policy has been successful in reducing repetition rates, more recent data suggests the decline in repetition rates has not been sustained. As discussed in Section 3.1.3, while the NIDS patterns agree with trends observed in data from the General Household Surveys (GHS) over the same period, more recent GHS 2017 and 2018 data do not support a continued declining trend in repetition in the FET phase.

Continuous improvements in ensuring that schools, districts and ultimately provinces adhere to the policy guidelines of repeating only once in a phase will require reliable data at the individual level (with unique identifiers per learner that are consistently used through the school career) to effectively track the number of times learners repeat per grade. In principle, such data should be available at a national level once the LURITS system, based on the collection of SA-SAMS data in all provinces as well as the introduction of a unique identity number for each learner, is fully implemented. However, progress in this regard still appears slow.

\subsubsection{DETERMINANTS OF REPETITION AND DROPOUT, AND HOW THEY ARE LINKED}

As mentioned earlier, repetition is often identified as the leading determinant of dropout. In the South African context, there is evidence to suggest this may be true. Branson, Hofmeyr and Lam (2013) investigated the correlates of school dropout between 2008 and 2010 using earlier waves of NIDS. A key finding is that not keeping pace was a key determinant of school dropout, even after controlling for school quality and socioeconomic status. Specifically, they estimated that students who were more than two years older than the recommended age for their grade were 24 percentage points more likely to have dropped out by 2010. This estimate, though still concerning, is lower than Jimmerson et al's (2002) commonly cited finding that repetition increases the risk of dropping out by $30-50 \%$.

While repetition is typically identified as key determinant of dropout, home-background factors and school quality are the most critical determinants of repetition or grade failure in South Africa. Using self-reported responses in the 2007 NIDS questionnaire on which grades an individual passed or failed, Branson and Lam (2010) estimated the probability of failure controlling for household individual attributes and proxies for school quality. In this context, 'failure' could be better described as repeating, as failure implies not meeting a prescribed threshold in a standardized examination. They 
were able to explain about half of the higher failure rates of the black African sample by controlling for parental education, household income and school quality as proxied by school fees.

Higher school quality is typically associated with less repetition. Branson, Hofmeyr and Lam identified that those who were behind but attending higher quality schools were partially protected from dropping out. This implies that access to a quality school (which may be accompanied by improved access to remedial support) can potentially mitigate the impacts of repetition on dropout (Branson, Hofmeyr, \& Lam, 2013).

One would expect that learners with lower academic ability or those who have not been able to master basic numeracy and literacy skills due to poor quality schooling are more likely to repeat. However, Branson and Lam's analysis also highlighted that there is a potential randomness associated with repetition, particularly for males. They argued that the lack of a correlation between past repetition and current grade repetition for males may be related to the poor evaluation system documented in Lam et al (2011). They also note strong racial inequalities in repetition patterns. Compared to whites, black Africans spend almost one additional year from the time they enter primary school until the time they leave secondary school. Despite spending longer in schools, black Africans on average end up more than one full grade behind whites. Regression analyses using the 2007 NIDS data indicated that household characteristics such as parental education and household expenditure could statistically account for most of the disparities in repetition rates between population groups, but differences remained.

Gender enters strongly as a determinant of repetition. In linear probability models using NIDS 2007 data, African males were 4 percentage points more likely to repeat than females (Branson \& Lam, 2010). Females appeared to both move through the schooling system faster and attain more grades than males.

\subsubsection{DOES GRADE REPETITION LEAD TO IMPROVED ACADEMIC PERFORMANCE? EVIDENCE FROM REPEATER SCORES IN THE WESTERN CAPE}

Each year, learners in grade 3, 6 and 9 in the Western Cape write an external assessment in language and mathematics. In earlier work for the Western Cape Education Department, the results of these systemic evaluations for learners who repeated grade 3 or 9 between 2011 and 2014 were analysed to determine whether grade repetition leads to learning gains. Quite different results emerged for the different grades.

\subsubsection{GRADE 3}

On average, grade repetition at grade 3 was associated with substantial and statistically significant improvements in the language and maths scores in the systemic evaluations. Among grade repeaters, the mean score for language increased from $25.3 \%$ to $39.3 \%$ on repetition of the grade. On average, greater improvements were achieved in maths. The mean first-time score for maths was $32.3 \%$ among grade repeaters. On average, this increased to $53.4 \%$ on repetition. This yielded an average improvement of 14 percentage points in language, and 21 percentage points in maths. The mean learner achieved a pass in maths on repetition but fell short of the pass mark for language.

Analysis of the results by district yielded interesting insights. The improvements associated with repetition were much lower in the Central Karoo than in other districts (for language, the average percentage point improvement was about half that of other districts, while maths scores improved about 3.5 percentage points less). Grade 3 repeaters in the Overberg district showed greater 
improvements than in other district in languages and maths. Learners who were older when entering grade 3 the first time experienced smaller improvements, on average 4 percentage points less than their counterparts. The improvement in language scores was significantly but only slightly better for repeaters in quintile 4 and 5 schools, while improvements in maths scores were slightly but significantly worse in quintile 1 schools. All differences reported above persisted in multivariate analysis, when available school-level and learner-level factors were controlled for. In multivariate analysis, the original percentage score was shown to be significantly associated with the eventual improvement.

\subsubsection{GRADE 6}

Girls experienced greater increases in language scores on repetition in grade 6, but boys experienced larger improvements in maths scores, controlling for other factors. Again, learners who were old for grade when entering grade 6 the first time experienced significantly smaller improvements in both language and maths than other repeaters. Repeat learners in the Overberg and West Coast were able to produce larger increases in language and maths scores in the year and were more likely to pass on repetition. Maths improvements were also greater in Cape Town. Significantly smaller improvements in maths occurred in the Central Karoo, when controlling for other factors. When the probability of passing both maths and language was considered in multivariate analysis, learners in Eden and Cape Winelands did significantly worse. It seems district, initial maths and language scores and the quintile of the school were the most important factors in repeater success. Most grade 6 repeaters did not pass the systemic evaluation the first time.

\subsubsection{GRADE 9}

The number of repeaters at grade 9 was much higher, approximately 19000 learners per year. The gains in learning associated with repetition were much lower in grade 9 than in grade 3, especially in maths. Among grade repeaters, the mean score for language only increased from $36.2 \%$ to $38.9 \%$ on repetition of the grade. The first-time marks and improvements were worse in maths. The mean firsttime score for maths was $14.9 \%$ among grade repeaters, barely increasing to $16.5 \%$ on repetition. For most repeaters, the gains in learning did not lead to satisfactory marks in the next year. Only $1.6 \%$ of grade 9 repeaters attained $40 \%$ in the systemic evaluation for maths after repeating the grade, while $45 \%$ attained $40 \%$ in language after repeating. Overall, repetition appeared to lead to very little gains in learning for grade $9 \mathrm{~s}$. Importantly, $58 \%$ of those who repeated grade 9 in this period were already 16 years or older when they entered the grade for the first-time. This group of learners show substantially less improvement in maths scores, following repetition. Repetition seems particularly wasteful for this group of learners.

At first glance, this analysis suggests that grade repetition may have been beneficial in grade 3 , as it was associated with substantial gains in learning, but appeared ill-advised in grade 9 . However, a more thorough analysis is required to draw hard policy conclusions, as it is not clear, for instance, how much grade 3 children who had repeated would have gained in terms of these tests scores if they had not repeated. It may very well be that their gains would have been as large or even larger for this grade 3 curriculum material. Unfortunately, the CEMIS and Systematic Evaluation data were not available for analysis for this project. Some information about gains between grades on the same test between grade 3 and grade 4 can be gleaned from data in the National School Effectiveness Study (NSES), but this needs to be thoroughly analysed to draw inferences that would allow stronger conclusions across the two datasets. 


\section{ANALYSIS OF DATA ON REPETITION AND DROPOUT}

\subsection{ANALYSIS USING HOUSEHOLD SURVEY AND SCHOOL CENSUS DATA}

\subsubsection{DATA}

The analysis now turns to the use of various datasets to provide an overview of repetition and dropout in South African schools. Each dataset has its own advantages and disadvantages, so together they provide a more comprehensive view than relying on just one or two.

The analyses draw on previous Department of Education or Department of Basic Education (DBE) analyses of the General Household Surveys (GHS) and own analyses of the Community Survey 2016 to obtain national level school indicators. The Community Survey, which is conducted in between Censuses, has the advantage of having a very large sample with almost 1 million youth between the ages of 6 and 18 .

Data from the Annual Survey of Schools (ASS) is also utilised to present a picture of flows through the education system. (The ASS, along with SA-SAMS and LURITS are all components of EMIS.) There are some problems with the accuracy of the administrative data, so care must be taken to ensure that the conclusions drawn are not too greatly influenced by data errors. Of concern is the accuracy of schoollevel data on repeaters by grade. Additionally, the more recent years of ASS data Resep received from the DBE for this study is limited to seven provinces. Our analyses of repetition and dropout are therefore limited to a subset of schools and learners from 7 provinces in the ASS with fewer data errors. Our data subset is for 16 to $17 \%$ of all learners in $26 \%$ of schools in 7 provinces. We focus on the data years 2010 to 2011 or 2015 to 2016, which appear to be more reliable than other years. Box 1 provides more details on how we reach a more consistent and reliable ASS data subset and outlines the method used to calculate repetition and dropout rates.

We also use SA-SAMS data for the Northern Cape which is unique in that it tracks learners from year to year. A description of this data and our useable sample is discussed in Section 3.3.

\section{Box 1: Establishing a reliable and consistent Annual of Survey of Schools sample and how we calculated repetition and dropout rates}

\section{Calculating Repetition and Dropout Rates:}

Since individual learners are not tracked in the national EMIS, nor are promotion or dropout numbers reported, it is necessary to estimate promotion and dropout using school-level enrolment and repetition data, according to the UNESCO method. A limiting factor for the analysis is the low reporting of repetition numbers, as well as zero repetition being recorded as a missing value.

Imputation of repetition was done in two steps. Firstly, a value of zero was imputed if repetition data for an observation was missing (blank), but at least one repetition entry was recorded for that same school in the same year, regardless of grade. If repetition information was missing for all grades of a school in the same year, then the absolute value of the previous year's repetition was imputed for each grade and gender. 
A further limiting factor was that school-level data do not allow for calculating promotion and dropout rates for the highest grade of a school. This is because dropout rates are calculated according to the UNESCO method by using the enrolment in a grade in one year, the repetition rate in the next year in the same grade, and enrolment also in the second year in the next grade. Where a school did not offer the next grade, it is thus impossible to calculate dropout. To keep a comparable sample, only schools with a highest grade of 7 or 12 were retained in the final sample, and schools that did not report data for one or more of the grades were also excluded from the final sample. Additionally, Grade 12 repetition and Grade 7 and 12 dropout statistics are not calculated.

\section{Creating a reliable subset of schools}

Only public (Quintile 1 to 5) schools are included in the final sample, and restrictions are placed on various school characteristics. Schools were excluded from the sample if they possessed any of the following characteristics:

- Total school enrolment below 100 or above 2000 learners

- Enrolment greater than 500 learners in a single grade

- Total school repetition greater than $50 \%$ for schools with total school enrolment exceeding 150 learners

- School or grade repetition of more than $100 \%$

- School drop-in (that is, negative dropout) of more than 50 learners, or school dropout (drop-in) of more than $20 \%$ (-20 percent) of total school enrolment.

Individual observations (whereby each observation represents a grade and gender, for example, Grade 1 females) were excluded from the sample if:

- Repetition or dropout for an observation was greater than $100 \%$ (or less than $-100 \%$ in the case of dropout)

- Promotion and dropout data could not be calculated as a result of missing repetition data.

Finally, the sample was restricted to 2010 and 2015 (with promotion and dropout calculated using 2010 to 2011 and 2015 to 2016 data), and only schools with at least one observation in both years were retained in the final sample.

In a few cases, calculated dropout for grade 9 was negative, i.e. implying drop-in, for specific schools. In such cases, Grade 10 enrolment was imputed to cause grade 9 dropout to equal zero. This had only a minor effect on aggregate numbers.

After eliminating schools and grades with low quality data, we only have 16 to $17 \%$ of learners in $26 \%$ of schools for 7 provinces remaining. A large contributing factor is the poor data quality in the Eastern Cape, resulting in only 8 to $9 \%$ of the learners being retained (11 to $12 \%$ of schools), but all the other provinces are also problematic, with only the Western Cape retaining more than $20 \%$ of learners in both years. Unfortunately, as we've already mentioned, 2010 to 2011 and 2015 to 2016 are the best years in terms of data quality. 


\subsubsection{GRADE ATTAINMENT AND ENROLMENT}

While this report is concerned specifically with repetition in South Africa, repetition rates alone provide an incomplete picture of learner flows in an education system. Various measures should be used to highlight the efficiency of an education system from different angles as the use of one measure without the other does not provide a comprehensive overview of the education system (Department of Education, Ministerial Committee on Learner Retention, 2008). For example, while inequalities in repetition rates by learner wealth or school quintile may highlight the significant progress that still needs to be made in equalising schooling outcomes, isolating only recent trends masks the significant progress that has been made in offering schooling opportunities to all South Africans. Furthermore, where dropout rates are noted to be much higher from grades 9 to 11, this should be contextualised internationally. For this reason, we initiate our analysis with a look at grade attainment in South Africa and the progress that has been made in this regard, while briefly comparing enrolment among adolescents in South Africa with other neighbouring states.

South Africans are more educated now than they have ever been in the past 100 years. One way to observe this is to compare grade attainment levels for different age cohorts. A recent study for the World Bank on the demand for education in the five countries of the South African Customs Union (South Africa, Botswana, Lesotho, Namibia and Swaziland, now known as Eswatini) showed successively higher educational attainment for successive birth cohorts between 1930 and the early $1990 s^{13}$ for those people alive at the time of the 2011 census (Van der Berg \& Knoesen, 2015). While almost everyone born in the early 1990 s completed full primary, the proportion completing grade 10 hovered around $80 \%$ and those with matric around $50 \%$. This latter figure (and perhaps also the former one) is definitely an over-estimate: It has been shown in other Statistics South Africa data sets that many of those who profess that the highest level of education they have achieved is matric subsequently admit that they have not passed matric when pertinently asked that.

Figure 1, using the Community Survey 2016, illustrates how the gap in educational attainment by race has dramatically closed over time. The largest improvements in grade attainment observed have been for black Africans with more than a doubling in average years of completed schooling from 4 to 5 years among those born in the 40 s to 10 to 11 years of schooling among those born in the $80 \mathrm{~s}$ or $90 \mathrm{~s}$. Almost 2 in 5 black Africans born between 1941 and 1945 had no schooling and only 2 in 100 had a completed secondary education (matric). The opposite holds true for those born between 1991 and 1996: 2 in 5 have a completed secondary and less than 2 in 100 had no schooling at all (see Table 3). Additionally, today there are multiple times more black Africans with post-secondary education and specifically bachelors' degrees than in the 1980s or 1990s (van Broekhuizen, 2015).

\footnotetext{
${ }^{13}$ As some persons are still engaged in education, such figures could not yet be obtained for more recent birth cohorts.
} 
Figure 1: Average years of schooling by age cohort, Community Survey 2016
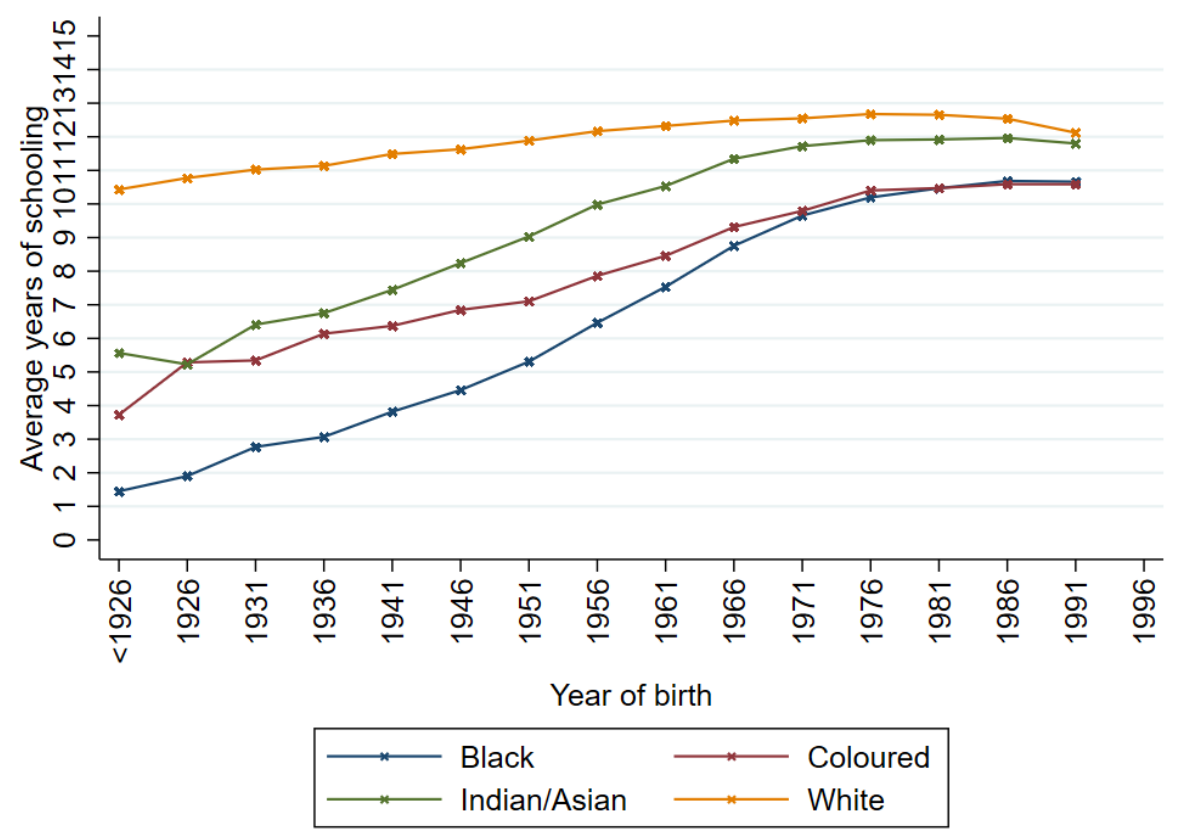

Source: Community Survey 2016, own calculations.

Table 3: Educational attainment by age cohort, Community Survey 2016

\begin{tabular}{lccc|ccc} 
& \multicolumn{3}{c|}{ All South Africans } & \multicolumn{3}{c}{ Black South Africans } \\
\cline { 2 - 7 } & $\begin{array}{c}\text { No } \\
\text { schooling } \\
\text { Year of birth }\end{array}$ & $\begin{array}{c}\text { Completed } \\
\text { primary } \\
\%\end{array}$ & $\begin{array}{c}\text { Completed } \\
\text { secondary } \\
\text { (Matric) } \\
\%\end{array}$ & $\begin{array}{c}\text { No } \\
\text { schooling } \\
\%\end{array}$ & $\begin{array}{c}\text { Completed } \\
\text { primary } \\
\%\end{array}$ & $\begin{array}{c}\text { Completed } \\
\text { secondary } \\
\text { (Matric) } \\
\%\end{array}$ \\
\hline $1926-1930$ & 44.8 & 3.2 & 8.9 & 61.6 & 2.8 & 1.4 \\
$1931-1935$ & 33.4 & 4.0 & 12.2 & 50.3 & 4.5 & 2.0 \\
$1936-1940$ & 28.9 & 4.7 & 13.7 & 45.9 & 4.9 & 2.5 \\
$1941-1945$ & 25.1 & 5.4 & 12.9 & 36.5 & 6.2 & 3.4 \\
$1946-1950$ & 21.1 & 5.8 & 13.7 & 30.1 & 6.7 & 4.5 \\
$1951-1955$ & 17.5 & 6.5 & 13.9 & 23.9 & 7.5 & 6.6 \\
$1956-1960$ & 13.0 & 7.0 & 17.1 & 17.3 & 8.1 & 11.1 \\
$1961-1965$ & 9.7 & 6.9 & 21.2 & 12.5 & 8.0 & 16.2 \\
$1966-1970$ & 6.9 & 5.6 & 27.5 & 8.6 & 6.3 & 24.2 \\
$1971-1975$ & 4.9 & 4.3 & 34.3 & 5.8 & 4.6 & 32.5 \\
$1976-1980$ & 3.7 & 3.1 & 38.2 & 4.2 & 3.3 & 36.9 \\
$1981-1985$ & 3.2 & 3.0 & 39.8 & 3.6 & 3.1 & 39.2 \\
$1986-1990$ & 2.8 & 2.5 & 43.0 & 3.1 & 2.6 & 42.8 \\
$1991-1995$ (21-25 yrs) & 2.2 & 2.3 & 44.2 & 2.4 & 2.4 & 42.5 \\
\hline \hline
\end{tabular}

Source: Community Survey 2016, own calculations. Each cell shows the percentage of an age cohort with a specified level of education. 
At various points in the analysis that follows we report on dropout rates in addition to repetition rates. It is also important to contextualise the extent of dropout in an international setting. Comparing enrolment rates among adolescents with neighbouring countries is one way to do this. When compared with other Southern African countries, South Africa is doing very well regarding school enrolment. Figure 3 shows attendance at school for SACU countries by age around the year 2011 (the South African figures are taken from the 2011 census). As is apparent, South African educational attendance is quite high, remaining above $90 \%$ even up to age 18 , although some older individuals shown to be at "school" here are actually attached to other educational institutions, as responses to further census questions show.

Figure 2: Educational attainment of South Africans, Census 2011

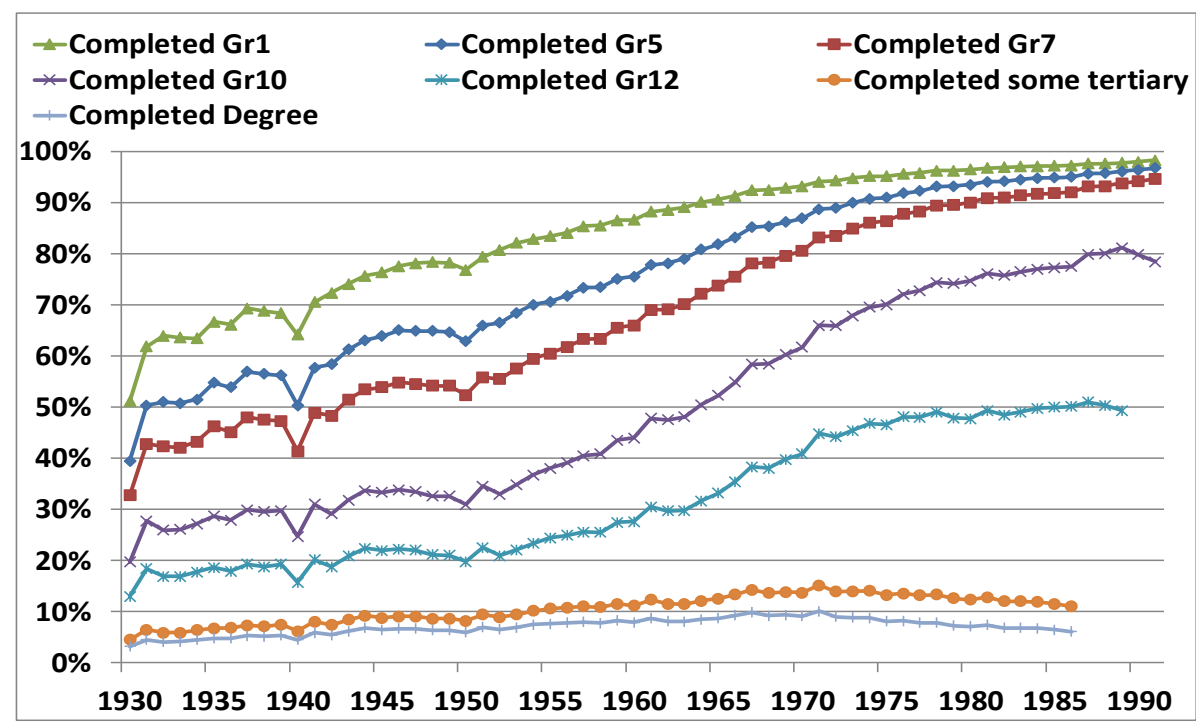

Source: Van der Berg and Knoesen, (2015) using Census 2011.

Figure 3: Percentage of each age group attending school in SACU countries

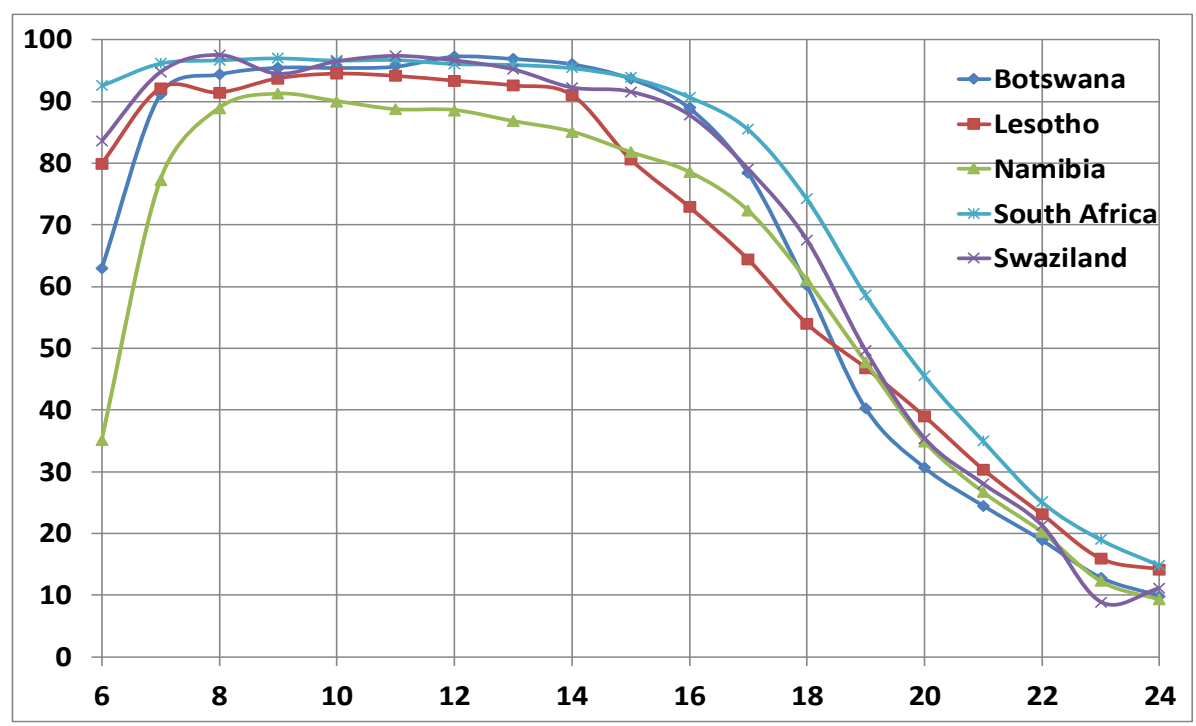

Source: Van der Berg and Knoesen, (2015) using 2011 censuses (Botswana, Namibia, South Africa) and 2010 labor force surveys (Lesotho, Swaziland). 


\subsubsection{REPETITION RATES}

The national repetition rate is about $10 \%$, as indicated in the General Household Survey (GHS). This is the average repetition rate reported across grades 1 to 12 and over the years 2014 to 2018. But average repetition rates mask significant differences in the extent of repetition by grade.

Repetition rates from grade 9 up to grade 11 are much larger compared with lower grades, with grade 10 recording the highest levels of grade repetition across the years at an average of $21 \%$ from 2014 to 2018. Once learners reach grade 12 , repetition rates are much lower, indicating that the big hurdle to writing a matric is getting through grades 9 to 11 (Branson \& Lam, 2010).

The decline in repetition in the higher grades from 2013 to 2015 compared with say 2009, as seen in Figure 5, agrees with the findings of Kika and Kotzé (2018) using the National Income Dynamics Study (NIDS). But the 2016-2018 GHS data suggest that this downward trend FET phase repetition rates has not been sustained. In this respect, there is no clear evidence that the promulgation of repetition policy in the FET phase at the end of 2012 has had much influence in reducing overall repetition in practice. There appears to be a significant inertia within the system with respect to FET repetition practices. However, examining trends in foundation phase repetition, there have been significant declines in repetition rates since 2013 with 2018 repetition levels at the lowest they have been in the past decade (see Figure 6). But household surveys tend to under-estimate repetition, particularly in grade 1. Estimates of grade 1 repetition in the GHS averages 7\% from 2014 to 2018, but grade 1 repetition rates from the Learner Unit Record Information and Tracking System (LURITS) are indicated to be as much as $15 \%$ (Department of Basic Education, 2016). ${ }^{14}$

Table 4: Repetition rates, General Household Surveys 2009 to 2018

\begin{tabular}{l|cccccccccc|c|c|} 
& $\mathbf{2 0 0 9}$ & $\mathbf{2 0 1 0}$ & $\mathbf{2 0 1 1}$ & $\mathbf{2 0 1 2}$ & $\mathbf{2 0 1 3}$ & $\mathbf{2 0 1 4}$ & $\mathbf{2 0 1 5}$ & $\mathbf{2 0 1 6}$ & $\mathbf{2 0 1 7}$ & $\mathbf{2 0 1 8}$ & $\begin{array}{c}\text { Ave. } \\
\mathbf{0 9 - 1 3}\end{array}$ & $\begin{array}{c}\text { Ave. } \\
\mathbf{1 4 - 1 8}\end{array}$ \\
\hline Gr. 1 & 6.7 & 5.5 & 6.7 & 8.8 & 10.5 & 8.8 & 7.3 & 7.5 & 5.6 & 5.4 & 7.7 & 6.9 \\
Gr. 2 & 7.1 & 8.3 & 8.3 & 9.5 & 9.1 & 9.0 & 9.1 & 6.9 & 7.7 & 6.1 & 8.5 & 7.8 \\
Gr. 3 & 7.1 & 8.9 & 7.7 & 9.4 & 9.5 & 9.3 & 8.5 & 7.6 & 6.7 & 6.4 & 8.5 & 7.7 \\
Gr. 4 & 7.0 & 6.1 & 8.2 & 10.7 & 9.1 & 7.5 & 9.0 & 7.5 & 8.8 & 7.5 & 8.1 & 8.1 \\
Gr. 5 & 6.7 & 6.9 & 5.9 & 8.1 & 9.4 & 7.6 & 7.0 & 7.0 & 5.7 & 4.9 & 7.4 & 6.4 \\
Gr. 6 & 6.4 & 6.6 & 7.4 & 7.2 & 7.6 & 8.4 & 7.4 & 7.2 & 6.5 & 5.4 & 7.0 & 6.9 \\
Gr. 7 & 4.9 & 5.2 & 6.2 & 6.5 & 7.8 & 6.9 & 7.8 & 7.6 & 4.6 & 6.7 & 6.1 & 6.7 \\
Gr. 8 & 8.0 & 6.5 & 7.7 & 10.3 & 8.6 & 10.0 & 12.7 & 10.5 & 10.5 & 11.6 & 8.2 & 11.1 \\
Gr. 9 & 10.3 & 11.2 & 13.4 & 14.9 & 16.3 & 17.0 & 15.0 & 12.0 & 11.2 & 10.8 & 13.4 & 13.3 \\
Gr. 10 & 16.6 & 18.9 & 21.1 & 22.1 & 24.2 & 21.1 & 20.4 & 23.2 & 22.1 & 19.5 & 20.7 & 21.3 \\
Gr. 11 & 15.8 & 17.9 & 18.1 & 19.9 & 21.0 & 17.6 & 16.2 & 18.6 & 20.3 & 16.4 & 18.6 & 17.8 \\
Gr. 12 & 8.3 & 10.5 & 11.0 & 8.9 & 8.9 & 6.3 & 8.1 & 8.2 & 10.1 & 10.9 & 9.5 & 8.8 \\
\hline \hline
\end{tabular}

Source: General Household Surveys, 2009 to 2018, own calculations.

\footnotetext{
${ }^{14}$ The underreporting of grade 1 repetition rates in household survey data could be due to parents viewing repeating at a young age as the consequence of not being 'school ready' rather than due to failure. Although the GHS question does not use the terms 'repetition' or 'grade failure' as a reason for repeating. It asks, "Is X doing the same grade that he/she did last year or before (if there was a break in his/her education)?
} 
Figure 4: National repetition rates by grade over the period 2009-2013 and 2014-2018, GHS

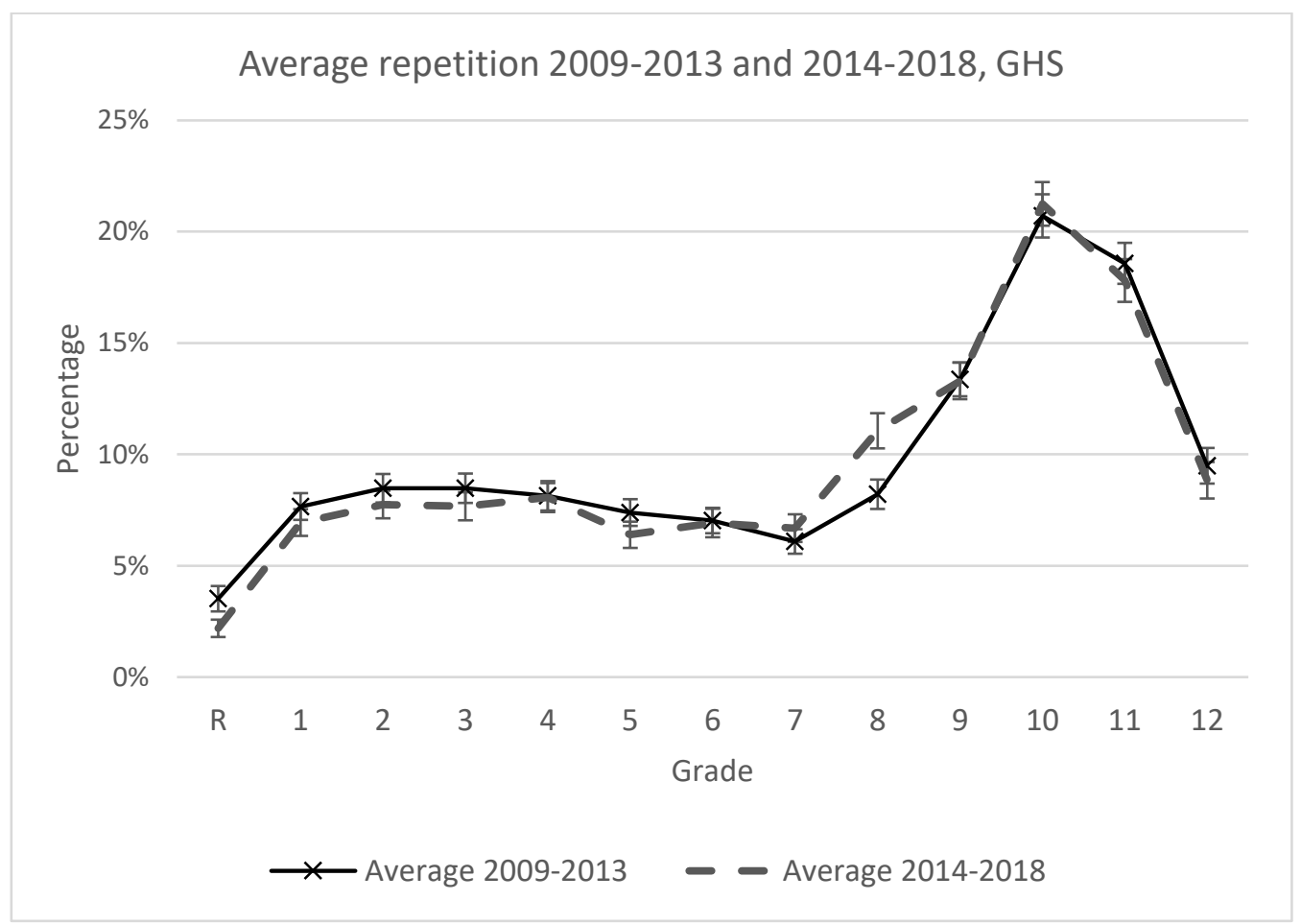

Source: General Household Surveys, own calculations. 95\% error bars are shown around each of the mean estimates.

Figure 5: Trends in national repetition rates for grades 9 to 12, 2009 to 2018, GHS

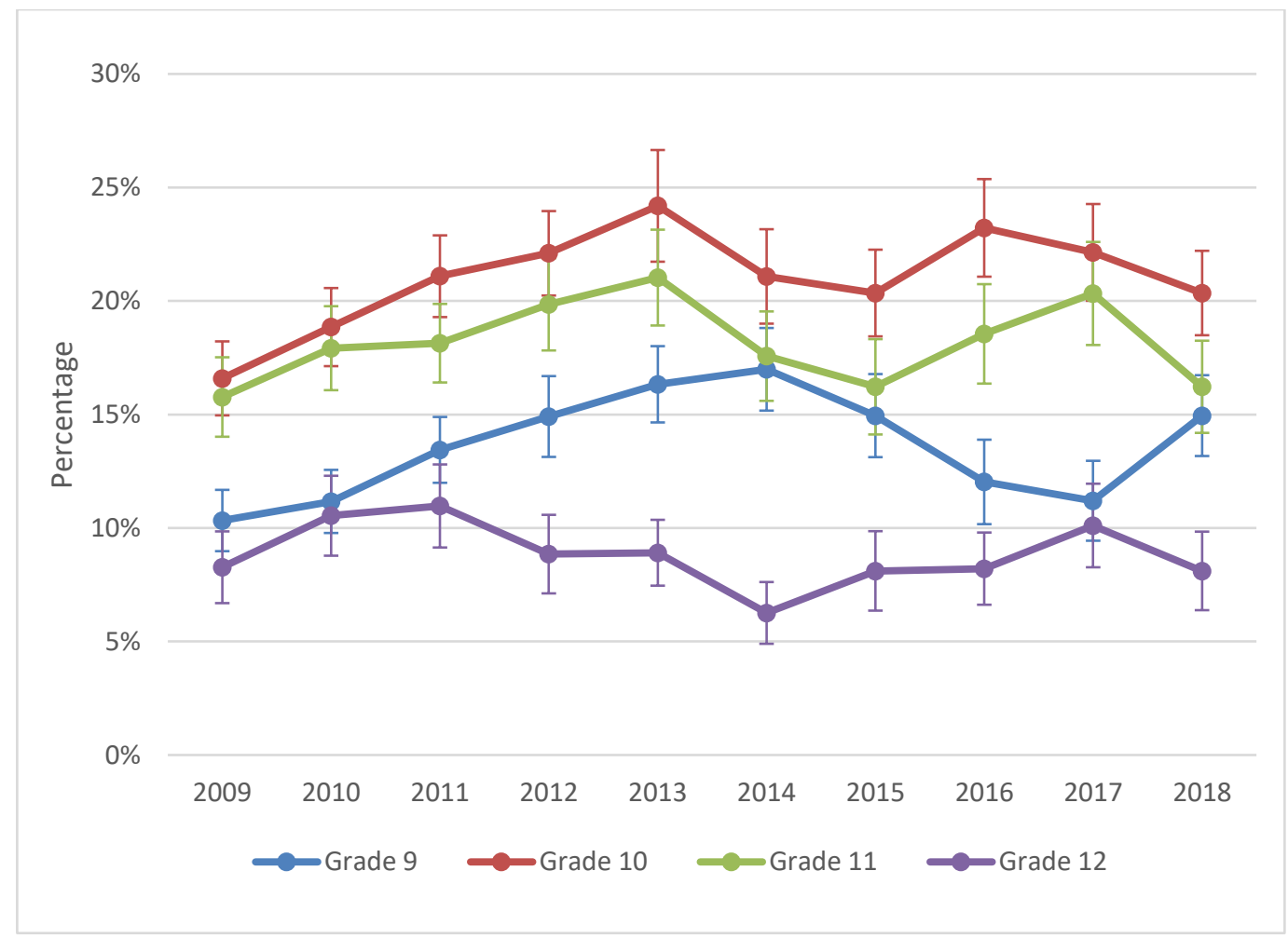

Source: General Household Surveys, 2009-2018, own calculations. 95\% error bars are shown around each of the mean estimates. 
Figure 6: Trends in national repetition rates in the foundation phase, 2009 to 2018, GHS

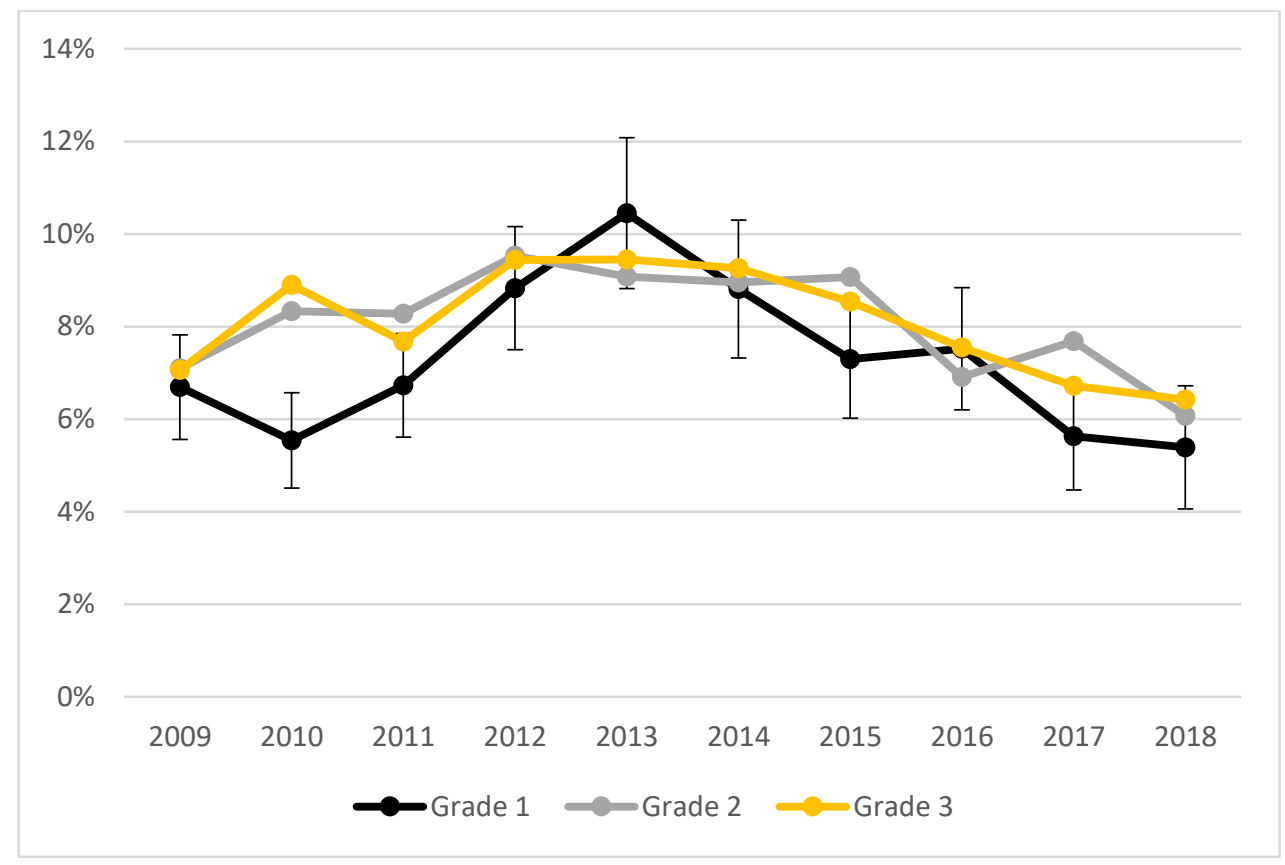

Source: General Household Surveys, 2009-2018, own calculations. 95\% error bars for grade 1 are shown around each of the mean estimates.

Moreover, the DBE notes that more recent preliminary analysis of LURITS data indicates that it could be even higher than that (Department of Basic Education, 2018). Repetition rates from LURITS are, however, calculated using only data from a sub-set of schools rather than the population of public schools (due to issues in tracking learners from year to year and data reliability).

It is not only household survey data that under-estimate repetition. Administrative data probably suffer from a similar issue, but for different reasons. In work undertaken for and incorporated into Chapter 2 of the report of the Ministerial Committee on Learner Retention (Department of Education, Ministerial Committee on Learner Retention, 2008), Charles Simkins pointed to the deficiencies with regard to repetition of the EMIS data as self-reported by schools. In particular, it is unclear how blanks in the survey returns by schools should be interpreted. He then noted that if a school reports blanks for repetition numbers in some grades but actual numbers for other grades, it was probably appropriate to regard such blanks as zeroes. However, when all repeater figures were blanks, it was difficult to know whether that meant that there were zero repeaters in all grades, or simply that the school had not completed that part of the return form. Consequently, he and the Committee concluded that official repetition figures probably under-estimated repetition, and in using the UNESCO methodology to calculate dropout based on enrolment and repetition numbers, dropout would be over-estimated.

We took effort to use a sample of schools from the Annual Survey of schools - for 7 provinces - that had more reliable data on repetition. Repetition rates for this sample are reported in Figure 7. Here repetition rates relate to repeaters in 2011 or 2016 expressed as a percentage of enrolment in the same grade in 2010 or 2015 . Data labels are only shown for 2015 . What is encouraging is that repetition rates calculated using this subset of schools tend to agree with LURITS estimates until about grade 9. Repetition in grade 1 is between 16 and 17\% for the periods 2010 to 2011 and 2015 and 2016 . This again confirms the high rates of repetition in grade 1 , the response of teachers and schools to children not being school ready. Repetition then declines to between 10 and $11 \%$ in grade 3 while 
repetition in grade 9 is 15 to $17 \%$. Our estimates of repetition in grade 10 at over $25 \%$ are somewhat higher than expected when considering both LURITS or the GHS rates and notably higher for grade 11 in both 2010 and 2015.

Due to the limited sample of schools we could retain from Annual Survey of Schools data, we are cautious at providing provincial estimates of repetition rates from this data. Nevertheless, a consistent and clear pattern emerging, is that of 7 provinces (excluding the Free State and Mpumalanga), the Western Cape and Gauteng have the lowest repetition rates in the primary phase (Grades 1-7). This is not surprising given that the educational performance of these two provinces is typically the best of all 9 provinces (Wills, Shepherd, \& Kotze, 2018). This is also confirmed using the GHS data for the years 2014 to 2018, but the GHS also shows how much lower repetition rates are in these two provinces (and in KwaZulu-Natal) at the FET level, particularly in grade 10 (see Appendix Figure A6). Grade 10 repetition rates in the GHS averaged $12 \%$ in the Western Cape from 2014-2018 compared to provinces such as North West and Limpopo where grade 10 repetition rates exceed well over $30 \%$. Additionally, repetition and dropout patterns diverge notably across provinces from grades 9 onwards.

Figure 7: Repetition rates using a reliable and consistent ASS school-level sample from 7 provinces, 2010 and 2015

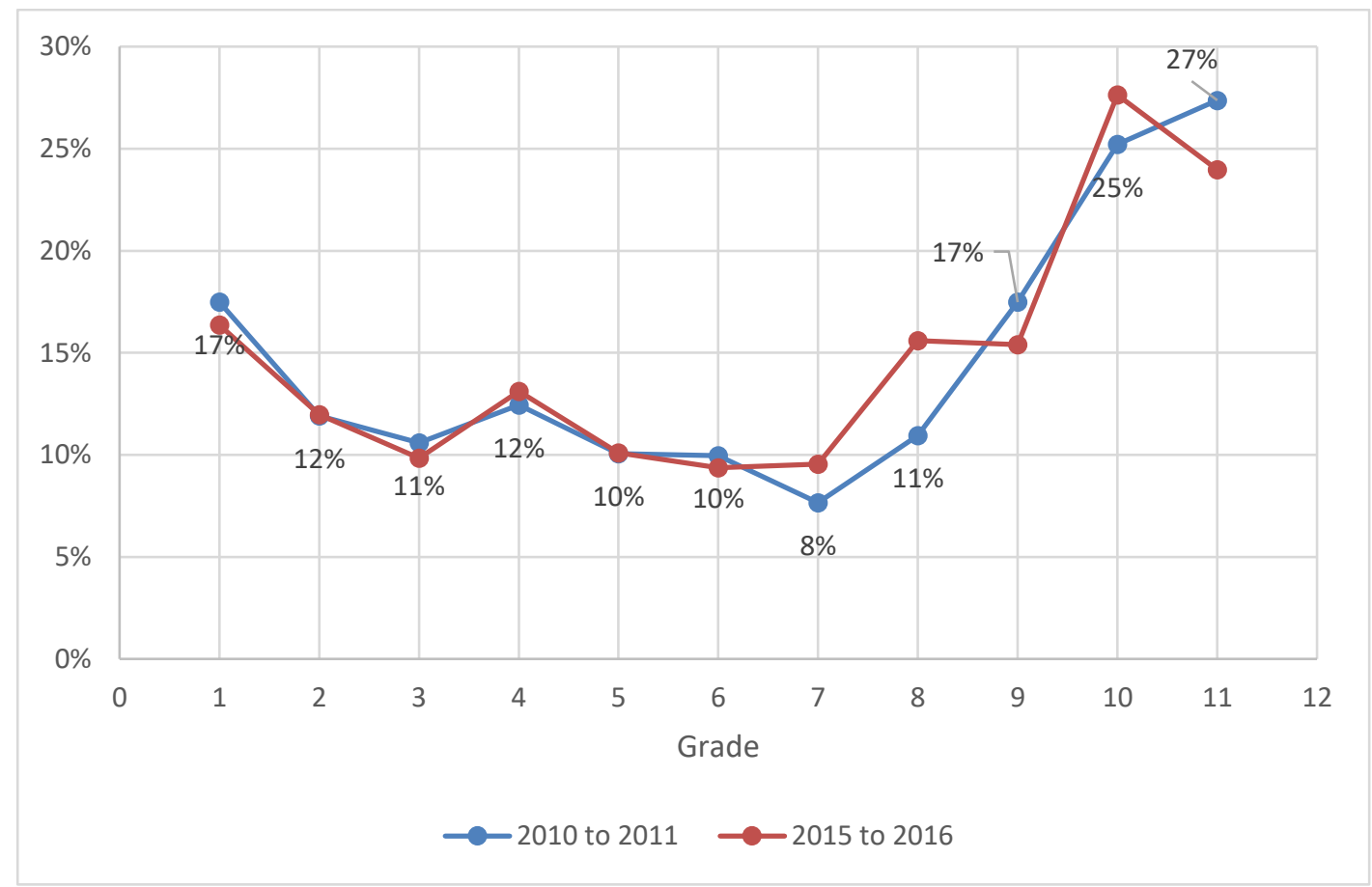

Source: A subset of Annual Survey of Schools data 2010-2011 and 2015-2016 for 7 provinces, excluding Free State and Mpumalanga. Notes: The sample excludes schools with unreliable or improbable data on repetition or dropout. Because learners are not observed one year after grade 12, it is not possible to calculate dropout and repetition rates in grade 12 using the UNESCO method. 
Figure 8: Percentage of learners repeating, LURITS (Reproduced from DBE 2016 'Progress in the Sector' Report)

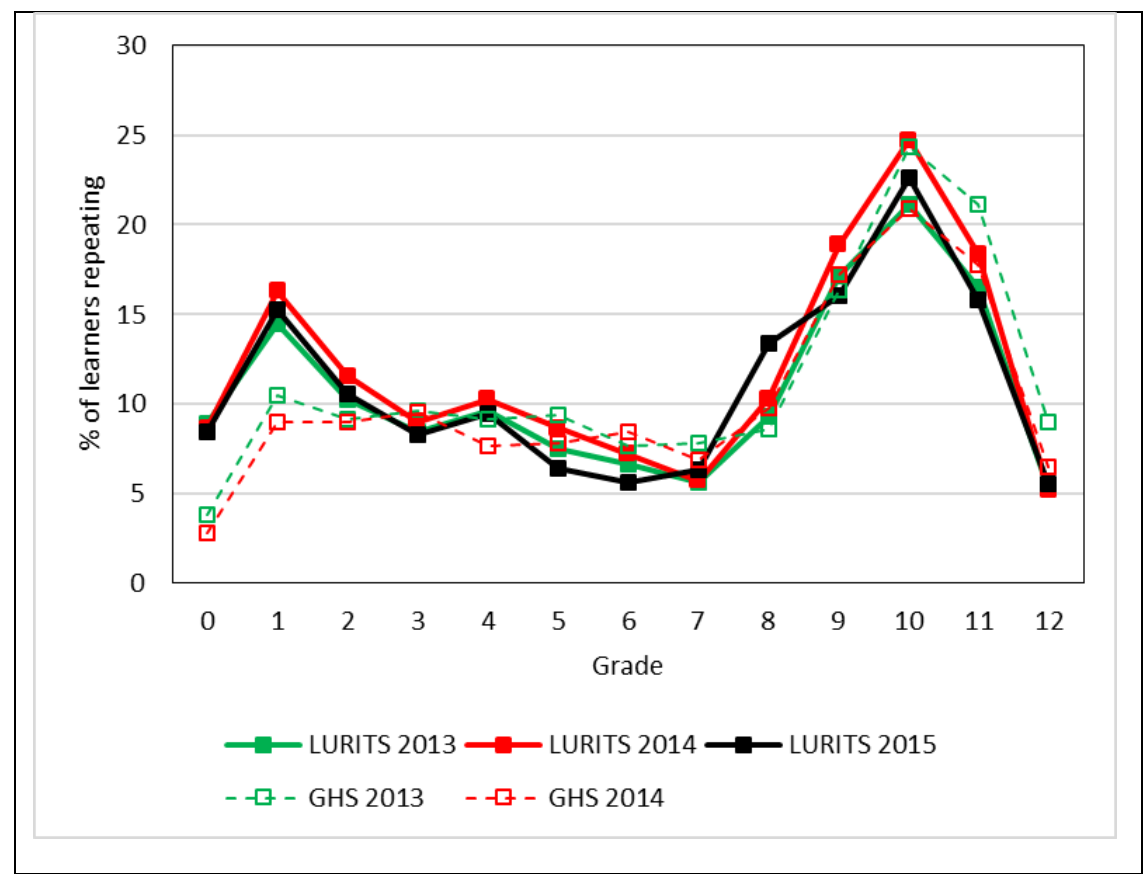

Source: Department of Basic Education, (2016, p. 14) using LURITS and GHS data. Notes: "All ordinary schools, public and independent, are considered here. The statistic reflected here is the percentage of enrolled learners who did the same grade in the previous year. This should not be confused with the repeater rate, which describes the percentage of learners in a grade who will end up repeating in the next year. The grade repetition statistics obtained from LURITS are based on a sub-set of the data which excludes schools which were considered to have insufficient data, in particular poor levels of linkages of learners across years. This exclusion is unlikely to affect aggregate statistics to a large degree (especially considering the high level of correspondence with the household data), yet figures need to be interpreted cautiously. Blips in the trend, for instance the increase in grade 8 repetition in 2015 seen in the above graph, might be the result of the fact that certain schools were excluded" (Department of Basic Education, 2016, p. 14)

\subsubsection{NOT ON TRACK AND OVER-AGE LEARNERS}

As the impacts of grade failure accumulate over time and rates of repetition increase in higher grades, the proportion of each age group that is no longer on track with respect to completing school rises considerably with age.

The Community Survey of 2016 contains information on both the year and month of birth for each household member and their highest completed years of schooling. Using this data, Figure 9 constructs a picture of the educational status of youth of specific ages (8 to 20). The top of the bar at each age represents the total percentage of youth that are enrolled in an educational institution. The red series highlights the percentage that are on track at school, having completed the expected grade for age. ${ }^{15}$ The results for the 10-year-old group do not follow the expected patterns - we do not trust the years of schooling data for this group. Hence, their results are excluded from the figure.

\footnotetext{
${ }^{15}$ This assumes that a child should turn 7 within the year that they start grade 1 in line with policy. If children do not repeat at any point, then a 13-year-old is expected to have completed grade 6, while a 19-year-old should have completed grade 12 (matric).
} 
Roughly $87 \%$ of 8 -year-olds are in a primary school and on track - they have completed grade 1 . By age 13 , however, only $63 \%$ of learners are in primary school and on track (and an additional $2.5 \%$ are in educational institutions other than ordinary schools and are on track). By age 17 when learners should have completed grade 11 , less than half $(47 \%)$ have completed the expected grade for age.

In the Appendix (Figures A1-3) we use the same data to provide provincial comparisons of the percentage of children aged 13 (should have a grade 6), 16 (should have a grade 10), or 17 (should have a grade 11) that are in school and on-track. At each of these ages, a larger percentage of Gauteng learners are on track than any other province, while the lowest percentage of learners on track are in the Eastern Cape. An interesting province is KwaZulu-Natal which appears to be doing a particularly good job of moving learners through the system (and indeed repetition rates are low in the FET phase in this province). This may explain why KwaZulu-Natal (along with Gauteng) now has one of the largest proportions of youth with a matric pass, showing some of the most significant improvements in getting learners through 12 years of schooling over the past two decades as seen in Error! Reference source not found. (Appendix).

The proportion of youth that are not on track by age is also reproduced in Figure 10, but here estimates of learners that are at least 1 year behind the expected completed grade for age are expressed as a proportion of youth that are currently enrolled in a primary or secondary school (rather than of all youth). The age group analysed is limited to age 11 to 19 . By age 11 , children should have completed grade 4 . But $21 \%$ of 11 -year-olds in school are not track. The proportion of children that are at least 1 year behind almost doubles to $40 \%$ among 14 -year-olds and more than triples to $62 \%$ among 18 -yearolds, who are expected to have completed grade 11 .

Figure 9: Educational status of youth aged 8 to 20, Community Survey 2016

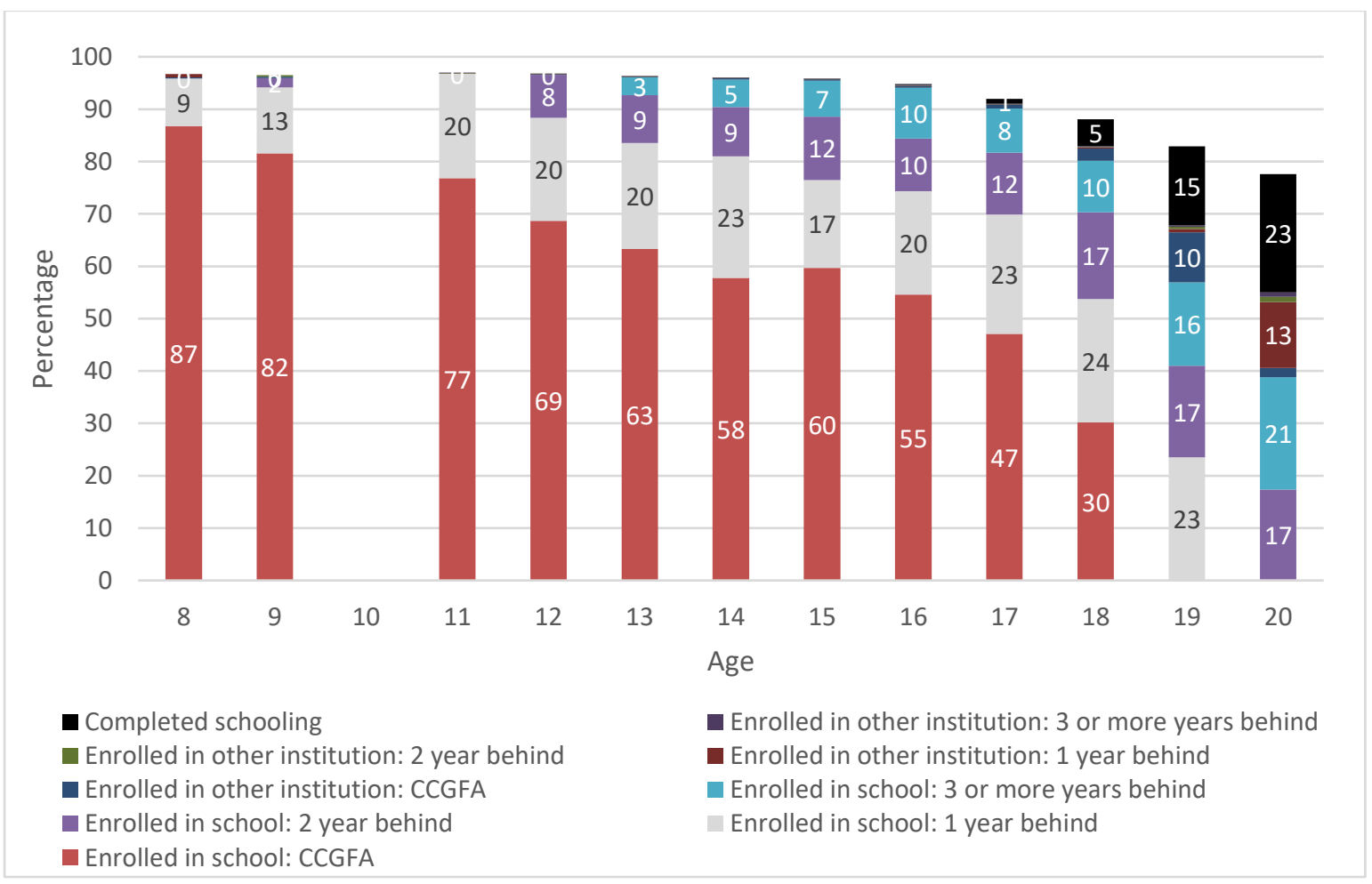

Source: Community Survey, 2016. Own calculations. Notes: There are data validity concerns with the years of schooling variable for children born in 2006 (here age 10) and therefore those statistics are excluded. CCGFA stands for 'completed correct grade for age'. Age is derived to correspond to birth year. 
At the level of the school, repetition patterns are expressed in successively higher proportions of children that are over-age for their grade. We illustrate this using our EMIS data for seven provinces in Figure 11. Here we define grade 1 children as over-age if they were nine years old at the time of the Annual School Survey in September, i.e. their grade plus 8 years. The same threshold is used for other grades. The figure highlights key features that characterise patterns of over-age learners. The steady rise in the proportion of children that are over-age for their grade with each successive grade is evident. In grade 1 about $12 \%$ of children in 2015 were over-age, but by the start of the intermediate phase (grade 4) nearly a third of learners are over-age. The profile peaks to nearly $60 \%$ in grades 10 and 11. The figure also shows interesting trends in over-age learners. The prevalence of over-age learners in the primary phase was on a downward trend over the decade 2000 to 2009, with lower proportions more or less maintained from 2009 to 2014. However, the period 2009 to 2014 saw a significant increase in the proportions of over-age learners in grades 9 to 12. By 2014, the issue of over-age learners in grade 10 and 11 is potentially the worst it had been since the end of 1990s. In this regard, the promulgation of repetition policy in the FET phase in 2013 was well timed. We are however cautious about the 2014 EMIS data on age, particularly for the Eastern Cape. When we exclude the Eastern Cape from the time trends, the 'blip' observed for 2014 is removed (see Figure A5).

There is some indication of a decline in over-age learners in 2015 and 2016 at higher grades even when we remove the Eastern Cape sample from the analysis. At higher grades, a factor that may have contributed to this, was the decision taken in 2015 to advance most grade 11 learners who had failed to grade 12 .

Figure 10: Percentage of children aged 11 to 18 enrolled in school that are not on track, Community Survey 2016

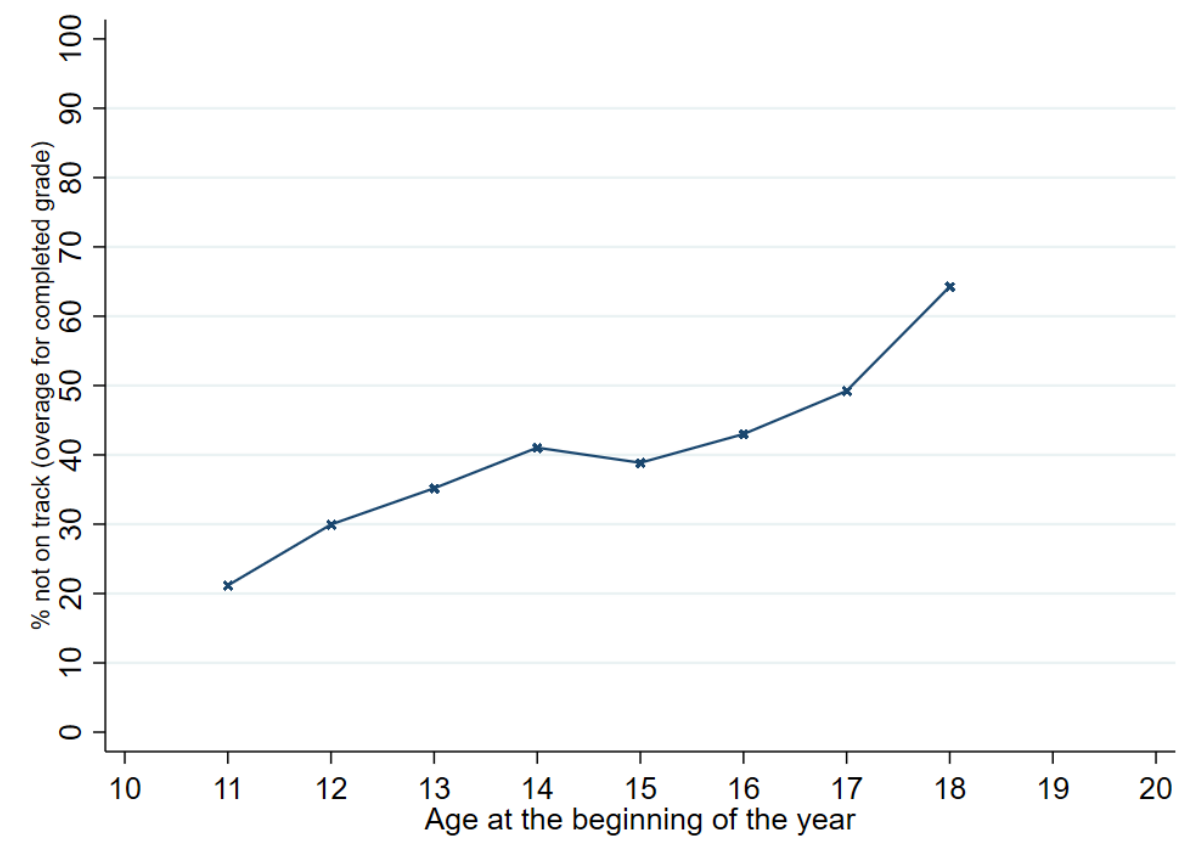

Source: Community Survey, 2016. Notes: 'Not on track' indicates that the child is at least 1 year behind the grade they should have completed given their current age. There are data validity concerns with the years of schooling variable for children born in 2006. Hence estimates are not shown for children younger than 11. Age here is current year less year of birth. 
Figure 11: Trends in the percentage of learners by grade that are over-age, EMIS 2000 to 2016 for 7 provinces

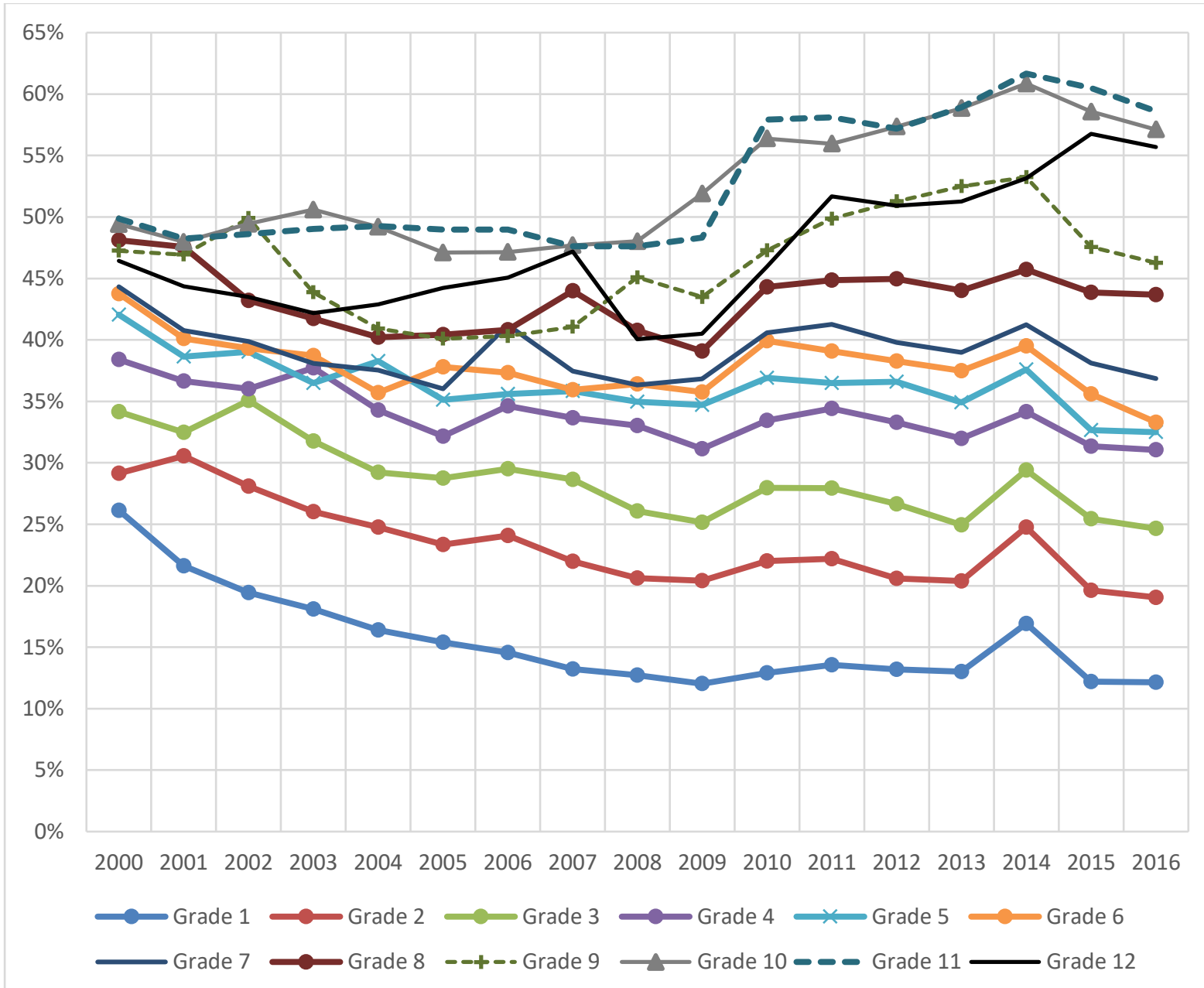

Source: EMIS 2000 to 2016 for 7 provinces, own calculations. Free-State and Mpumalanga are excluded. Notes: The age for grade data is a distinct dataset from the Annual Survey of Schools data subset that we use in other figures and tables. Where applicable, the 2003 and 2004 data on age were recoded to be consistent with the coding of ages in other years. We are cautious about the 2014 EMIS data on age for grade, particularly for the Eastern Cape. When we exclude the Eastern Cape from the time trends (see the Appendix) the 'blip' observed for 2014 is removed.

\subsubsection{DROPOUTS}

Dropout rates can be calculated from Annual Schools Survey data using the UNESCO method. Essentially, this calculates dropouts using information from two years. To determine how many students have been promoted from one grade to the next, this figure can be calculated as enrolment in the next grade in the next year, minus those who are repeating that grade. If enrolment in the initial grade in the initial year was $X$, and $Y$ persons were promoted and $Z$ repeat the initial grade, dropout from the initial grade is then simply calculated as $X-Y-Z$.

Calculating dropout in this way is of course subject to some error. Those considered dropouts from the system could have joined another education system, e.g. students considered 'dropouts' from the public-school system could simply have moved to private schools, or they could have have died or moved to another country. Similarly, movements from another country or province could also affect the accuracy of the dropout estimates, or students who have dropped out in one year may re-enter 
into the system in another year. For example, using SA-SAMS data for the Northern Cape we see some learners re-enter after dropping out. Still, at the broad system level (though not necessarily for individual schools, districts or even provinces), these estimates provide a good indication of the extent of dropout from the system.

Figure 12 shows dropouts between 2010 to 2011 and then 2015 to 2016 for our ASS subset for 7 provinces. No dropouts are shown for grade 12 or grade 7, as it not possible to calculate dropout rates in grade 7 or grade 12 using the UNESCO method, which requires enrolment numbers in the subsequent grade. Dropout rates are generally low through primary school, though still higher than is desirable. The real dropout problem is now concentrated in grade 10 and grade 11 , where almost $9 \%$ and then $22 \%$ of children in those grades dropped out between 2010 and 2011. Dropout rates in grade 10 and 11 are considerably lower for the 2015 to 2016 sample. It is not clear what accounts for the large discrepancies. One factor that has been mentioned by some educational officials and teachers is that some schools encourage learners who have performed poorly in grade 11 to write matric as private candidates, and therefore not to enrol in matric in the public school system. This would lead to an upward estimate of dropout in grade 11.

We are cautious to draw conclusions about provincial dropout patterns from this ASS data. Nevertheless, the enrolment rates by age from the Community Survey 2016 are indicative of higher levels of dropout in the FET phase in the Western Cape and Northern Cape provinces. The percentage of 17-year-olds not enrolled in an educational institution in 2016 was $14 \%$ in the Western Cape and $13 \%$ in the Northern Cape. By comparison, these estimates for 17 -year-olds were between $6 \%$ and $7 \%$ in Gauteng, Free State, KwaZulu-Natal and Mpumulanga and as low as $4 \%$ in Limpopo (see Figure A3).

Figure 12: Dropout rates using a reliable and consistent ASS school-level sample from 7 provinces, 2010 and 2015

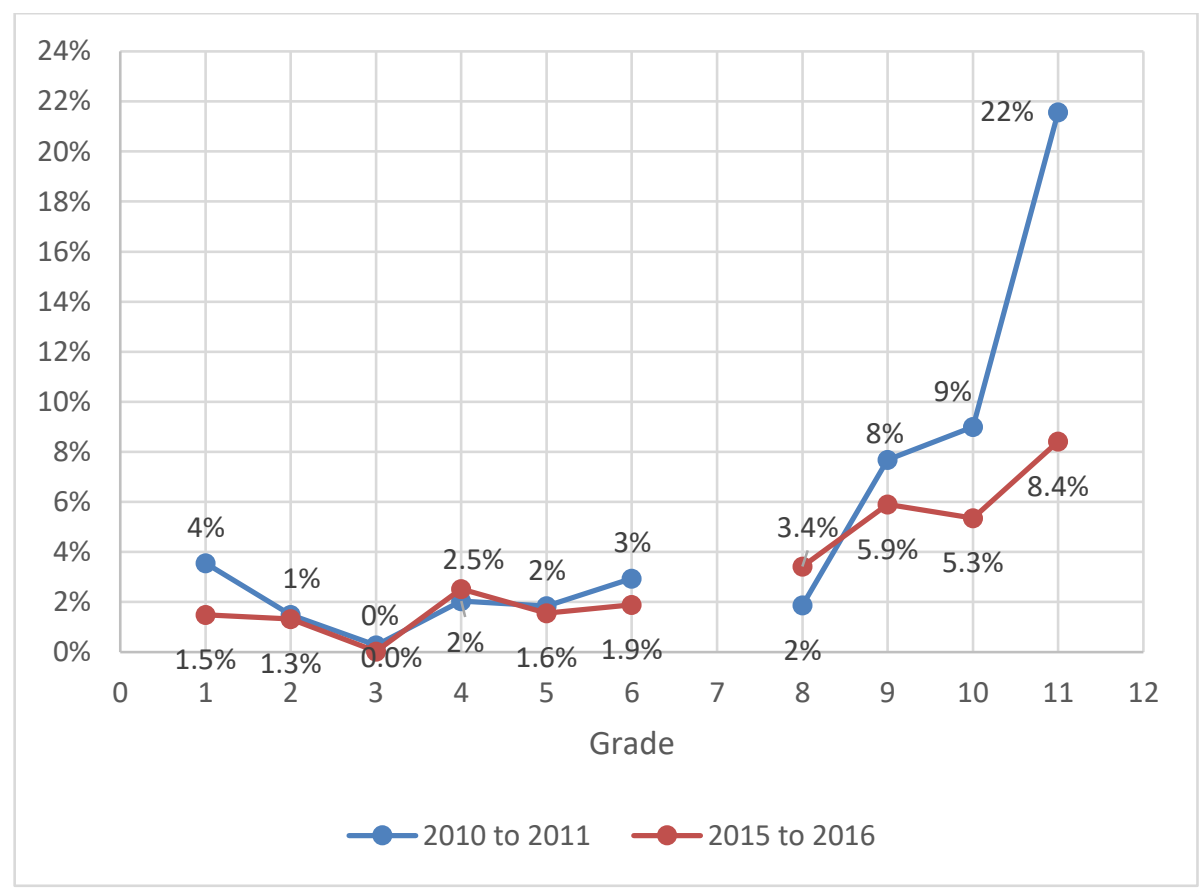

Source: A subset of Annual Survey of Schools data 2010-2011 and 2015-2016 for 7 provinces, excluding Free State and Mpumalanga. Notes: The sample excludes schools with unreliable or improbable data on repetition or dropout. Where primary schools end in grade 7 and secondary school at grade 12, it not possible to calculate dropout rates in grade 7 or grade 12 using the UNESCO method, which requires enrolment numbers in the next grade. 


\subsection{INEQUALITIES IN SCHOOL OUTCOMES: WEALTH AND GENDER}

Inequalities in educational attainment and school success are well-documented in the South African literature. There are considerable gaps in grade attainment, learner performance levels and postsecondary education outcomes by race and household wealth. This section highlights how inequalities persist in school outcomes in post-apartheid South Africa, expressed in considerable differences in rates of repetition, dropout and over-age learners by household or school wealth. The analysis should, however, be contextualised against the earlier discussion on the significant progress that has been made in reducing inequalities in grade attainment in post-apartheid South Africa. Additionally, we document the large gender discrepancies that emerge.

\subsubsection{HOUSEHOLD AND SCHOOL WEALTH}

Using the Community Survey 2016, it is possible to identify the wealth of learners' households using questions on household assets. Figure 13 shows how much more likely the poorest learners will fall behind at school. Just over a quarter (26\%) of 11 -year-old learners living in the poorest $20 \%$ of households are at least 1 grade behind the grade they should have completed (grade 4), but only $15 \%$ of 11 -year-olds in the wealthiest $20 \%$ of households are behind. By age 15 the gap has widened considerably: Roughly a half (52\%) of 15 -year-olds enrolled in school, living in the poorest $20 \%$ of households are at least 1 year behind completing grade 8 , compared with almost a quarter $(24 \%)$ of those in the wealthiest $20 \%$ of households.

Due to higher rates of dropouts by learners in poorer households, the percentage of youth that are not enrolled in any educational institution is significantly higher among youth in the poorest households. This is seen in Figure 14, which reports the proportion of youth (without a completed matric) not enrolled in any educational institution. To get as close as possible to a picture of dropout, the sample excludes youth who have completed matric or who have never attended school. The percentage of youth not enrolled is low in primary school, but then rises from age 14, with large and widening gaps between the poorest and wealthiest learners. The proportion of 18-year-olds (excluding those who have a matric) that are not enrolled in school is 3.6 times higher among those living in the poorest $20 \%$ of households compared with those in the wealthiest $20 \%$ of households.

While household wealth is a strong determinant of schooling outcomes, the key source of these inequalities in school outcomes are situated in unequal access to quality schooling. Where children in poorer schools are less likely to master basic skills of literacy and numeracy, learning deficits give rise to an inability to keep pace with the curriculum. This, in addition to haphazard assessment, are key reasons for higher repetition and dropout rates in poorer schools.

Using our subset of data from the ASS for which the school quintile is known, significant differences in repetition rates are observed between wealthier and poorer schools at all grades. While repetition in grade 1 - expressed as the number of repeaters in 2016 over enrolment in that grade in 2015 - was $18 \%$ in quintile 1 schools, it was $11 \%$ in quintile 5 schools. From grades 2 to 9 , repetition rates in quintile 1 schools are at least double that in quintile 5 schools but diverge further from grade 10 onwards. In 2015 the grade 10 repetition rate in quintile 1 schools was triple that in quintile 5 schools. The patterns are quite stable when comparing the 2010 and 2015 estimates. 
Figure 13: Percentage of children in school that are not on track by household wealth quintile, Community Survey 2016

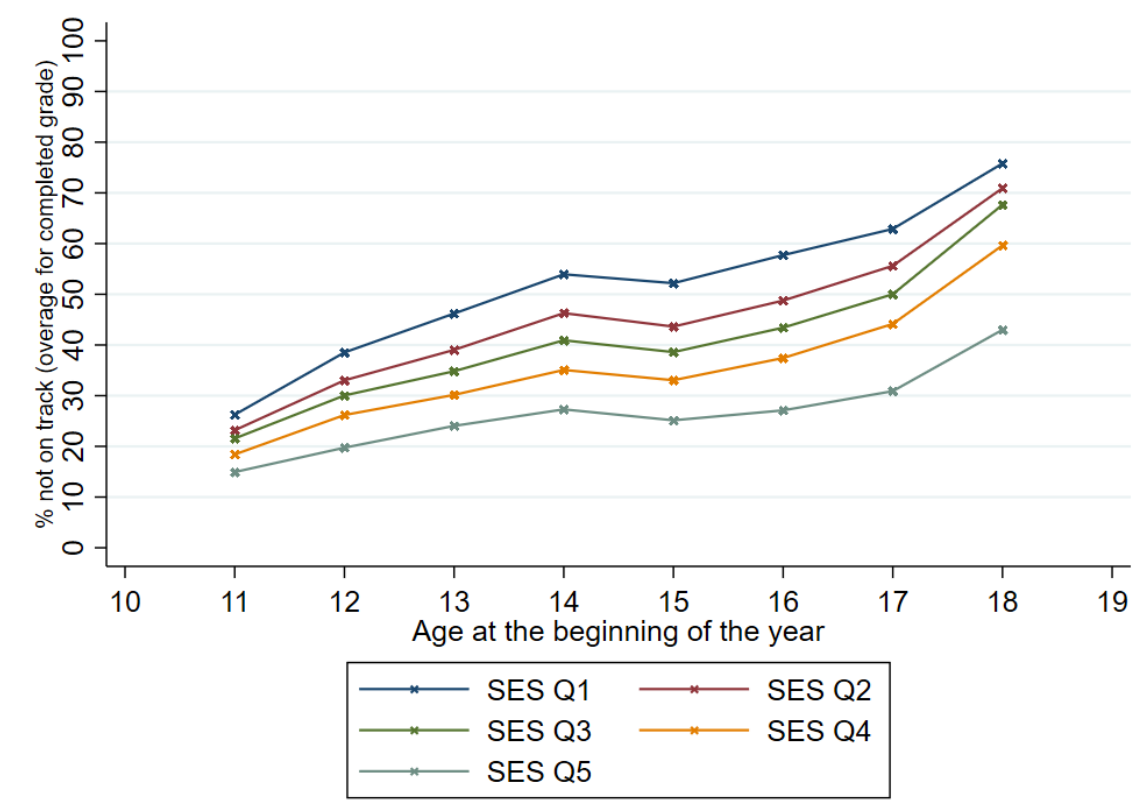

Source: Own calculations from Community Survey, 2016. Notes: 'Not on track' indicates that the child is at least 1 year behind the grade they should have completed given their current age. There are data validity concerns with the years of schooling variable for children born in 2006. Hence estimates are not shown for children younger than 11. Household wealth or socioeconomic status (SES) is determined using questions on assets in the household. Age here is current year less year of birth.

Figure 14: Percentage of youth aged 7 to 19 not enrolled in any educational institution by household wealth quintile, Community Survey 2016

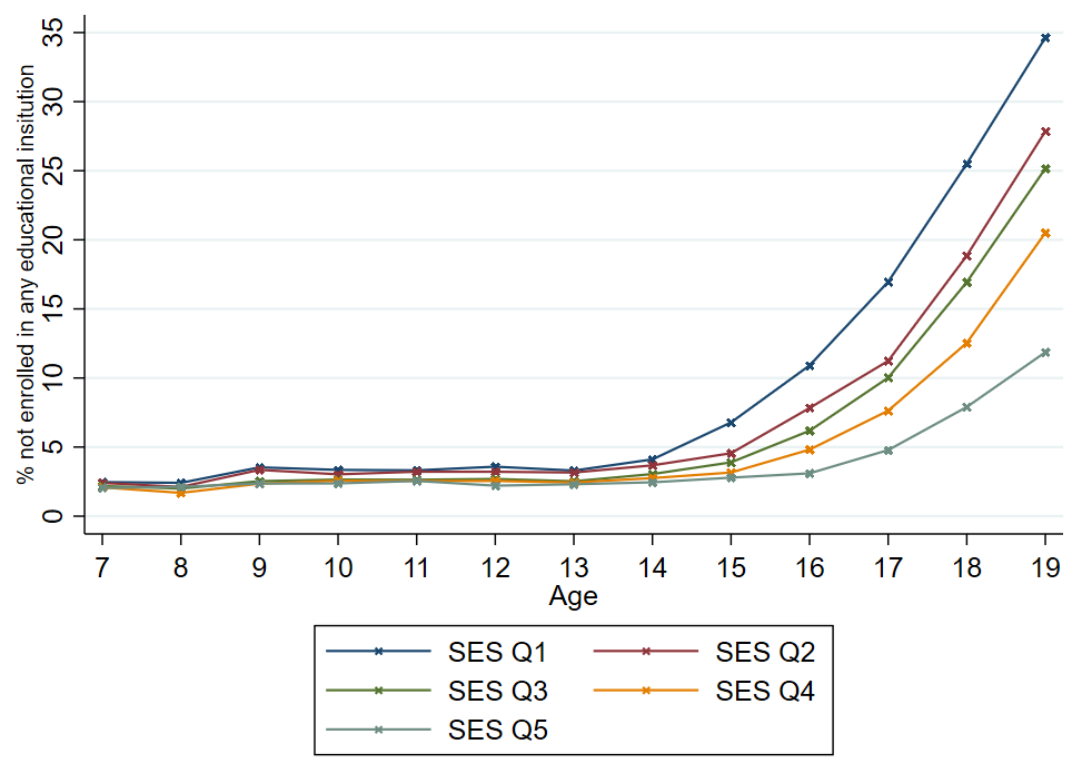

Source: Community Survey, 2016. Own calculations. Notes: Sample excludes individuals who have completed matric or have never ever attended school (i.e. years of schooling is zero). Household wealth or socioeconomic status (SES) is determined using questions on assets in the household. Age is age at the date of the survey (5/6 March 2016). 
Figure 15: Repetition rates across Quintile 1 and Quintile 5 schools using a reliable and consistent ASS school-level sample from 7 provinces for 2010 and 2015

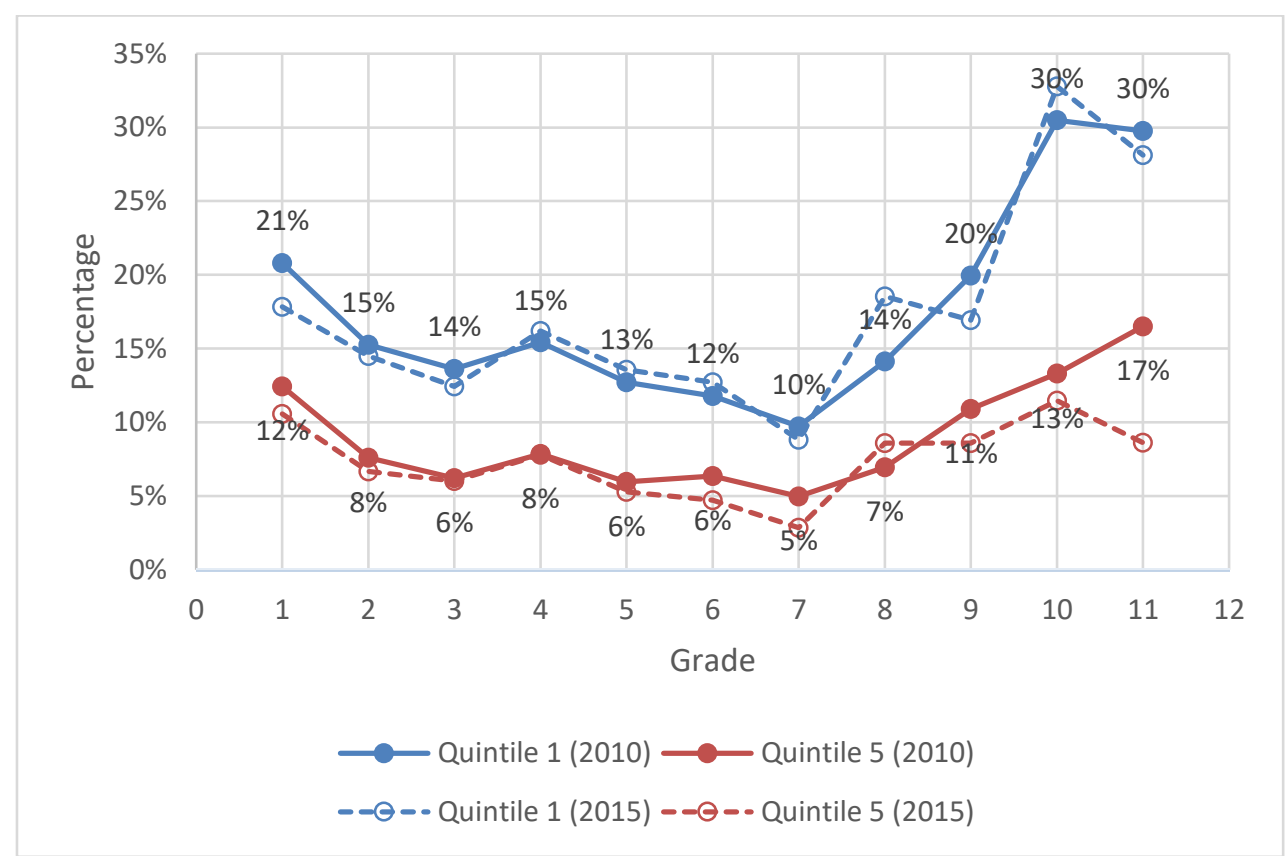

Source: A subset of Annual Survey of Schools data 2010-2011 and 2015-2016 for 7 provinces, excluding Free State and Mpumalanga. Notes: The sample excludes schools with unreliable or improbable data on repetition or dropout. Because learners are not observed one year after grade 12, it is not possible to calculate repetition rates in grade 12 using the UNESCO method. Data labels are only shown for 2015.

\subsubsection{GENDER}

In a study by Spaull and Broekhuizen (2017), titled 'the Martha Effect', a comprehensive account is given of the female advantage in almost all aspects of the schooling system. Females do better in virtually all international tests of learning and at almost all grade levels. Except for lower performance in the STEM ${ }^{16}$ fields at later stages, the female advantage is also sustained into post-secondary education.

With more recent data, we show below that females are more likely than males to be on track in terms of completed grade for age and are less likely to drop out. Figure 16, based on the Community Survey 2016 , shows that at age 11 , almost a quarter of males $(24 \%)$ are at least one grade behind for age compared to $17 \%$ of females. By age $15,45 \%$ of males are at least one grade behind for age compared to $30 \%$ of females, illustrating the widening gap.

\footnotetext{
${ }^{16}$ Science, Technology, Engineering and Mathematics.
} 
Figure 16: Percentage of children that are in school but not on track by gender, Community Survey 2016

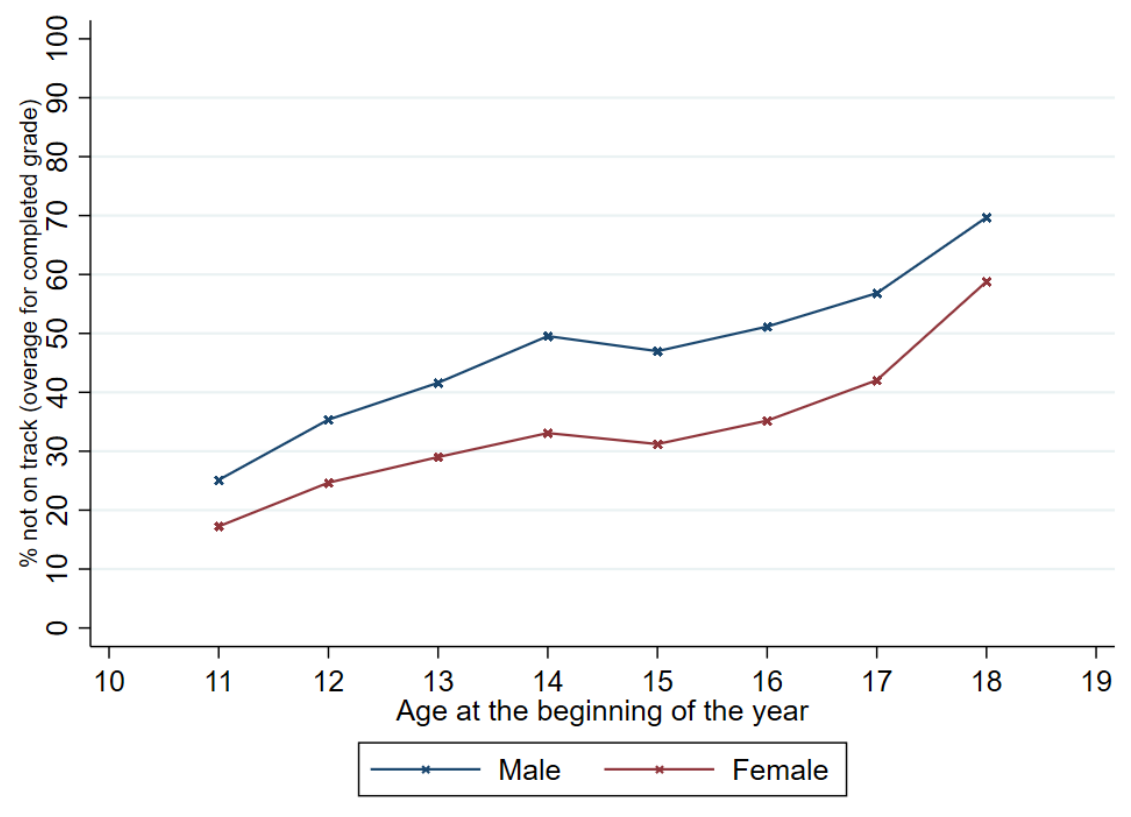

Source: Community Survey, 2016. Notes: 'Not on track' indicates that the child is at least 1 year behind the grade they should have completed given their current age. There are data validity concerns with the years of schooling variable for children born in 2006. Hence estimates are not shown for children younger than 11. Age here is current year less year of birth.

The female advantage in grade completion is already observed in grade 1 and becomes more pronounced in grade 4 . This is implied by estimates of repetition by gender using the ASS data subset for 7 provinces, as seen in Figure 17. Female repetition rates in 2010 and 2015 are about 4 percentage points lower than male repetition rates in grade 1 , and 6 to 7 percentage points lower in grade 4 . From grade 8 to 10 , a 5 to 7 percentage point difference remains, but then narrows in grade 11 . The gap narrows at later grades as a larger group of boys than girls (who are less likely to repeat), drop out from school in grades 9 and 10, as seen in Figure 18.

Comparing the proportions of girls and boys that repeat and drop out, however can understate gender differences. When comparing the ratios of boys to girls that repeat or drop out using absolute numbers, the differences are typically much wider.

Differential repetition rates across boys and girls means that there are more boys than girls in all grades up to grade 9 , because fewer girls than boys spend more than one year in a grade. The higher repetition rates mean that more boys are concentrated in the lower grades. This is seen in Figure 19, which reports the gender parity index across grades using national EMIS figures on public school enrolment by gender for 2009, 2016 and 2018 (but only data labels are shown for 2018). Once boys start dropping out on a large scale in grades 10 and 11, the gender parity index is considerably above 1 (or 100\%), implying a far larger number of girls than boys remain at school in these higher grades This pattern has remained quite consistent in the past 10 years again suggesting an inertia in repetition practices within the public education system. 
Figure 17: Repetition rates by gender using a reliable and consistent ASS school-level sample from 7 provinces, 2010 and 2015

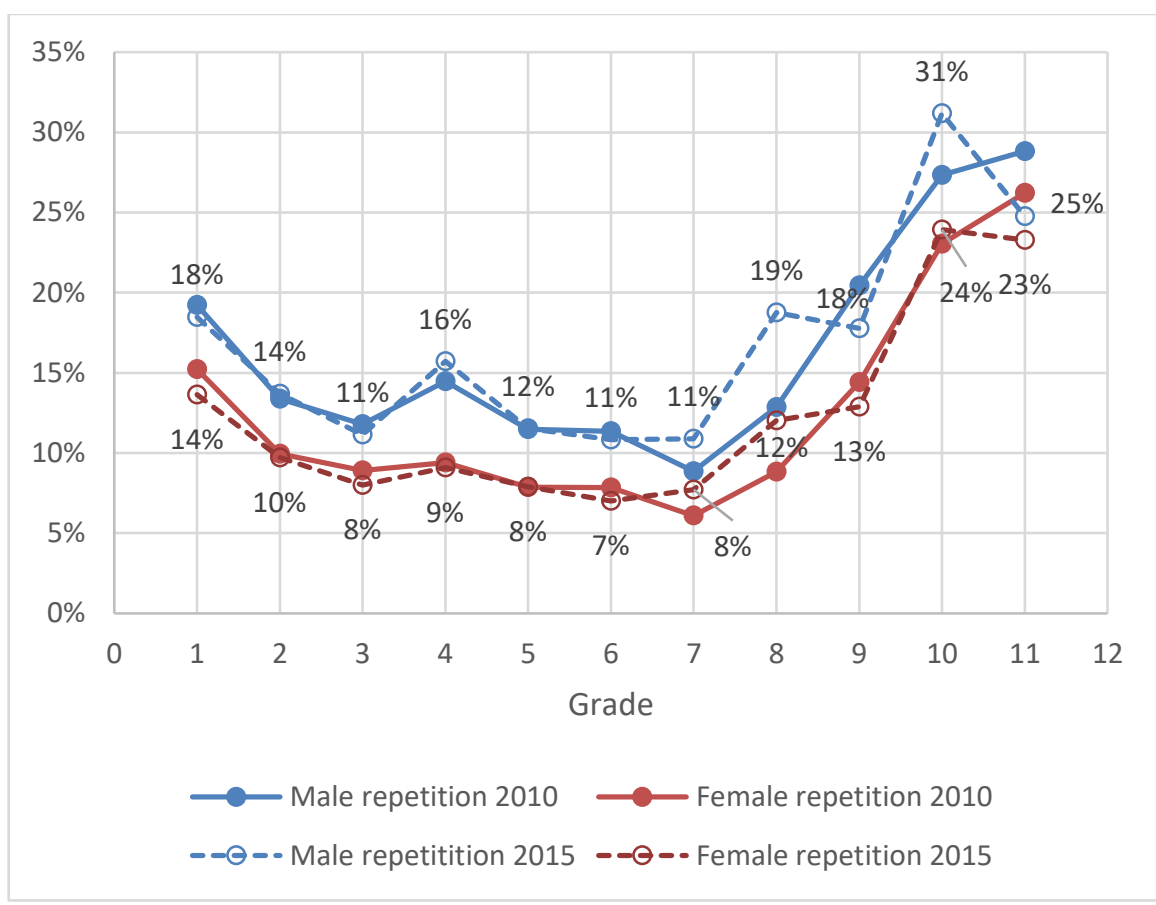

Source: A subset of Annual Survey of Schools data 2010-2011 and 2015-2016 for 7 provinces, excluding Free State and Mpumalanga. Notes: The sample excludes schools with unreliable or improbable data on repetition or dropout. Since learners are not observed one year after grade 12, it is not possible to calculate repetition rates in grade 12 using the UNESCO method. Data labels are only shown for 2015.

Figure 18: Dropout rates by gender using a reliable and consistent ASS school-level sample from 7 provinces, 2010 and 2015

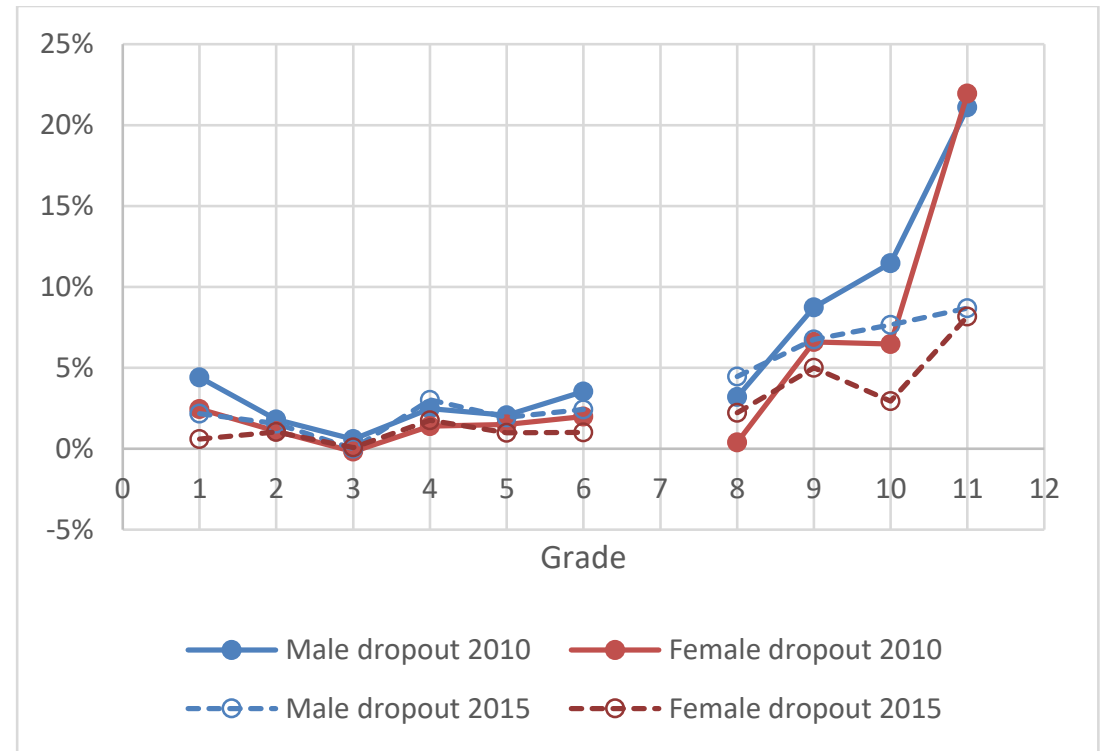

Source: A subset of Annual Survey of Schools data 2010-2011 and 2015-2016 for 7 provinces, excluding Free State and Mpumalanga. Notes: The sample excludes schools with unreliable or improbable data on repetition or dropout. Where primary schools end in grade 7 and secondary school at grade 12, it is not possible to calculate repetition and dropout rates in grade 7 or grade 12 using the UNESCO method, which requires enrolment numbers in the next grade. 
Figure 19: Gender parity index by grade, national EMIS statistics $(2009,2016,2018)$

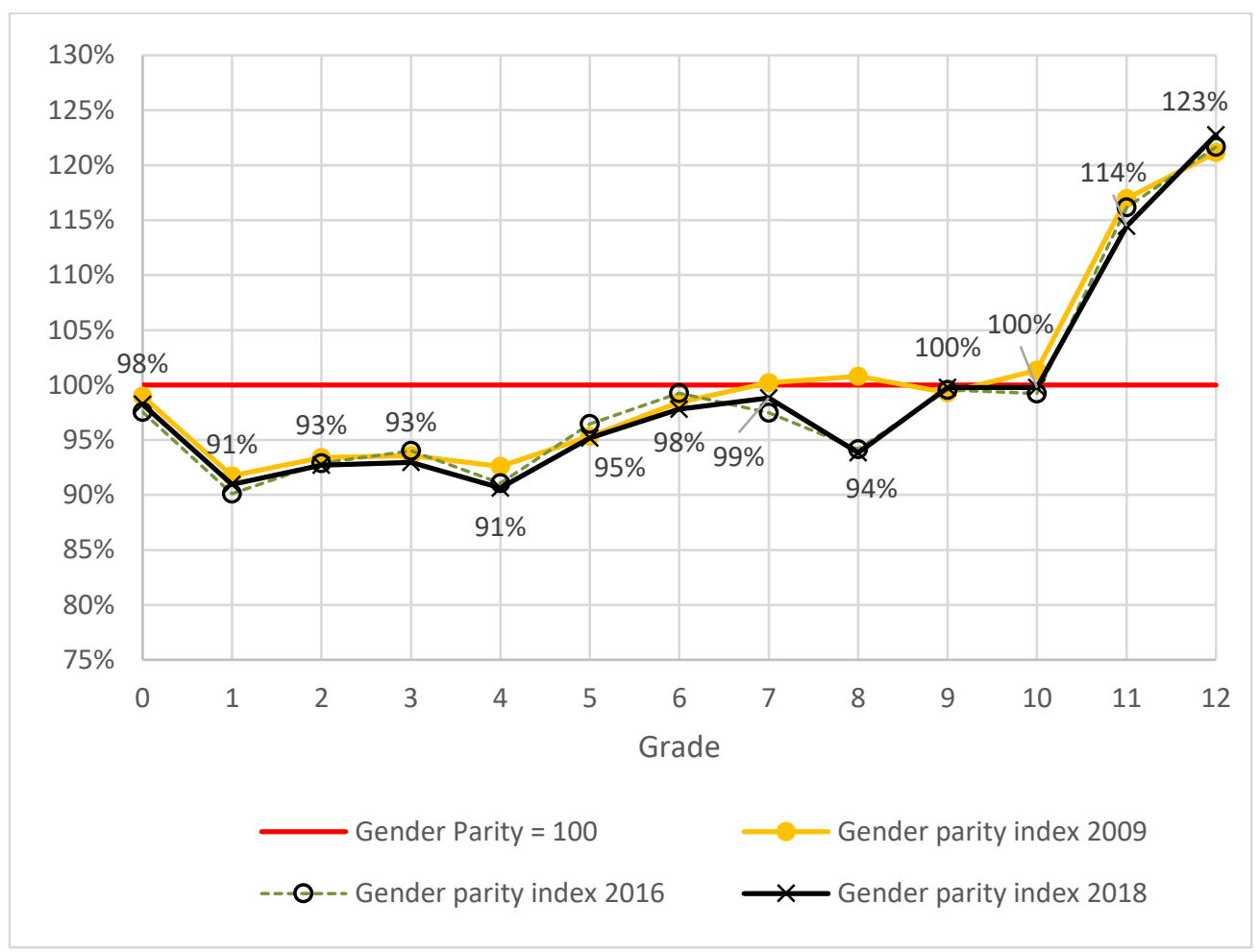

Source: The national enrolment data for females and males are taken from the School Realities reports for 2009, 2016 and 2018. Notes: Enrolments for public ordinary schools are used. Data labels are only shown for 2018.

\subsection{AN ANALYSIS OF REPETITION AND DROPOUT IN THE NORTHERN CAPE USING SA-SAMS DATA}

Up to this point, the discussion of repetition was based on cross-sectional household datasets or school-level ASS data. The SA-SAMS data for the Northern Cape provides a unique opportunity to track individual learners from year to year within the Northern Cape province. Rather than inferring rates of repetition from total grade enrolment and numbers of repeaters per grade, we have repeater data at the individual level. With five years of data (2014 to 2018) we can observe flows through the system for 4 periods. Better estimates of dropout are obtained with learner-level data compared with schoollevel data, although one cannot know if a learner dropped out of school altogether, moved to a private school or went to a school in another province. While it is possible to calculate repetition in grade 7 because SA-SAMS follows learners into high school, data accuracy is compromised by switches to secondary schools.

The SA-SAMS data provides a rich source of information, but it is also subject to data errors. Again, we limit the sample to a sub-set of schools with more reliable data (where learner IDs are consistent across years and other data are of sufficient quality). See Box 2 for a further discussion on this cleaning process. 


\section{Box 2: Establishing a data subset from the Northern Cape SA-SAMS}

The SA-SAMS data available for this study tracks learners within the Northern Cape and records each learner's grade every year from 2014 to 2018. In addition to this, learner details such as gender and date of birth, and school details such as quintile and school EMIS number are captured.

To reach the final sample, observations with missing data or obvious errors in terms of grade, gender, date of birth, school EMIS number, and quintile were excluded. To account for errors where learners were not captured in a specific year, grade was imputed where possible. If, for example, a student had a recorded grade of 5 in 2014 and grade 7 in 2016, but a missing value in 2015, a grade of 6 was imputed for 2015.

Finally, learner records were retained in the sample if they were in a school that recorded data every year from 2014 to 2018, or if the learner's grade was recorded in every year. This was to avoid incorrectly attributing dropout status to learners in schools that did not record data, but to retain learners in the sample who may have moved from a school that did not record data every year to one that did. We retained $79 \%$ of the original learner sample and $93 \%$ of the original school sample.

\begin{tabular}{|c|c|c|c|c|c|c|}
\hline 1. Retention of learners in sample & 2014-2018 & 2014 & 2015 & 2016 & 2017 & 2018 \\
\hline $\begin{array}{l}\text { Learner numbers in original SA-SAMS } \\
\text { NC sample }\end{array}$ & 435389 & 238989 & 293914 & 280881 & 288949 & 270278 \\
\hline Number of retained learners in sample & 345646 & 208965 & 231401 & 239533 & 245297 & 249142 \\
\hline $\begin{array}{l}\text { Learners retained as } \% \text { of original } \\
\text { learner sample }\end{array}$ & $79 \%$ & $87 \%$ & $79 \%$ & $85 \%$ & $85 \%$ & $92 \%$ \\
\hline Enrolment in Northern Cape & & 289004 & 290139 & 292595 & 292377 & 295339 \\
\hline Retained learners as \% of total enrolled & & $72 \%$ & $80 \%$ & $82 \%$ & $84 \%$ & $84 \%$ \\
\hline 2. Retention of schools in sample & 2014-2018 & 2014 & 2015 & 2016 & 2017 & 2018 \\
\hline $\begin{array}{l}\text { School numbers in original SA-SAMS NC } \\
\text { sample }\end{array}$ & 618 & 592 & 616 & 564 & 570 & 569 \\
\hline Number of retained schools in sample & 573 & 549 & 567 & 564 & 565 & 565 \\
\hline $\begin{array}{l}\text { Schools retained as \% of original school } \\
\text { sample }\end{array}$ & $93 \%$ & $93 \%$ & $92 \%$ & $100 \%$ & $99 \%$ & $99 \%$ \\
\hline Schools in the Northern Cape & & 577 & 581 & 574 & 579 & 582 \\
\hline Retained schools as \% of schools & & $95 \%$ & $98 \%$ & $98 \%$ & $98 \%$ & $97 \%$ \\
\hline
\end{tabular}

Note: Enrolment and school numbers in the Northern Cape are obtained from the DBE's release of EMIS statistics or School Realities reports.

\subsubsection{REPETITION IN THE NORTHERN CAPE}

Figure 20 shows repetition rates (repeaters as \% of the previous year's enrolment) for the Northern Cape, based on SA-SAMS data. The data is quite stable over the years. The repetition pattern that emerges in the Northern Cape is higher repetition in the first year of each phase. Again, we see that repetition is typically quite high in grade 1 at $15 \%$, but that may be heavily influenced by children not being school ready, and some of them being too young as well. In grade 4 , the beginning of the second school phase, repetition is again typically higher and again in grade 8 . The peak repetition rate in the 
Northern Cape, however, appears to be at the start of the FET phase (grade 10). Between 2016 and 2018 repetition in grade 10 was as high as $28 \%$ to $31 \%$.

Figure 20: Percentage of previous year's learners repeating, Northern Cape SA-SAMS sample

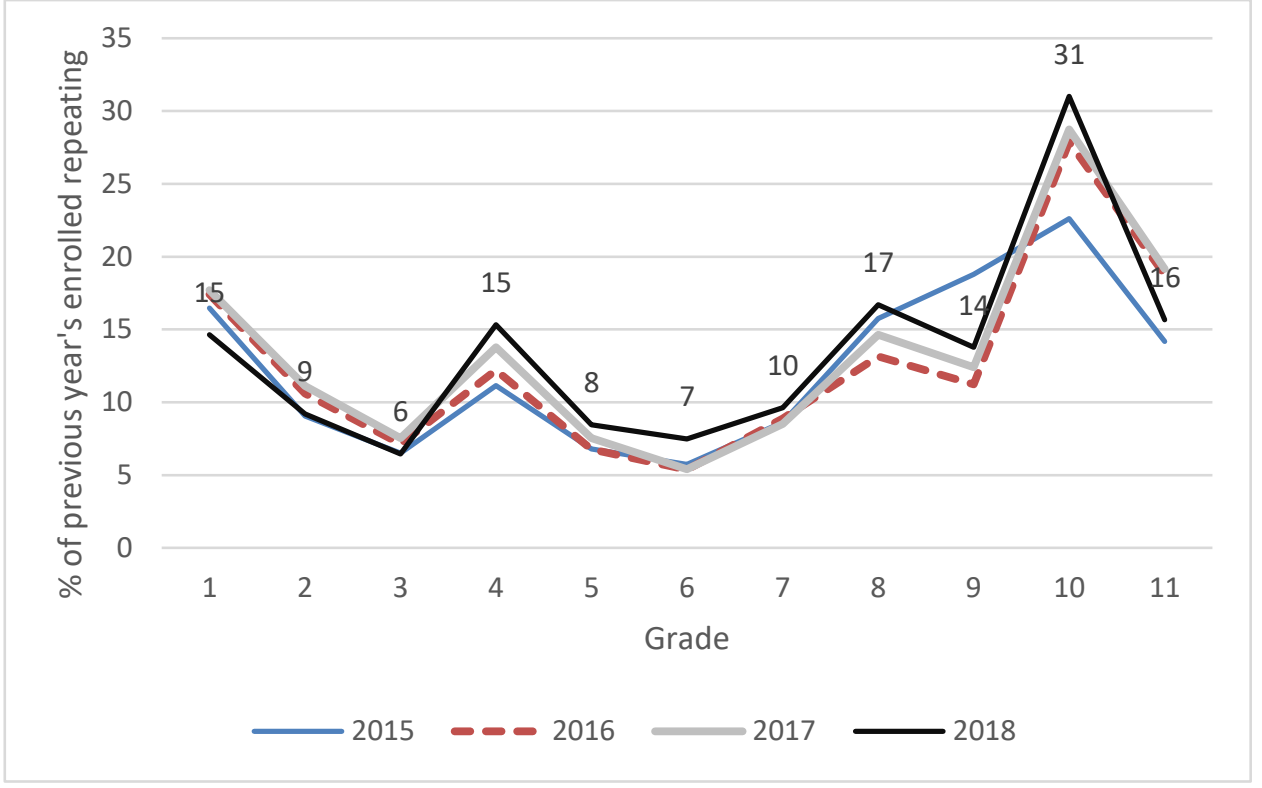

Source: Subset of SA-SAMS data for the Northern Cape Province.

\subsubsection{DROPOUT IN THE NORTHERN CAPE: 1 YEAR TRANSITIONS}

Table 5 provides a dynamic illustration of flows through the system from one year to another for pooled samples of grade 1 learners, grade 9 learners and grade 10 learners in the Northern Cape. (We pool across years of data to increase the sample size, and outcomes are only recorded for learners' first year in that grade.)

The likelihood of drop out is much higher among repeaters than non-repeaters. Of Grade 10 s who were repeating, about $16 \%$ drop out a year later (1892/11925). But among non-repeating Grade 10s, only $7 \%$ dropped out a year later. Among grade $9 \mathrm{~s}$, the probability of dropout a year later is also about twice as high if you are a repeater than a non-repeater.

The calculation of dropout rates using the UNESCO method (with school-level data) cannot account for the possibility that some learners who drop out of school may return at some point. With individual-level data, we can get sense of what percentage of learners who drop out are likely to reenter into schooling. SA-SAMS data for the Northern Cape indicates that among grade $1 \mathrm{~s}$ who drop out, 20\% (414/2039) re-enter within a year. The re-entry rates within a year for grade 9 and 10 s who had dropped out are $11 \%$ and $13 \%$ respectively. But these estimates should be treated as upper limits on re-entry into public schools as one can't rule out that some 're-entries' may be due to problems in correctly linking learners across grades, schools or due to learners being schooled outside the Northern Cape public school system for a period of time. 
Table 5: Transitions using SA-SAMS data for the Northern Cape

\begin{tabular}{|c|c|c|c|c|c|c|c|c|}
\hline \multirow{2}{*}{\multicolumn{2}{|c|}{$\begin{array}{l}\text { GRADE } 1 \text { (pooled } \\
\text { sample for } 3 \text { years) }\end{array}$}} & \multicolumn{5}{|c|}{ Outcome year $n+1$} & \multirow{2}{*}{\multicolumn{2}{|c|}{ Total }} \\
\hline & & Promoted & Repeats & Drops out & $\begin{array}{l}\text { Remains } \\
\text { dropped }\end{array}$ & $\begin{array}{c}\text { Re- } \\
\text { enters }\end{array}$ & & \\
\hline \multirow{3}{*}{$\frac{1}{\frac{1}{0}}$} & \multirow{3}{*}{$\begin{array}{l}\text { Promoted in Gr. } 1 \\
\text { Repeating Gr. } 1 \\
\text { Drops out }\end{array}$} & 43952 & 6012 & 1603 & & & \multirow{3}{*}{\multicolumn{2}{|c|}{$\begin{array}{ll}51567 & (78 \%) \\
12521 & (19 \%) \\
2039 & (3 \%)\end{array}$}} \\
\hline & & 11336 & 378 & 807 & & & & \\
\hline & & & & & 1625 & 414 & & \\
\hline & Total & $\begin{array}{l}55288 \\
(84 \%) \\
\end{array}$ & $\begin{array}{c}6390 \\
(10 \%) \\
\end{array}$ & $\begin{array}{l}2410 \\
(4 \%) \\
\end{array}$ & $\begin{array}{l}1625 \\
(2 \%) \\
\end{array}$ & $\begin{array}{c}414 \\
(1 \%) \\
\end{array}$ & \multicolumn{2}{|c|}{$66127 \quad(100 \%)$} \\
\hline \multirow{2}{*}{\multicolumn{2}{|c|}{$\begin{array}{l}\text { GRADE } 9 \text { (pooled } \\
\text { sample for } 3 \text { years) }\end{array}$}} & \multicolumn{5}{|c|}{ Outcome year $n+1$} & \multirow{2}{*}{\multicolumn{2}{|c|}{ Total }} \\
\hline & & Promoted & Repeats & Drops out & $\begin{array}{l}\text { Remains } \\
\text { dropped } \\
\text { out }\end{array}$ & $\begin{array}{c}\text { Re- } \\
\text { enters }\end{array}$ & & \\
\hline \multirow{3}{*}{$\begin{array}{l}\text { ᄃ } \\
\frac{1}{0} \\
\stackrel{0}{2}\end{array}$} & \multirow{3}{*}{$\begin{array}{l}\text { Promoted Gr. } 9 \\
\text { Repeating Gr. } 9 \\
\text { Drops out }\end{array}$} & 18770 & 10088 & 2941 & & & \multirow{3}{*}{\multicolumn{2}{|c|}{$\begin{array}{ll}31799 & (72 \%) \\
6574 & (15 \%) \\
6002 & (14 \%) \\
\end{array}$}} \\
\hline & & 4896 & 555 & 1123 & & & & \\
\hline & & & & & 5332 & 670 & & \\
\hline \multicolumn{2}{|r|}{ Total } & $\begin{array}{c}23666 \\
(53 \%) \\
\end{array}$ & $\begin{array}{c}10643 \\
(24 \%) \\
\end{array}$ & $\begin{array}{c}4064 \\
(9 \%) \\
\end{array}$ & $\begin{array}{c}5332 \\
(12 \%) \\
\end{array}$ & $\begin{array}{l}670 \\
(2 \%) \\
\end{array}$ & \multicolumn{2}{|c|}{$44375 \quad(100 \%$} \\
\hline \multirow{2}{*}{\multicolumn{2}{|c|}{$\begin{array}{l}\text { GRADE } 10 \text { (pooled } \\
\text { sample for } 3 \text { years) }\end{array}$}} & \multicolumn{5}{|c|}{ "Outcome year $n+1$} & \multirow{2}{*}{\multicolumn{2}{|c|}{ Total }} \\
\hline & & Promoted & Repeats & Drops out & $\begin{array}{l}\text { Remains } \\
\text { dropped } \\
\text { out }\end{array}$ & $\begin{array}{c}\text { Re- } \\
\text { enters }\end{array}$ & & \\
\hline \multirow{3}{*}{$\frac{1}{2}$} & \multirow{3}{*}{$\begin{array}{l}\text { Promoted Gr. } 10 \\
\text { Repeating Gr. } 10 \\
\text { Drops out }\end{array}$} & 18757 & 4572 & 1945 & & & \multirow{3}{*}{\multicolumn{2}{|c|}{$\begin{array}{rr}25274 & (60 \%) \\
11925 & (28 \%) \\
5135 & (12 \%) \\
\end{array}$}} \\
\hline & & 7870 & 2163 & 1892 & & & & \\
\hline & & & & & 4468 & 667 & & \\
\hline \multicolumn{2}{|r|}{ Total } & $\begin{array}{l}26627 \\
(63 \%)\end{array}$ & $\begin{array}{c}6735 \\
(16 \%)\end{array}$ & $\begin{array}{c}3837 \\
(19 \%)\end{array}$ & $\begin{array}{l}4468 \\
(11 \%)\end{array}$ & $\begin{array}{c}667 \\
(2 \%)\end{array}$ & 42334 & $100 \%)$ \\
\hline
\end{tabular}

Source: SA-SAMS subset for the Northern Cape. Notes: The transition matrices are obtained using a pooled group of learners in grade 1/9/10 in the years 2014, 2015 and 2016 to increase the sample sizes. The rows show the outcome for a learner at the end of year $n$, while the columns show the outcome for the learner at the end of year $n+1$. This repetition rates in this table should not be compared to the previous figure as the samples are different. Here we only follow a grade sample who are in their year $n$ grade for the first time.

\subsubsection{THE IMPLEMENTATION OF REPETITION POLICY IN THE NORTHERN CAPE}

According to policy, learners should not repeat more than once in a phase. Using the SA-SAMS data we can estimate to what extent this policy is being implemented by identifying how many learners repeat more than once in a phase. The results of this analysis are shown in Table 6. As expected, we find that there is better adherence to repetition policy in the foundation phase and intermediate phase when compared with the FET phase. Of the Northern Cape learners who are identified in 2014 or 2015 as being in grade 1, between 2 to $3 \%$ of the sample repeat more than once in the phase. In the intermediate phase, non-adherence to policy affects only $1-2 \%$ of learners. In the FET phase, however, about $8 \%$ of learners are repeating a grade in this phase at least twice. Despite the promulgation of FET policy by 2013, the Northern Cape data reveals that much progress still needs to be made to ensure the policy is implemented. Progress is also needed in other provinces. Kika an Kotze's (2018) national estimate from the 2017 NIDS data indicates that $7 \%$ of youth aged 15 to 30 had repeated more than once in the FET phase. 
Table 6: Repetition per phase, SA-SAMS data for the Northern Cape

In first year of phase in 2014:

In first year of phase in $\mathbf{2 0 1 5}$

(for the first time):

Tracking learner success from grade 1 to 3 (Foundation phase)

\begin{tabular}{lll|lll} 
& Frequency & $\%$ & & Frequency & $\%$ \\
\hline No repetition & 13134 & $61 \%$ & No repetition & 13121 & $58 \%$ \\
1 repetition & 5264 & $25 \%$ & 1 repetition & 6574 & $29 \%$ \\
2 repetitions & 624 & $3 \%$ & 2 repetitions & 432 & $2 \%$ \\
3 repetitions & 29 & $0 \%$ & 3 repetitions & 11 & $0 \%$ \\
Dropout & 2397 & $11 \%$ & Dropout & 2573 & $11 \%$ \\
\hline Total & 21448 & $100 \%$ & & 22711 & $100 \%$ \\
\hline \hline
\end{tabular}

Tracking learner success from grade 4 to 6 (Intermediate phase)

\begin{tabular}{lll|lll} 
& Freq & $\%$ & & Freq & $\%$ \\
\hline No repetition & 13464 & $68 \%$ & No repetition & 11671 & $64 \%$ \\
1 repetition & 2955 & $15 \%$ & 1 repetition & 4065 & $22 \%$ \\
2 repetitions & 410 & $2 \%$ & 2 repetitions & 264 & $1 \%$ \\
3 repetitions & 42 & $0 \%$ & 3 repetitions & 17 & $0 \%$ \\
4 repetitions & 1 & $0 \%$ & & & \\
Dropout & 2895 & $15 \%$ & Dropout & 246 & $12 \%$ \\
\hline Total & 19767 & $100 \%$ & Total & 18263 & $100 \%$ \\
\hline \hline
\end{tabular}

\begin{tabular}{lll|lll}
\hline & \multicolumn{2}{c}{ Tracking learner success from grade 10 to 12 (FET phase) } & & \\
& Freq & $\%$ & & Freq & $\%$ \\
\hline No repetition & 7339 & $45 \%$ & No repetition & 5414 & $43 \%$ \\
1 repetition & 3028 & $18 \%$ & 1 repetition & 3002 & $24 \%$ \\
2 repetitions & 945 & $6 \%$ & 2 repetitions & 876 & $7 \%$ \\
3 repetitions & 272 & $2 \%$ & 3 repetitions & 147 & $1 \%$ \\
4 repetitions & 25 & $0 \%$ & & & $25 \%$ \\
Dropout & 4796 & $29 \%$ & Dropout & 3212 & $25 \%$ \\
\hline Total & 16405 & $100 \%$ & Total & 12651 & $100 \%$ \\
\hline \hline
\end{tabular}

Source: SA-SAMS subset for the Northern Cape province.

\subsubsection{PROBABILITIES OF PROMOTION, DROPOUT AND REACHING GRADE 12 IN THE NORTHERN CAPE}

For much of this report we have shown patterns of repetition and dropout by grade, household wealth, school quintile or gender. But what are the strongest determinants of repetition or dropout when all these factors are considered together? We answer this question using the Northern Cape SASAMS data. While background characteristics on learners in SA-SAMS is limited, it remains instructive for these purposes.

Columns 1 and 2 of Table 7 shows the results of linear probability regression models that estimate whether Northern Cape learners in grades 1 to 11 in 2015 were successfully promoted by the end of the year (i.e. did not repeat) or whether they dropped out by the end of the year. The third column then estimates the probability that grade 9 learners in 2014 will have been promoted to grade 12 with a maximum of 1 year of repetition 
The results are summarised below. It is cautioned that these are merely correlations and should not be interpreted as causal connections. The findings are also specific to the Northern Cape, although general patterns often follow broader national trends.

- Being male is more strongly associated with repetition than with dropout in the Northern Cape: After accounting for school quintile, being over-age, the learner's current grade and population group, females are $5 \%$ more likely to be promoted than males. What is unexpected is that gender is not significantly associated with dropout in the Northern Cape. Additionally, grade 9 female learners are no more likely than grade 9 males to be promoted to grade 12 within 3 to 4 years.

- Over-age learners are less likely to be promoted and are more likely to drop out than learners that are the correct grade for age or underage. There is a steady decline in the probability of promotion with each year that learners are over-age. This implies that repetition is likely to be proceeded by more repetition. Learners who are 2 years over-age are $10 \%$ less likely to be promoted and $10 \%$ more likely to drop out.

- Grade 9 learners who are over-age are particularly at risk of not being promoted to grade 12 in good time. For example, being 1-year over-age reduces their chances of promotion to grade 12 within 3 to 4 years by $22 \%$, being 2 years older by as much as $37 \%$, being 3 years older by nearly $50 \%$.

- The probability of dropout in the Northern Cape is highest in grade 9 but remains high in grade 10.

- Of all primary grades, the probability that learners are promoted is lowest in grade 1 . Across all grades, the likelihood of being promoted is lowest in grade 10.

- School quintile is more strongly associated with differences in repetition than in dropout in the Northern Cape. Learners in quintile 5 schools are $6 \%$ more likely to be promoted than learners in quintile 1 schools. Although learners in quintile 2 to 4 schools are no more likely to be promoted than learners in quintile 1 schools, dropout rates do not appear to be significantly different across school quintiles, except for slightly higher dropout in quintile 3 schools compared with quintile 1 schools.

- Attending a wealthier school is significantly correlated with whether grade 9 learners reach matric in good time. Grade 9 learners in quintile 5 schools are $12 \%$ more likely to get to matric within 4 years than learners in quintile 1 schools.

- Factors that are unmeasured here are much more important in determining whether learners are promoted, as seen in the large coefficients on the constant term in columns 1 and 3 . 
Table 7: Estimating the probability of promotion, dropout or reaching matric, 2015 SA-SAMS data for the Northern Cape

\begin{tabular}{|c|c|c|c|}
\hline \multirow[t]{2}{*}{ Sample: } & \multicolumn{2}{|c|}{ Learners in the Northern Cape SA-SAMS in 2015} & \multirow{2}{*}{$\begin{array}{c}\text { Grade } 9 \text { learners in the } \\
\text { Northern Cape in } 2014 \\
\text { 3. Promoted to Gr } 12 \text { by } \\
2017 \text { or } 2018\end{array}$} \\
\hline & $\begin{array}{l}\text { 1. Outcome end of 2015: } \\
\text { Promoted }\end{array}$ & $\begin{array}{l}\text { 2. Outcome end of 2015: } \\
\text { Drops out }\end{array}$ & \\
\hline Female & $\begin{array}{c}0.051^{* * *} \\
(0.00)\end{array}$ & $\begin{array}{l}0.002 \\
(0.00)\end{array}$ & $\begin{array}{l}0.009 \\
(0.01)\end{array}$ \\
\hline $\begin{array}{l}\text { Population group: } \\
\text { Coloured }\end{array}$ & $\begin{array}{c}-0.038^{* * *} \\
(0.01)\end{array}$ & $\begin{array}{c}0.028^{* * *} \\
(0.01)\end{array}$ & $\begin{array}{c}-0.097^{* * *} \\
(0.02)\end{array}$ \\
\hline Population group: White & $\begin{array}{c}0.026^{*} \\
(0.02)\end{array}$ & $\begin{array}{c}0.065^{* * *} \\
(0.01)\end{array}$ & $\begin{array}{c}0.102^{* * *} \\
(0.04)\end{array}$ \\
\hline $\begin{array}{l}\text { Population group: } \\
\text { Asian/Indian }\end{array}$ & $\begin{array}{l}0.021 \\
(0.02)\end{array}$ & $\begin{array}{c}0.031^{* *} \\
(0.01)\end{array}$ & $\begin{array}{l}-0.04 \\
(0.08)\end{array}$ \\
\hline Population group: Other & $\begin{array}{c}-0.023^{*} \\
(0.01)\end{array}$ & $\begin{array}{c}0.039 * * * \\
(0.01)\end{array}$ & $\begin{array}{c}0.253^{* *} \\
(0.11)\end{array}$ \\
\hline Grade 2 & $\begin{array}{c}0.064^{* * *} \\
(0.01)\end{array}$ & $\begin{array}{l}-0.001 \\
(0.00)\end{array}$ & \\
\hline Grade 3 & $\begin{array}{c}0.084 * * * \\
(0.01)\end{array}$ & $\begin{array}{l}0.012 \\
(0.01)\end{array}$ & \\
\hline Grade 4 & $\begin{array}{c}0.044^{* * *} \\
(0.01)\end{array}$ & $\begin{array}{l}0.001 \\
(0.00)\end{array}$ & \\
\hline Grade 5 & $\begin{array}{c}0.104^{* * *} \\
(0.01)\end{array}$ & $\begin{array}{l}-0.004 \\
(0.00)\end{array}$ & \\
\hline Grade 6 & $\begin{array}{c}0.103^{* * *} \\
(0.01)\end{array}$ & $\begin{array}{c}0.010^{* *} \\
(0.01)\end{array}$ & \\
\hline Grade 8 & $\begin{array}{c}-0.030^{* *} \\
(0.01)\end{array}$ & $\begin{array}{c}0.063^{* * *} \\
(0.01)\end{array}$ & \\
\hline Grade 9 & $\begin{array}{c}-0.028^{* *} \\
(0.01)\end{array}$ & $\begin{array}{c}0.080^{* * *} \\
(0.01)\end{array}$ & \\
\hline Grade 10 & $\begin{array}{c}-0.174^{* * *} \\
(0.02)\end{array}$ & $\begin{array}{c}0.065^{* * *} \\
(0.01)\end{array}$ & \\
\hline Grade 11 & $\begin{array}{c}-0.074^{* * *} \\
(0.02)\end{array}$ & $\begin{array}{c}0.049 * * * \\
(0.02)\end{array}$ & \\
\hline 1-year over-age & $\begin{array}{c}-0.037^{* * *} \\
(0.01)\end{array}$ & $\begin{array}{c}0.035^{* * *} \\
(0.00)\end{array}$ & $\begin{array}{c}-0.225^{* * *} \\
(0.01)\end{array}$ \\
\hline 2 years over-age & $\begin{array}{c}-0.103^{* * *} \\
(0.01)\end{array}$ & $\begin{array}{c}0.101^{* * *} \\
(0.01)\end{array}$ & $\begin{array}{c}-0.370^{* * *} \\
(0.02)\end{array}$ \\
\hline 3 years over-age & $\begin{array}{c}-0.164^{* * *} \\
(0.01)\end{array}$ & $\begin{array}{c}0.173^{* * *} \\
(0.01)\end{array}$ & $\begin{array}{c}-0.462^{* * *} \\
(0.02)\end{array}$ \\
\hline 4 years over-age & $\begin{array}{c}-0.180^{* * *} \\
(0.02)\end{array}$ & $\begin{array}{c}0.201 * * * \\
(0.02)\end{array}$ & $\begin{array}{c}-0.525^{* * *} \\
(0.02)\end{array}$ \\
\hline 5 years over-age & $\begin{array}{c}-0.183^{* * *} \\
(0.03)\end{array}$ & $\begin{array}{c}0.230^{* * *} \\
(0.02)\end{array}$ & $\begin{array}{c}-0.573^{* * *} \\
(0.03)\end{array}$ \\
\hline$>=6$ years over-age & $-0.211 * * *$ & $0.269 * * *$ & $-0.585^{* * *}$ \\
\hline
\end{tabular}




\begin{tabular}{lcc|c} 
& $(0.04)$ & $(0.03)$ & $(0.03)$ \\
School quintile 2 & 0.017 & 0.002 & 0.056 \\
School quintile 3 & $(0.01)$ & $(0.01)$ & $(0.04)$ \\
& 0.005 & $0.016^{*}$ & $0.061^{*}$ \\
School quintile 4 & $(0.01)$ & $(0.01)$ & $(0.03)$ \\
& 0.023 & 0.002 & 0.058 \\
School quintile 5 & $(0.02)$ & $(0.01)$ & $(0.04)$ \\
& $0.055^{* * *}$ & 0 & $0.121^{* * *}$ \\
Independent school & $(0.02)$ & $(0.01)$ & $(0.04)$ \\
& 0.021 & -0.004 & $0.149^{* *}$ \\
Constant & $(0.05)$ & $(0.02)$ & $(0.08)$ \\
& $0.780^{* * *}$ & 0.001 & $0.644^{* * *}$ \\
& $(0.01)$ & $(0.01)$ & $(0.03)$ \\
Observations & & & 15,030 \\
R-squared & 177,198 & 177,198 & 0.165 \\
\hline
\end{tabular}

Source: Subset of SA-SAMS data for the Northern Cape Province. Notes: Robust standard errors in parentheses. ${ }^{* * *} p<0.01,{ }^{* *} p<0.05,{ }^{*} p<0.1$. Reference group: Black male in grade 1, not over-age, in a Quintile 1 school. In estimations 1 and 2 , grade 7 s are excluded from the sample due to data validity concerns for this group. 


\section{THE COSTS OF REPETITION AND DROPOUT}

How much does repetition cost taxpayers and society at large? We aim to provide an answer to this question, suggesting some possible estimates of the cost of repetition. We start by merely considering how much government may have to spend to accommodate repeaters. Then we provide a comparative illustration that considers how much value is lost to society when we account for forgone earnings of not completing school. Repetition may be one driver of cost, and sizeable costs. But this pales in comparison to the cost of a poorly functioning schooling system that constrains earnings opportunities when learners cannot obtain a matric or go onto obtain higher qualifications.

\subsection{EXTRA GOVERNMENT SPENDING ON REPETITION}

Costing repetition is not a straightforward exercise. As indicated throughout this report, different datasets provide different estimates of repetition rates. An accurate costing also requires having accurate figures on enrolment by grade and estimates of government spending per child. Furthermore, economies of scale complicate the determination of the exact cost of one repeater. ${ }^{17}$ Nevertheless, our estimates provide some suggestion of the impacts of repetition on the state.

We calculate the cost of repetition using the GHS 2016 repetition rates as a lower bound, and the ASS subset repetition rates as an upper bound. Since we were not able to calculate repetition rates for grade 12 using the school-level ASS subset, we interpolate an upper bound repetition rate at grade 12 as being 4 percentage points higher than the GHS 2016 estimates of grade 12 repetition. The basis for this decision is that the ASS and Northern Cape SA-SAMS repetition rates were on average 4 percentage points higher than GHS rates for each grade.

Lilenstein and Spaull (2019) identify that the cost per learner for the 2016/2017 government financial year was R16264. They used financial reports released by National Treasury on education spending to estimate this figure. We inflate this amount by the average Consumer Price Index for 2017 (4.5\%) to obtain a cost per learner in early 2018 prices. Enrolment numbers by grade in 2016 are obtained from the Department of Basic Education's released EMIS statistics for 2016.

If we use GHS 2016 estimates, then 1.18 million learners in grades 1 to 12 repeated in 2016. Using our ASS estimates, the number of learners repeating could have been as high as 1.69 million (see Table 8). In monetary terms, this implies that the cost of having repeaters in the public education system was between 20 and 29 billion rand (in 2018 prices). At these costs, repetition would absorb between 8 to $12 \%$ of the national budget allocated to basic education in 2018/2019. ${ }^{18}$ If we were to include repetition in Grade $R$, which does occur but is more difficult to calculate, these estimates would be even higher.

With the highest repetition rates in grade 10 , repeaters in this grade account for 17 to $21 \%$ of the total costs of repetition in Grades 1 to 12 . If just grade 10 repetition rates were to just halve, as a conservative estimate R2 billion could be saved and reallocated to innovative research and experimentation of remediation programmes at earlier grades.

\footnotetext{
${ }^{17}$ For example, a $10 \%$ increase in class sizes is not necessarily going to lead to an immediate $10 \%$ increase in the number of teachers appointed and the cost of their appointment.

${ }^{18}$ In the 2018/19 budget speech, R246.8 billion was allocated to basic education (Africa, 2018).
} 
Table 8: Estimating public spending on repetition in South Africa in 2016

\begin{tabular}{|c|c|c|c|c|c|c|c|c|c|c|c|c|c|}
\hline & Gr1 & Gr2 & Gr3 & Gr4 & Gr5 & Gr6 & Gr7 & Gr8 & Gr9 & Gr10 & Gr11 & Gr12 & Total \\
\hline $\begin{array}{l}\text { Total enrolment in } 2016 \\
\text { (in thousands) }\end{array}$ & 1148 & 1124 & 1066 & 1077 & 983 & 908 & 863 & 912 & 867 & 1067 & 865 & \multicolumn{2}{|l|}{665} \\
\hline \multicolumn{14}{|l|}{ Lower bound costings } \\
\hline $\begin{array}{l}\text { Repetition rates using GHS } \\
2016\end{array}$ & $7.5 \%$ & $7 \%$ & $7.3 \%$ & $7.4 \%$ & $6.8 \%$ & $6.9 \%$ & $7.6 \%$ & $11 \%$ & $11.9 \%$ & $23.5 \%$ & $18.3 \%$ & $8 \%$ & \\
\hline $\begin{array}{l}\text { Number of repeaters } \\
\text { (in thousands) }\end{array}$ & 86 & 79 & 78 & 80 & 67 & 63 & 66 & 100 & 103 & 251 & 158 & 53 & 1183 \\
\hline $\begin{array}{l}\text { Spending on repetition } \\
\text { (in millions, } 2018 \text { prices) }\end{array}$ & R1 463 & R1 337 & R1 323 & R1 355 & R1 136 & R1 065 & R1 115 & R1 705 & R1 754 & R4 262 & R2 689 & R905 & R20 108 \\
\hline \multicolumn{14}{|l|}{ Upper bound costings } \\
\hline $\begin{array}{l}\text { Repetition rates using ASS } \\
\text { subset (2015) for } 7 \text { provinces }\end{array}$ & $16.4 \%$ & $12.0 \%$ & $9.8 \%$ & $13.1 \%$ & $10.1 \%$ & $9.4 \%$ & $9.5 \%$ & $15.6 \%$ & $15.4 \%$ & $27.6 \%$ & $24.0 \%$ & $11.5 \% *$ & \\
\hline $\begin{array}{l}\text { Number of repeaters } \\
\text { (in thousands) }\end{array}$ & 188 & 134 & 105 & 141 & 99 & 85 & 82 & 142 & 134 & 295 & 207 & 77 & 1690 \\
\hline $\begin{array}{l}\text { Spending on repetition } \\
\text { (in millions, } 2018 \text { prices) }\end{array}$ & R3 195 & R2 286 & R1 784 & R2 402 & R1 685 & R1 445 & R1 400 & R2 418 & R2 270 & R5 011 & R3 521 & R1 305 & R28 722 \\
\hline
\end{tabular}

Notes: Public ordinary school enrolment figures as per the DBE's Education Statistics for 2016 report are used. *Grade 12 repetition rate is estimated as 4 percentage points higher than GHS 2016 estimates (because our limited ASS sample and SA-SAMS (Northern Cape) estimates are typically 4 percentage points higher than GHS estimates across grades). Lilenstein and Spaull (2019) identify that the cost per learner for the 2016/2017 government financial year was R16264. We inflate this amount by the average Consumer Price Index for 2017 (4.5\%) to obtain a cost per learner at the beginning of 2018 of R16996. 


\subsection{COSTS OF REPEATING AND DROPPING OUT: THE STORY OF A 21- YEAR-OLD}

In this section, we consider what difference it would make, in monetary terms, if a 21-year-old who had repeated 3 times and failed to attain matric, had been more successful? Specifically, we calculate short-run and long-run costs for this individual - considering both fiscal costs and forgone earnings when compared with 21-year-olds with alternate educational and employment trajectories.

There are direct costs imposed upon the fiscus (and taxpayers) of a learner repeating school or continuing with post-secondary schooling. But what this costing exercise shows is that there are far greater costs to society if a learner does not obtain a matric or higher qualifications. Their forgone lifetime earnings, and what this means in terms of lost income for the economy, vastly outweigh the direct costs of repetition or higher education.

Poorer schooling outcomes in the FET phase, and particularly non-completion of matric - are associated with lower productivity jobs and in turn lower income levels (Moses, Van der Berg, \& Rich, 2017). This is illustrated in Figure 21, which shows typical earnings profiles for South African adults using the Post-Apartheid Labour Market Series. The figure visualises three facts which shape the cost calculations that follow:

1) The returns to having a bachelors' degree are multiple times larger than having a matric.

2) Individuals with a completed matric have a much steeper earnings profile than those with no completed matric.

3) Having a grade 10 versus a grade 9 provides only marginal additional benefit in labour market. But the earnings profiles are different enough for learner advancement through the FET phase to potentially yield better outcomes for society than drop-out after grade 9 .

Figure 21: A monthly earnings profile for South Africans with a grade 9, matric or a 3-year degree

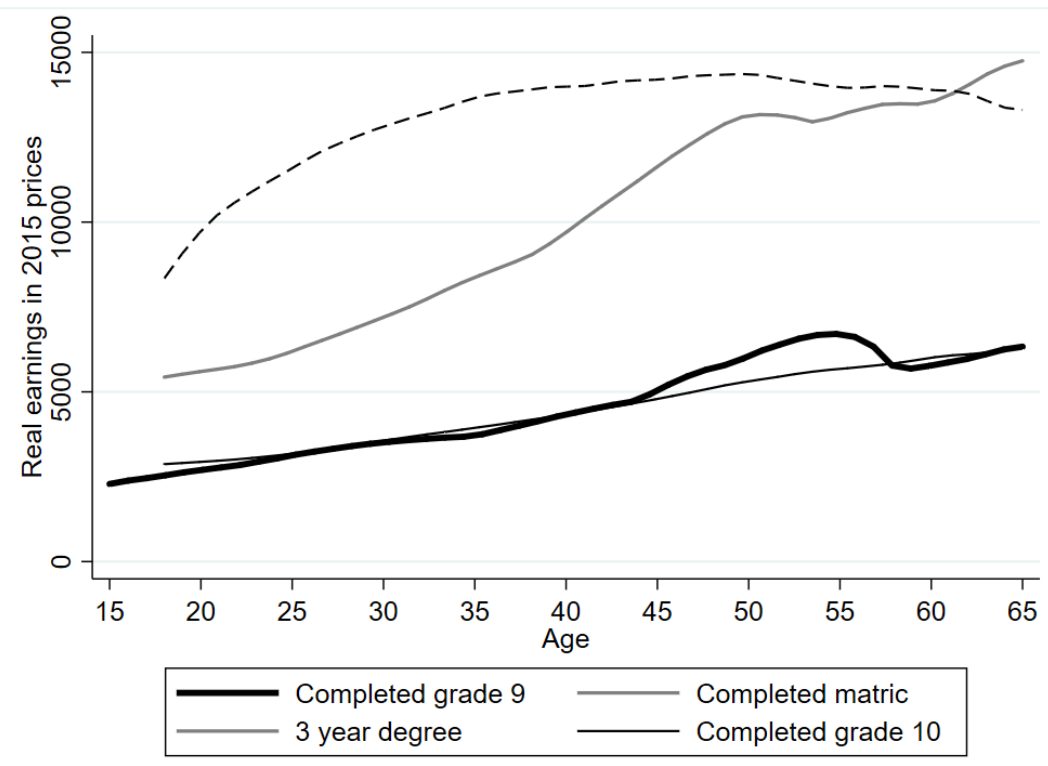

Source: Post-Apartheid Labour Market Series (Andrew, Lam, \& Wittenberg, 2017), own calculations. Notes: Local polynomial regression lines. The real earnings variable in PALMS version 3.2 has been used. Calculated in 2015 rand prices. 
Table 9 provides cost calculations related to our 21-year-old who repeats a grade three times but never completes matric (dropouts at 19 with a grade 10). The costs are expressed relative to the government cost of educating and the cumulative incomes earned of three comparator 21-year-olds as follows;

1) Individual repeats three times; obtains a matric by age 21 but obtains no post-secondary education. This individual commences work age 22 and remains employed until age 65 .

2) Individual never repeats a grade; obtains a matric by age 18 but obtains no post-secondary education. This individual commences working at age 19 and remains employed until age 65.

3) Individual never repeats a grade; obtains a matric by age 18 and goes on to obtain a bachelors' degree within 3 years. This individual commences work at age 22 and remains employed until age 65 .

A cost comparison is also shown for an individual who drops out at the end of grade 9 and enters the labour force at age 16 . The table highlights three cost categories:

A) Direct costs: Additional government spending per learner

B) Forgone earnings before age 22

C) Forgone earnings from age 22 to 65 . This cost category distinguishes short-run from longrun total costs calculated at the bottom of the table.

The cost calculations rely on making some critical assumptions about life trajectories. In particular we assume that as soon as schooling or post-schooling ends for each individual, they find employment in the labour market. In the current South African economic climate with high youth unemployment this is unlikely, and thus the foregone earnings calculated reflect an upper bound estimate.

Box 3: Assumptions made and data used in estimating costs of three comparative scenarios

1. We assume that all individuals considered turned 7 in grade 1 , attended no-fee schools and did not incur additional personal school costs (all schooling costs are born by the state).

2. Per learner costs of schooling are obtained from the analysis of state expenditure patterns by Lilenstein and Spaull (2019).

3. The cost of tertiary education (full-time equivalent per student spending at public universities) is obtained from a recent report on post-school education and training in South Africa (Department of Higher Education and Training, 2018). Per funding student costs are expressed in 2018 prices, assuming an annual average increase of $2.5 \%$. We assume that individuals and households do not incur additional costs of attending university. See Table $1 \mathrm{~A}$ in the Appendix for costings used in this example.

4. Data on earnings are obtained from the Post-Apartheid Labour Market Series version 3.2 (Andrew, Lam, \& Wittenberg, 2017). Median incomes at various ages for specific years of education obtained are used in estimating forgone earnings. Median incomes are preferred over calculated average incomes as they display a more stable profile with age. See Table A2 in the Appendix for earnings used in the costing.

5. All individuals commence work within a year of leaving school or university and remain employed until age 65. They do not obtain higher qualifications while working.

6. We do not distinguish between male and females or between race groups.

7. All values are expressed in 2018 prices.

8. We do not use multipliers to scale up to potential GDP estimates. 
Comparison 1: Repeats three times but obtains a matric by age 21. Does no further education. This individual commences work at age 22 and remains employed until age 65.

It is a very sub-optimal outcome if a learner repeats three times but does not go on to complete a matric (i.e. highest completed education is a grade 10). The long-run cost of repeating but not getting the matric versus repeating but finally obtaining a matric is about R1.7 million.

Comparison 2: Never repeats a grade; obtains a matric by age 18 but obtains no post-secondary education. This individual commences work at age 19 and remains employed until age 65.

In the short run, the relative costs of repetition and not obtaining a matric is estimated here at R85 000. The long-run cost of repeating but only obtaining a grade 10 versus not repeating and reaching matric is also almost R1.7 million. The long-run costs do not differ much from the previous comparator scenario. Due to the higher returns in the labour market to having a matric versus incomplete secondary education, forgone earnings are a much stronger contributor to long run costs here than the direct costs of repetition. In fact, the additional direct costs of repetition account for merely $1 \%$ of the total lost value.

The R20 billion annual cost of repetition estimated above, is roughly equivalent to the additional lifetime earnings of having just $\mathbf{1 2} \mathbf{0 0 0}$ more youth obtain a matric every year rather than dropping out after grade 10.

Comparison 3: Never repeats a grade; obtains a matric by age 18 and obtains a bachelors' degree within 3 years. This individual commences work at age 22 and remains employed until age 65.

Initially, in the short run there are greater costs incurred by the state and individual of obtaining a post-secondary education (here completing a degree by aged 21) compared with the costs of financing a learner who repeats three times and leaves school without a matric certificate. However, in the longrun, due to the high returns to post-secondary education, there is a net loss of more than R7 million to the economy of not going on to complete a bachelors' degree by age 21 . This scenario is an important illustration of the immense cost to the nation of poor-quality primary and secondary schooling, which limits opportunities for learners to achieve better matric passes to enter postsecondary education. The problem of poor-quality schooling in general - of which repetition is a symptom - is a far greater cost to individuals and the South African economy than considering the issue of repetition in isolation.

It is important to note that dropout presents an inferior economic outcome for the individual and economy than even repeating three times but only obtaining a grade 10 . In the short run, it is less burdensome for the state to accommodate dropout than repetition. But in the long run, there are greater losses associated with the individual who drops out after grade 9 than the individual who repeats three times only getting a grade 10 . This suggests that it is still better for the economy if learners advance through the FET phase, evening obtaining an incomplete secondary education, rather than dropping out after grade 9. In this respect, if the effect of repetition in stimulating dropout outweighs the benefits of mastery of skills that could encourage successful advancement through the school system, then repetition is a sub-optimal practice.

While this discussion has been primarily concerned with the monetary costs of repetition, the literature review highlighted various other non-monetary costs of repeating such as negative implications for child morale, social equity concerns as poorer children are left behind, increased age ranges within classes and importantly larger class sizes in earlier grades. The last issue, is particularly pertinent in the South African context given that large class sizes characterise a large proportion of 
foundation phase classrooms. A dedicated study should be made of the relationship between repetition and class size in South Africa, and how this may ultimately influence learning outcomes. A current limitation in doing this analysis is accessing data that contains both reliable data on repetition and class sizes.

Table 9: An example of the costs of repetition and dropout

\section{1 year-old: Has repeated 3 times, dropped out after grade 10}

21-year-old: Dropped out end of grade 9 (never repeated)

\section{A. Direct costs: Additional government spending per learner}

1. Repeats 3 times and completes matric (no PSET) by 21

$-\mathrm{R} 33992$

$-R 101975$

2. Never repeats and completes matric (no PSET) by 18

R16 996

- R50 988

3. Never repeats, completes matric, obtains 3 year degree by 21

$-R 248992$

- R316 975

\section{B. Relative forgone earnings before age 22}

1. Repeats 3 times and completes matric (no PSET) by 21

R124 690

R129 184

2. Never repeats and completes matric (no PSET) by 18

R68 154

R4 494

3. Never repeats, completes matric, obtains 3 year degree by 21

R56 536

R129 184

\section{Relative forgone earnings age 22-65}

1. Repeats 3 times and completes matric (no PSET) by 21

2. Never repeats and completes matric (no PSET) by 18

3. Never repeats, completes matric, obtains 3 year degree by 21

\section{TOTAL SHORT-RUN costs by the time learner turns $21(A+B)$}

1. Repeats 3 times and completes matric (no PSET) by 21

2. Never repeats and completes matric (no PSET) by 18

3. Never repeats, completes matric, obtains 3 year degree by 21

$-R 192455$

TOTAL LONG-RUN COSTS - add relative forgone earnings aged 22-65 (A + B + C)

1. Repeats 3 times and completes matric (no PSET) by 21

2. Never repeats and completes matric (no PSET) by 18

R1 691227

R2 000319

3. Never repeats, completes matric, obtains 3 year degree by 21

R7 234111

R7 679511

Notes: Negative values indicate a net benefit relative to the comparator group. Values are in 2018 prices. PSET stands for Post-School Education and Training. 


\section{CONCLUSION}

The literature review in Section 2 of this report illustrates the continuing debate about the role of repetition in schools. This debate has important implications for South Africa. The data analysis in this report has confirmed the large extent of repetition and dropout, and the very high costs associated with it. The costs of repetition are direct and mostly affect the state by tying down human and fiscal resources. It is wasteful and can therefore be regarded as one measure of the inefficient performance of the South African school system. But as this report has illustrated, dropout is even more problematic from the perspective of the individuals concerned and the whole society. It prevents individuals from developing their human capital to the full, and this cost extends over the productive and indeed full lifetime of the affected individuals and affects the whole economy. What is more, in the long run the costs of dropout completely dwarf that of repetition.

In South Africa, the debate around repetition and dropout is a debate about only two manifestations of a weak education system. There will always be pragmatic and other considerations that affect policy on repetition, and this debate should continue. Yet the most important factor that requires attention is the quality of the education provided in our schools. To improve this to the benefit of children remains the main priority. Improvements of this nature will also make it easier to implement sensible policies on repetition and to provide remediation and support where these are needed. Moreover, by freeing resources currently needed to deal with repetition, improved education quality would also make remediation more feasible.

Yet though the focus of policy should be on improving the quality of education, issues of access, repetition and dropout remain important manifestations not only of the weaknesses, but also of the inequities in the education system. These manifestations need to be studied and reported on, and it is important that stakeholders and the policy community engage with these issues. To do so productively requires that the data required to inform public debates should be improved. Good administrative data are of paramount importance for good analysis and informed decision-making. The Education Management Information System (EMIS) needs more attention to ensure that data are made available timeously, are complete, and that it be of good quality. The transition from the old form-based ASS to SA-SAMS and eventually a fully operational learner tracking system, LURITS, is only one part of the challenge. It is imperative that officials at national, provincial and district level should be engaged in verifying and using the data. It would also be of public interest for national debates that these data be made available, and anonymised, as a public resource to researchers. That is one way to ensure that data deficiencies become clearer more quickly and that corrective action can be taken to build a better data system. 


\section{REFERENCES}

Africa, T. (2018, February 21). \#BudgetSpeech2018: Basic education allocated R246.8 billion. Retrieved from Independent Online: https://www.iol.co.za/news/politics/budgetspeech2018-basiceducation-allocated-r2468-billion-13407118

Agasisti, T., \& Cordero, J. (2017). The determinants fo repetition rates in Europe: early skills or subsequent parents' help? Journal of Policy Modeling, 39(2017), 129-146.

Ahmed, A., \& Mihiretie, D. (2015). Primary school teachers and parents' views on automatic promotion practices and its implications for education quality. International Journal of Educational Development, 43(2015), 90-99.

Alexander, K., Entwisle, D., \& Dauber, S. (2003). On the success of failure: A reassessment of the effects of retention in the primary school grades (2nd ed.). Cambridge, United Kingdom: Cambridge University Press.

Alexander, R. (2015). Teaching and learning for all? The quality imperative revisited. International Journal of educational Development, 40(2015), 250-258.

Allen, C., Chen, Q., Willson, V., \& Hughes, J. (2009). Quality of research design moderates effects of grade retention on achievement: a meta-analytic, multilevel analysis. Educational Evaluation and Policy Analysis, 31(4), 480-499.

Allensworth, E. (2004). Ending social promotion: Dropout rates in Chicago after implementation of the eigth-grade promotion gate. Chicago: Consortium on Chicago School Research.

Anagnostopoulos, D. (2006). "Real students" and "true demotes": ending social promotion and the moral ordering of urban high schools. American Educational Research Journal, 43(1), 5-42.

Andre, P. (2009). Is grade repetition one fo the causes of early school dropout? Evidence from Senegalese primary schools. Munich: Munich Personal RePEc Archive Working Paper No. 25665.

Andrew, K., Lam, D., \& Wittenberg, M. (2017). Post-Apartheid Labour Market Series [dataset]. Version 3.2. Cape Town: DataFirst [producer and distributor].

Baert, S., Cockx, B., \& Picchio, M. (2015). Modeling the effects of grade retention in high school. Munich: CESifo Working Paper No. 5679, Center for Economic Studies and Ifo Institute.

Bali, V., Anagnostopoulos, D., \& Roberts, R. (2005). Toward a political explanation of grade retention. Educational Evaluation and Policy Analysis, 27(2), 133-155.

Belot, M., \& Vandenberghe, V. (2014). Evaluating the 'threat' effects of grade repetition: exploiting the 2001 reform by the French-speaking community of Belgium. Education Economics, 22(1), 73-89.

Branson, N., \& Lam, D. (2010). Education inequality in South Africa: Evidence from the National Income Dynamics Study. Journal of Studies in Economics and Econometrics, 34(3), 85-109.

Branson, N., Hofmeyr, C., \& Lam, D. (2013). Progress through school and the determinants of dropout in South Africa. A Southern Africa Labour and Development Research Unit Working Paper. Cape Town: SALDRU, University of Cape Town.

Brodaty, T., Gary-Bobo, R., \& Prieto, A. (2008). Does speed signal ability? The impact of grade repetitions on employment and wages. Ammersee: Centre for Economic Policy Research \& Institute for the Study of Labor: 10th European Summer Sumposium in Labour Economics.

Brophy, J. (2006). Grade repetition. Paris: UNESCO \& International Academy of Education.

Cham, H., Hughes, J., West, S., \& Im, M. (2015). Effect of retention in elementary grades on grade 9 motivation for educational attainment. Journal of School Psychology, 53(2015), 7-24.

Chen, X. L., Zhang, L., Shi, Y., \& Rozelle, S. (2010). Does taking one step bakc get you two steps forward? Grade retention and school performance in poor areas in rural China. International Journal of Educational Development, 30(2010), 544-559.

Choi, A., Gil, M., Mediavilla, M., \& Valbuena, J. (2018). Predictors and effects of grade repetition. Revista De Economia Mundial, 48(2018), 21-42. 
Conboy, J. (2011). Retention and science performance in Portugal as evidenced by PISA. Procedia Social and Behavioral Sciences, 12(2011), 311-321.

Darling-Hammond, L., \& Falk, B. (1997). Using standards and assessments to support student learning. Phi Delta Kappan, 79(3), 190-199.

Davoudzadeh, P., McTernan, M., \& Grimm, K. (2015). Early school readiness predictors of grade retention from kindergarten through eighth grade: a multilevel discrete-time survival analysis approach. Early Childhood Research Quarterly, 32(2015), 183-192.

De Brauw, A., Gilligan, D., Hoddinott, J., \& Roy, S. (2015). The impact of Bolsa Familia on schooling. World Development, 70, 303-316.

Department of Basic Education. (2012). National policy pertaining to the programme and promotion requirements of the National Curriuclum Statement Grades R-12, published as Government Notices No. 1115 and 1116 in Government Gazette No. 36042. Pretoria: Department of Basic Education.

Department of Basic Education. (2016). Report on progress in the schooling sector against key learner performance and attainment indicators. Pretoria: Department of Basic Education.

Department of Basic Education. (2018). General Household Survey: Focus on Schooling 2016. Department of Basic Education. Retrieved from https://www.education.gov.za/Portals/0/Documents/Reports/General\%2OHousehold\%20Su rvey\%202016\%20Focus\%20on\%20Schooling.pdf

Department of Education. (1998). National Policy Pertaining to the Conduct, Administration and Management of the National Senior Certificate Examination, published as Governemnt Notice NO. 574 in Government Gazette No. 30048 of July 2007. Pretoria: Department of Education.

Department of Education, Ministerial Committee on Learner Retention. (2008). Report of the Ministerial Committee on Learner Retention in the South African schooling system. Pretoria: Department of Education.

Department of Higher Education and Training. (2018). Investment Trends in Post-School Education and Training in South Africa. Pretoria: DHET.

Dinas, E., \& Stoker, L. (2014). Age-period-cohort analysis: a design-based approach. Electoral Studies, 33(2014), 25-40.

Eboatu, V., \& Omenyi, A. (2015). The impact of class repetition on students' academic achievement: implications for educational policy making. European Scientific Journal, 11(9), 259-267.

Ehmke, T., Drechsel, B., \& Carstensen, C. (2010). Effects of grade retention on achievement and selfconcept in science and mathematics. Studies in Educational Evaluation, 36(2010), 27-35.

Eider, E., \& Goldhaber, D. (2005). Grade retention: What are the costs and benefits. Journal of Education Finance, 31(2), 195-214.

Eisemon, T. (1997). Reducing repetition: Issues and strategies. Paris: UNESCO: International Institute for Educational Planning.

Eren, O., Depew, B., \& Barnes, S. (2017). Test-based promotion policies, dropping out, and juvenile crime. Journal of Public Economics, 153(2017), 9-31.

Fiske, E., Rwehera, M., Chu, S., \& Mputu, H. (1998). Wasted Opportunities: When schools fail, repetition and drop-out in primary schools. Paris: UNESCO.

Garcia-Perez, J., Hidalgo-Hidalgo, M., \& Robles-Zurita, J. (2014). Does grade retention affect students' achievement? Some evidence from Spain. Applied Economics, 46(12), 1373-1392.

Gary-Bobo, R., Gousse, M., \& Robin, J. (2016). Grade retentionand unobserved heterogeneity. Quantitative Economics, 7(2016), 781-820.

Glick, P., \& Sahn, D. (2010). Early academic performance, grade repetition, and school attainment in Senegal: A panel data analysis. The World Bank Economic Review, 24(1), 93-120.

Goos, M., Schreier, B., Knipprath, H., De Fraine, B., Van Damme, J., \& Trautwein, U. (2013). How can cross-country difference in the practice of grade retention be explained? A closer look at national educational policy factors. Comparative Education Review, 57(1), 54-84. 
Gustafsson, M., \& Taylor, S. (2018). Treating schools to a new adimistration: Evidence of the impact of better practices in the system-level administration of schools. Journal of African Economies, ejy005, https://doi.org/10.1093/jae/ejy005, 1-23.

Hanushek, E., Lavy, V., \& Hitomi, K. (2006). Do students care about school quality? Determinants of dropout behavior in developing countries. Cambridge, Massachusetts: National Bureau of Economic Research, NBER Working Paper 12737.

Hee Im, M., Hughes, J., Kwok, O., Puckett, S., \& Cerda, C. (2013). Effect of retention in elementary grades on transition to middle school. Journal of School Psychology, 51, 349-365.

Holmes, T., \& Matthews, K. (1984). The effects of nonpromotion on elementary and junior high school pupils: a meta-analysis. Review of Educational Research, 54(2), 225-236.

Hong, G., \& Yu, B. (2007). Early-grade retention and children's reading and math learning in elementary years. Educational Evaluation and Policy Analysis, 29(4), 239-261.

Hughes, J., Cao, Q., West, S., Smith, P., \& Cerda, C. (2017). Effect of retention in elementary grades on dropping out of school early. Journal of School Psychology, 65, 11-27.

Ikeda, M., \& Garcia, E. (2014). Grade repetition: A comparative studey of academic and non-academic consequences. OECD Journal: Economic Studies, 2013(1), 269-315.

J., L. (2006). Retention and academic achievement research revistied from a United States perspective. International Education Journal, 7(5), 731-777.

Jackson, G. (1974). The research evidence on the effects of grade retention. Review of Educational Research, 45(4), 613-635.

Jacob, B., \& Lefgren, L. (2004). Remedial education and student achievement: a regressiondiscontinuity analysis. The Review of Economics and Statistics, 86(1), 226-244.

Jacob, B., \& Lefgren, L. (2009). The effect of grade retention on high school completion. American Economic Journal: Applied Economics, 1(3), 33-58.

Jimerson, S. (2001). Meta-analysis of grade retention research: implication sfor practice in the 21st century. School Psychology Review, 30(3), 420-437.

Jimerson, S. (2001b). A synthesis of grade retention research: Looking backward and moving forward. The California School Psychologist, 6, 47-59.

Jimerson, S., Anderson, G., \& Whipple, A. (2002). Winning the battle and losing the war: Examining the relation between grade retention and dropping out of high school. Psychology in teh Schools, 39(4), 441-457.

Jimerson, S., Pletcher, S., Graydon, K., Schnurr, B., Nickerson, A., \& Kundert, D. (2006). Beyond grade retention and social promotion: promoting the social and academic competence of students. Psychology in the Schools, 43(1), 85-97.

Jones, S. (2013). Class size versus class composition: What matters for learning in East Africa? Finland: United Nations University, WIDER Working Paper No. 2013/365.

Kabay, S. (2016). Grade repetition and primary school dropout in Uganda. Harvard Educational Review, 86(4), 580-606.

Kaffenberger, M., \& Pritchett, L. (2017). More school or more learning? Evidence from learning profiles from the financial inclusion insights data. Research on Improving Systems of Education Working Paper No. 17/012.

Kika, J., \& Kotze, J. (2018). Unpacking Grade Repetition Patterns in Light of the Progression Policy in the Further Education and Training Phase. Pretoria: Department of Basic Education.

King, E., Orazem, P., \& Paterno, E. (1999). Promotion with and without learning: Effects on student dropout. Washington, D.C.: The World Bank: Impact Evaluation of Education Reforms Working Paper No. 18.

Klapproth, F., Schaltz, P., Brunner, M., Keller, U., Fischback, A., Ugen, S., \& Martin, R. (2016). Shortterm and medium-term effects of grade retention in secondary school on academic achievement adn psychosocial outcome variables. Learnign and Individual Difference, 50, 182194. 
Koppensteiner, M. (2014). Automatic grade promotion and student performance: Evidence from Brazil. Journal of Development Economics, 107, 227-290.

Koppensteiner, M. (2014). Automatic grade promotion and student performance: Evidence from Brazil. Journal of Development Economics, 107(2014), 277-290.

Lam, D., Ardington, C., \& Leibbrandt, M. (2011). Schooling as a lottery: Racial differences in school advancement in urban South Africa. Journal of Development Economics, 95(2), 121-136.

Lamote, C., Pinxten, M., Van den Noortgate, W., \& Van Damme, J. (2014). Is the cure worse than the disease? A longitudinal study on the effect of grade retention in secondary education on achievement and academic self-concept. Educational Studies, 40(5), 496-514.

Leighton, M., Souza, P., \& Straub, S. (2016). Social promotion in primary school: immediate and cumulated effects on attainment. Toulouse: Toulouse School of Economics Working Paper No. TSE-649.

Lilenstein , A., \& Spaull, N. (2019). Continual decline in government expenditure on children in South African schools - preliminary estimates. Unpublished paper. Stellenbosch: Stellenbosch University.

Lorence, J. (2006). Retention and academic ahievement research revisited from a United States perspective. International Education Journal, 7(5), 731-777.

Lorence, J. (2014). Third-grade retention and reading achievement in Texas: A nine year panel study. Social Science Research, 48, 1-19.

Lorence, J., \& Dworkin, A. (2006). Elementary grade retention in Texas and reading achievment among racial groups: 1994-2002. Review of Policy Research , 23(5), 999-1033.

Manacorda, M. (2012). The cost of grade retention. The Review of Economics and Statistics, 94(2), 596-606.

Martin, A. (2011). Holding back and holding behind: grade retention and students' non-academic and academic outcomes. British Educational Research Journal, 37(5), 739-763.

Morrison, K., \& On No, A. (2007). Does repeating a year improve performance? The case of teaching English. Educational Studies, 33(3), 353-371.

Moses, E., Van der Berg, S., \& Rich, K. (2017). A Society Divided: How Unequal Education Quality Limits Social Mobility in South Africa. Synthesis Report for the Programme to Support Pro-poor Policy Development. Stellenbosch: Stellenbosch University.

Motala, S. (2009). Physical access to schooling in South Africa: Mapping dropout, repitition and agegrde progression in two districts. Comparative Education, 45(2), 251-263.

Nagaoka, J., \& Roderick, M. (2004). Ending social promotion: the effects of retention. Chicago: Consortium on Chicago School Research.

Nalova, E. (2016). School characteristics and the implementation of automatic promotion: Implications for literacy in English-speaking primary schools in Cameroon. Journal of Education \& Social Policy, 3(6), 54-61.

Ndaruhutse, S., Brannelly, L., Latham, M., \& Penson, J. (2008). Grade repetition in primary schools in sub-Saharan Africa: an evidence base for change. Reading: CfBT Schools Trust.

N'tchougan-Sonou, C. (2001). Automatic promotion or large-scale repetition - which path to quality? International Journal of Educational Development, 21, 149-162.

OECD. (2014). PISA in focus 43 - 2014/09. Paris: OECD.

Okurut, J. (2015). Examining the effect of automatic promotion on students' learning achievements in Uganda's primary education. World Journal of Education, 5(5), 85-100.

Okurut, J. (2018). Automatic promotion and student dropout: Evidence from Uganda using propensity score in difference in differences model. Journal of Education and Learning, 7(2), 191-209.

Ou, S., \& Reynolds, A. (2010). Grade retention, postsecondary education, and public aid receipt. Educational Evaluation and Policy Analysis, 32(1), 118-139.

Peixoto, F., Monteiro, V., Mata, L., Sanches, C., Pipa, J., \& Almeida, L. (2016). "To be or not to be retained... That's the question!" Retention, self-esteem, self-concept, achievement goals, and grades. Frontiers in Psychology, 7(1550), 1-13. 
Picklo, D., \& Christenson, S. (2005). Alternatives to retention and social promotion: The availability of instructional options. Remedial and Special Education, 26(5), 258-268.

Powell, P. (2010). Repeating views on grade retention. Childhood Education, 87(2), 90-93.

Pritchett, L., \& Beatty, A. (2012). The negative consequences of overambitious curricula in developing countries. Washington, D.C.: Center for Global Development Working Paper No. 293.

Reschly, A., \& Christenson, S. (2013). Grade retention: historical perspectives and new research. Journal of School Psychology, 51, 319-322.

Roderick, M. (1994). Grade retention and school dropout: Investigating the association. American Educational Research Journal, 31(4), 729-759.

Schwerdt, G., West, M., \& Winters, M. (2017). The effects of test-based retention on student outcomes over time: Regression discontinuity evidence from Florida. Journal of Public Economics, 152, 154-169.

Sichombe, B., Nambira, G., Tjipueja, G., \& Kapenda, L. (2011). Evaluation of promotion policy requirements in Namibian schools. Windhoek: Namibia Ministry of Education \& National Institute for Educational Development.

Silberglitt, B., Jimerson, S., Burns, M., \& Appleton, J. (2006). Does the timing of grade retention make a difference? Examining the effects of early versus later retention. School Psychology Review, 35(1), 134-141.

Spaull, N., \& Kotze, J. (2015). Starting behind and staying behind in South Africa: The case of insurmountable learning deficits in mathematics. International Journal of Educational Development, 41, 13-24.

Spaull, N., \& Van Broekhuizen, H. (2017). The Martha Effect: The Compounding Female Advantage in Higher Education in South Africa. Stellenbosch Economic Working Papers 14/2017. Stellenbosch University.

Sunny, B., Elze, M., Chihana, M., Gondwe, L., Crampin, A., Munkhondya, M., .. Glynn, J. (2017). Failing to progress or progressing to fail? Age-for-grade heterogeneity and grade repetition in primary schools in Karonga district, northern Malawi. International Journal of Educational Development, 52, 68-80.

Tikly, L. (2015). What works, for whom, and in what circumstances? Towards a critical realist understanding of learning in international and comparative education. International Journal of Educational Development, 40, 237-249.

UNESCO. (2012). Opportunities lost: The impact of grade repetition and early school leaving. Montreal: UNESCO Institute for Statistics: Global Education Digest 2012.

Välijärvi, J., \& Sahlberg, P. (2008). Should 'failing' students repeat a grade? Retrospective response from Finland. Journal of Educational Change, 9, 385-389.

van Broekhuizen, H. (2015). Graduate unemployment, Higher Education access and success, and teacher production in South Africa. PhD Dissertation. Stellenbosch: Stellenbosch University.

Van der Berg, S., \& Knoesen, M. (2015). Implications of demographic projections for education in the five SACU countries. Stellenbosch: University of Stellenbosch.

Van der Berg, S., \& Shepherd, D. (2015). Continuous assessment and matriculation examination marks - an empirical examination. Outh AfricanJournal of Childhood Education, 78-94.

Van Wyk, C., Gondwe, A., \& De Villiers, P. (2017). Learner flow through patterns in the Western Cape using CEMIS datasets from 2007 to 2014: A longitudinal cohort analysis. Stellenbosch: Stellenbosch University, Department of Economics.

Vandecandelaere, M., Vansteelandt, S., De Fraine, B., \& Van Damme, J. (2016). The effects of early grade retention: Effect modification by prior achievement and age. Journal of School Psychology, 54, 77-93.

Vandecandelaere, M., Vansteelandt, S., De Fraine, B., \& Van Damme, J. (2016). The effects of early grade retention: Effect modification by prior achievement and age. Journal of School Psychology, 54, 77-93. 
Von Fintel, M., \& Van der Berg, S. (2017). 6. Marisa von Fintel \& SeWhat a difference a good school makes! Persistence in academic performance and the impact of school quality. Stellenbosch: Stellenbosch University, Department of Economics.

Walton, E. (2018). Teacher beliefs about grade repetition: An exploratory South African study. Citizenship Teaching \& Learning, 13(1), 45-60.

Wills, G., Shepherd, D., \& Kotze, J. (2018). Explaining the Western Cape Performance Paradox: An Econometric Analysis. In B. Levy, Cameron, Robert, U. Hoadley, \& V. Naidoo, The Politics and Governance of Basic Education (pp. 149-178). Oxford: Oxford University Press.

Winthrop, R., Anderson, K., \& Cruzalegui, I. (2015). A review of policy debates around learning in the post-2015 education and development agenda. International Journal of Educational Development, 40, 297-307.

World Bank. (2018). World Development Report 2018: Learning to realize education's promise. Washington, DC: World Bank. doi:10.1596/978-1-4648-1096-1. License: Creative Commons Attribution CC BY 3.0 IGO.

Wu, W., \& West, S. (2010). Effect of grade retention in first grade on psychosocial outcomes. Journal of Educational Psychology, 102(1), 135-152.

Wu, W., West, S., \& Hughes, J. (2008). Effect of retention in first grade on children's achievement trajectories over 4 years: a piecewise growth analysis using propensity score matching. Journal of Educational Psychology, 100(4), 727-740.

Zinth, K. (2005). Student promotion/retention policies. Denver: StateNotes, Education Commission of the States. 


\section{APPENDIX}

Figure A 1: Educational status of children aged 13 by province, Community Survey 2016

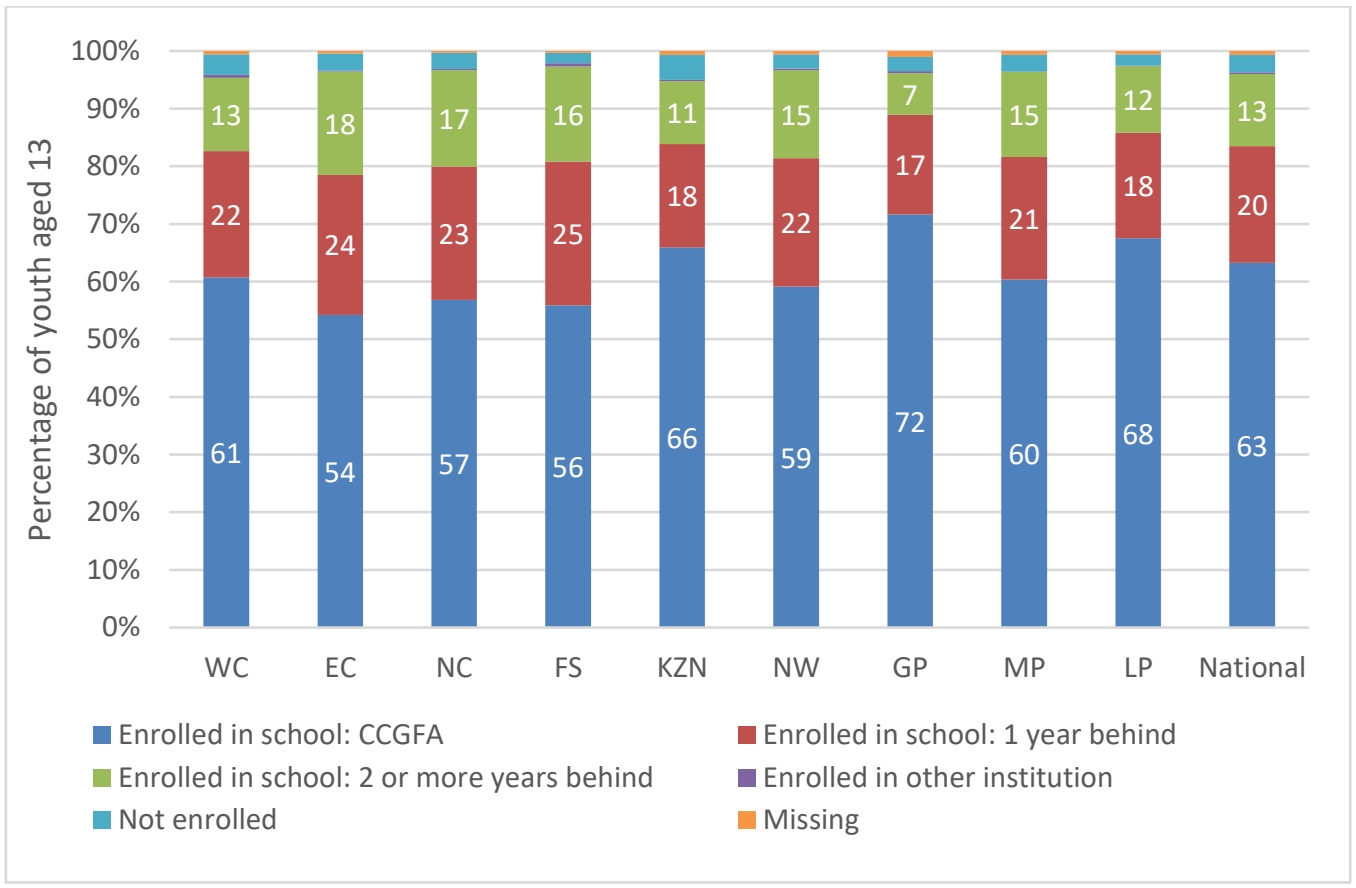

Source: Community Survey, 2016. Own calculations. Notes: CCGFA stands for 'completed correct grade for age'. Age is derived to correspond to birth year.

Figure A 2: Educational status of children aged 16 by province, Community Survey 2016

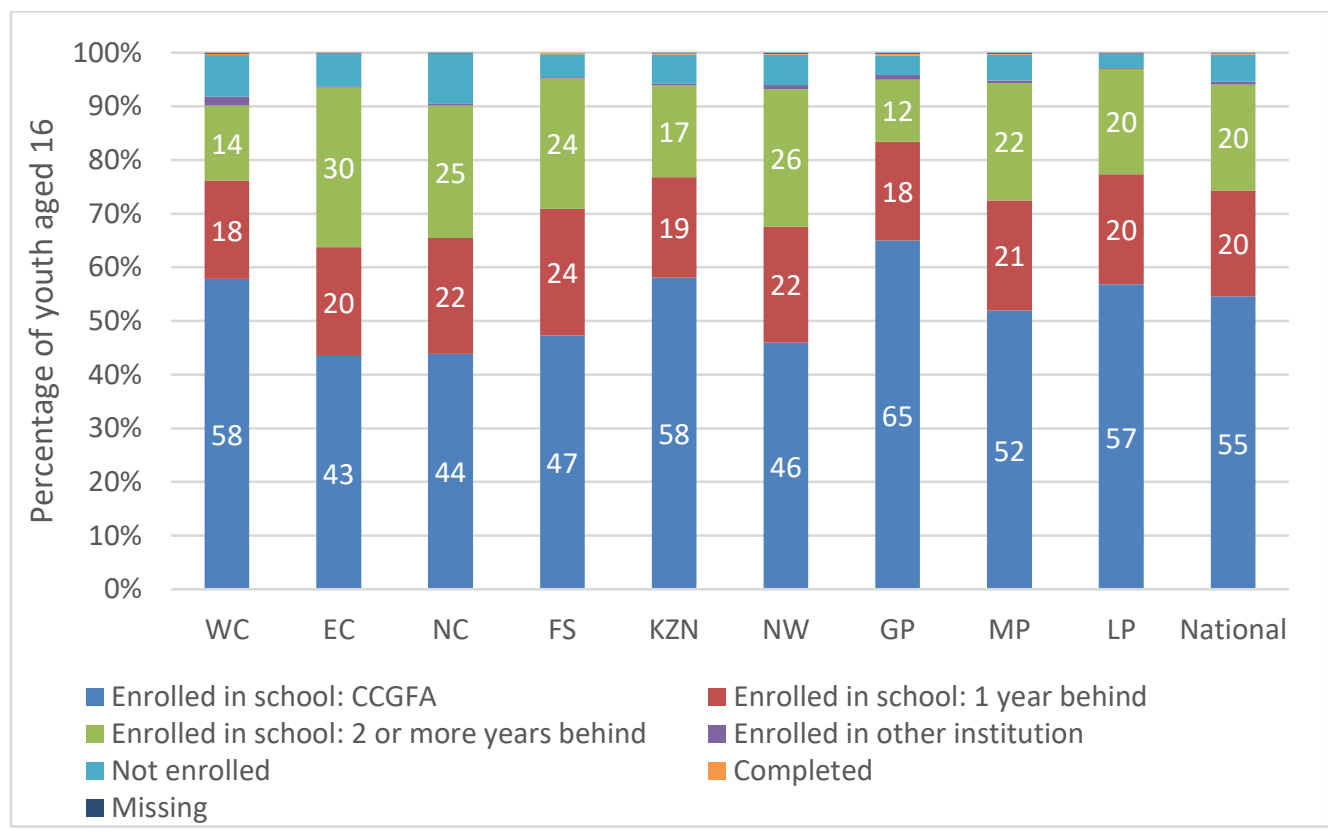

Source: Community Survey, 2016. Own calculations. Notes: CCGFA stands for 'completed correct grade for age'. Age is derived to correspond to birth year. 
Figure A 3: Educational status of children aged 17 by province, Community Survey 2016

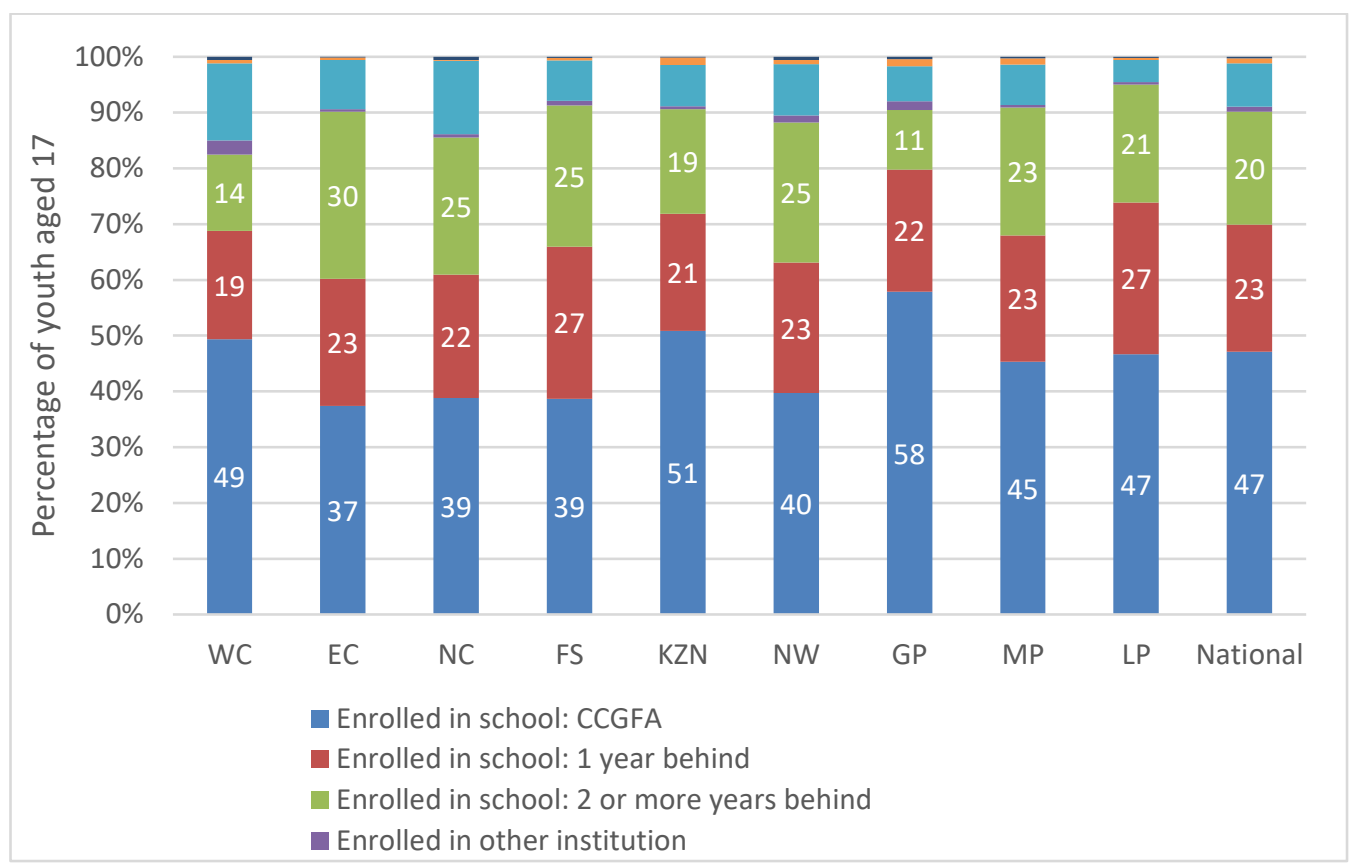

Source: Community Survey, 2016. Own calculations. Notes: CCGFA stands for 'completed correct grade for age'. Age is derived to correspond to birth year.

Figure A 4: Percentage of age-cohorts with a completed matric by province, Community Survey 2016
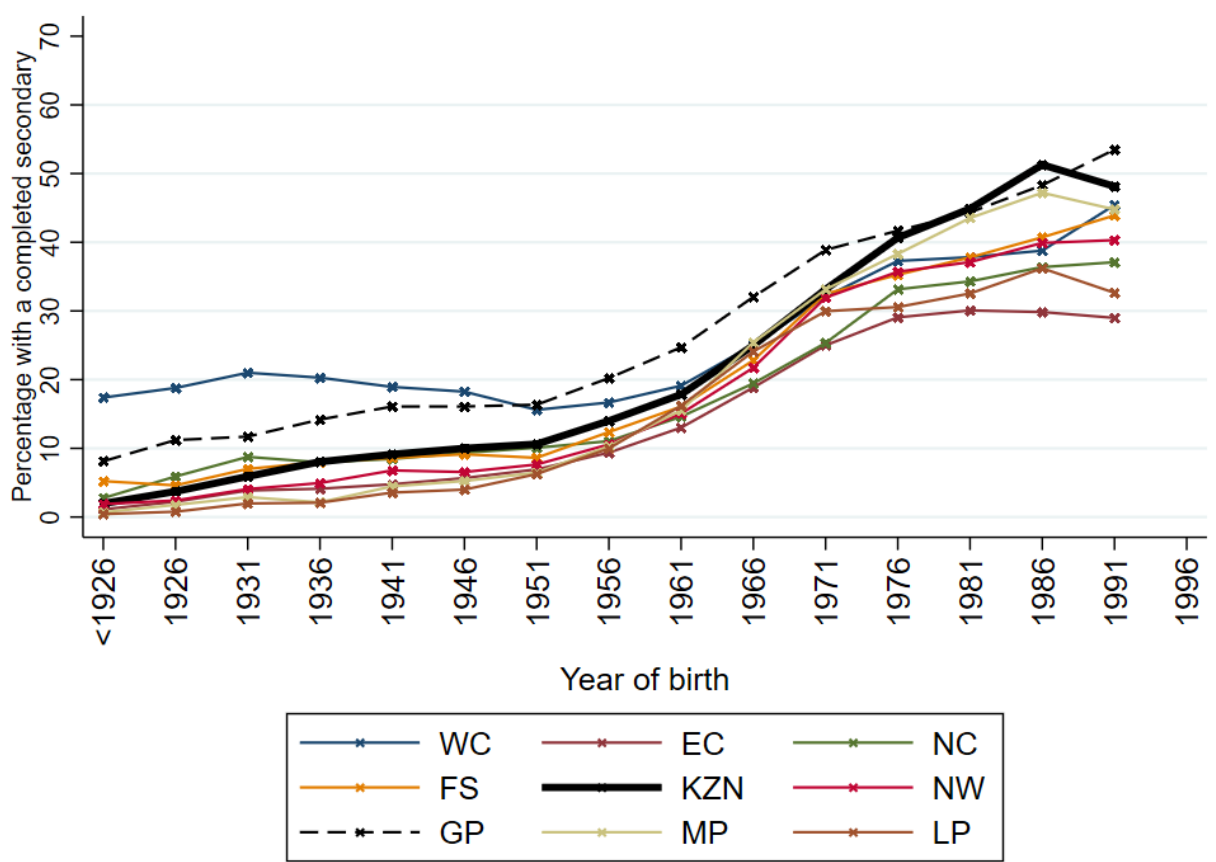

Source: Community Survey, 2016. Own calculations. Notes: CCGFA stands for 'completed correct grade for age'. Age is derived to correspond to birth year. 
Figure A 5: Trends in the percentage of learners by grade that are over-age, EMIS 2000 to 2016 for 6 provinces

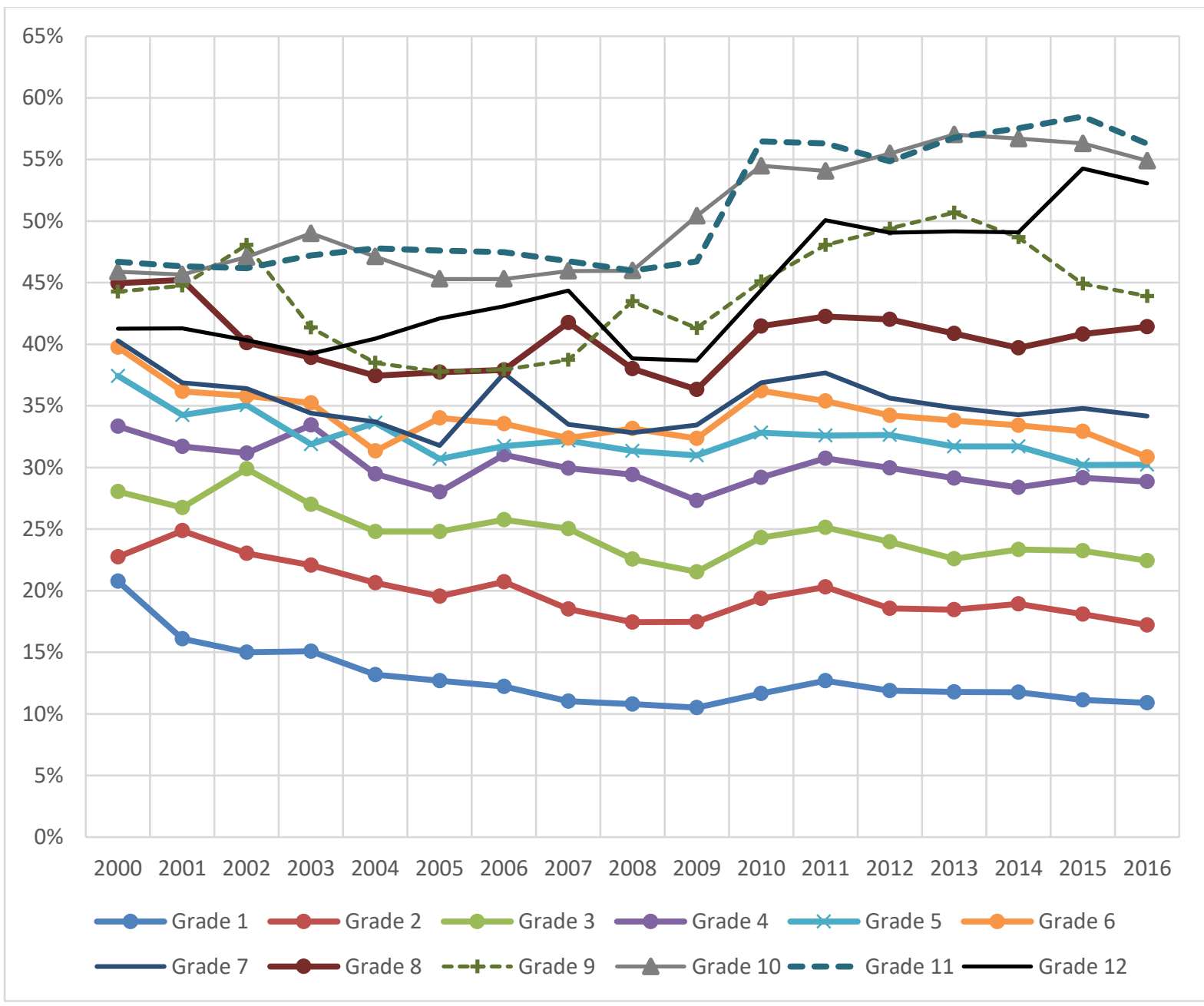

Source: EMIS 2000 to 2016 for 6 provinces, own calculations. Free-State, Mpumalanga and the Eastern Cape are excluded. Notes: The age for grade data is a distinct dataset from the Annual Survey of Schools data subset that we use in other figures and tables. Where applicable, the 2003 and 2004 data on age were recoded to be consistent with the coding of ages in other years. We however remain cautious about the 2014 EMIS data on age, particularly for the Eastern Cape and thus remove the Eastern Cape from this trend comparison. 
Figure A 6: Provincial repetition rates averaged across the years 2014-2018, GHS

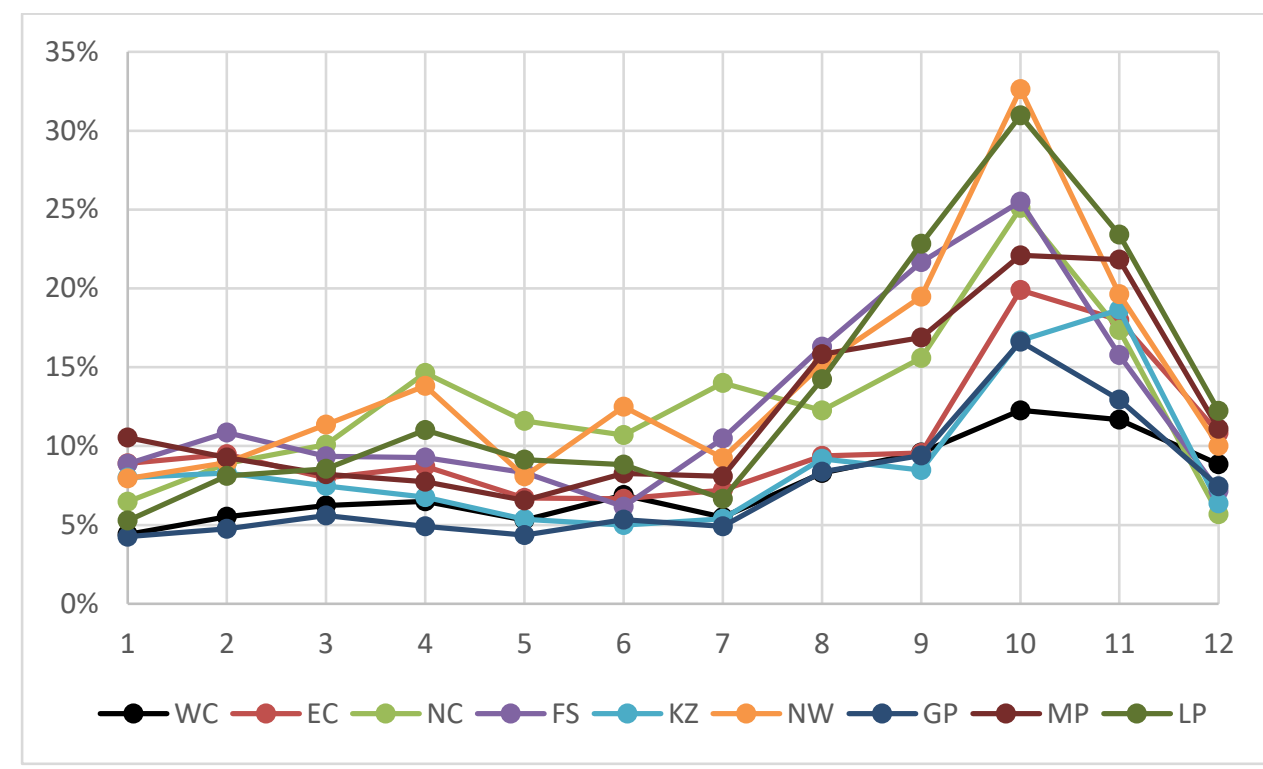

Source: General Household Surveys (2014 to 2018), own calculations. 
Table A 1: Government spending, estimates used for the 21-year-old costing example

\begin{tabular}{|c|c|c|c|c|c|}
\hline $\begin{array}{l}\text { Cost per } \\
\text { learner / } \\
\text { student at }\end{array}$ & $\begin{array}{c}\text { Repeats three } \\
\text { times, drops } \\
\text { out after grade } \\
10 \\
\text { (13 years in } \\
\text { school) }\end{array}$ & $\begin{array}{l}\text { Repeats three } \\
\text { times, } \\
\text { completes } \\
\text { matric } \\
\text { (15 years in } \\
\text { school) }\end{array}$ & $\begin{array}{l}\text { Drops out end } \\
\text { of grade } 9 \\
\text { (never } \\
\text { repeated) } \\
\text { (9 years in } \\
\text { school) }\end{array}$ & $\begin{array}{l}\text { Does not } \\
\text { repeat and } \\
\text { completes } \\
\text { matric (no } \\
\text { PSET) } \\
\text { (12 years in } \\
\text { school) }\end{array}$ & $\begin{array}{c}\text { Does not } \\
\text { repeat, } \\
\text { completes } \\
\text { matric, obtains } \\
\text { 3-year degree } \\
\text { by } 21\end{array}$ \\
\hline Age 7 & R16 996 & R16 996 & R16 996 & R16 996 & R16 996 \\
\hline Age 8 & R16 996 & R16 996 & R16 996 & R16 996 & R16 996 \\
\hline Age 9 & R16 996 & R16 996 & R16 996 & R16 996 & R16 996 \\
\hline Age 10 & R16 996 & R16 996 & R16 996 & R16 996 & R16 996 \\
\hline Age 11 & R16 996 & R16 996 & R16 996 & R16 996 & R16 996 \\
\hline Age 12 & R16 996 & R16 996 & R16 996 & R16 996 & R16 996 \\
\hline Age 13 & R16 996 & R16 996 & R16 996 & R16 996 & R16 996 \\
\hline Age 14 & R16 996 & R16 996 & R16 996 & R16 996 & R16 996 \\
\hline Age 15 & R16 996 & R16 996 & R16 996 & R16 996 & R16 996 \\
\hline Age 16 & R16 996 & R16 996 & & R16 996 & R16 996 \\
\hline Age 17 & R16 996 & R16 996 & & R16 996 & R16 996 \\
\hline Age 18 & R16 996 & R16 996 & & R16 996 & R16 996 \\
\hline Age 19 & R16 996 & R16 996 & & & R88 663 \\
\hline Age 20 & & R16 996 & & & R88 663 \\
\hline Age 21 (2018) & & R16 996 & & & R88 663 \\
\hline $\begin{array}{l}\text { Total cost per } \\
\text { learner in } 2018 \\
\text { prices }\end{array}$ & R220 946 & R254 938 & R152 963 & R203951 & R469 938 \\
\hline
\end{tabular}

Source: Lilenstein and Spaull (2019) and Department of Higher Education and Training (2018). Notes: ${ }^{*}$ The cost of a full-time equivalent student at public universities in South Africa in 2015 was R86500. This has been inflated by the average increase of $2.5 \%$ per student FTE expenditure between 2000 and 2015. All costs are expressed in 2018 prices. 
Table A 2: Cumulative annual earnings in 2018 prices used for the 21-year-old costing example

Estimates of cumulative annual earnings in 2018 prices

\begin{tabular}{|c|c|c|c|c|}
\hline & Median & P25 & p75 & Average \\
\hline \multicolumn{5}{|c|}{ Completed grade 9 only } \\
\hline Age 16-21 & R129 184 & R70 887 & R197 343 & R196 880 \\
\hline Age $22-65$ & R1 689195 & R879 073 & R3 084777 & R3 125343 \\
\hline \multicolumn{5}{|c|}{ Completed grade 10 only } \\
\hline Age $20-21$ & R56 536 & R33 027 & R138 417 & R109 004 \\
\hline Age 22-65 & R2 129930 & R1 076382 & R3 653292 & R3 831400 \\
\hline \multicolumn{5}{|c|}{ Completed matric } \\
\hline Age 19-21 & R124 690 & R75 617 & R211 983 & R228 681 \\
\hline Age 22-65 & R3 736007 & R1 841836 & R7 104488 & R6 927435 \\
\hline \multicolumn{5}{|c|}{ Complete a three-year degree by age 21} \\
\hline Age $22-65$ & R9 556496 & R5 449261 & R14 783544 & R29 117426 \\
\hline
\end{tabular}

Source: PALMS v3.2 (Andrew, Lam, \& Wittenberg, 2017); own calculations. Notes: 2015 prices inflated by the Consumer Price Index for South Africa - 6.4\% (2016), 4.5\% (2017), 4.4\% (2018). 